\title{
Informe sobre la convección muy organizada y de tipo supercelular del día 1 de julio de 2018 en la provincia de Zaragoza
}

Nota técnica 29 de AEMET

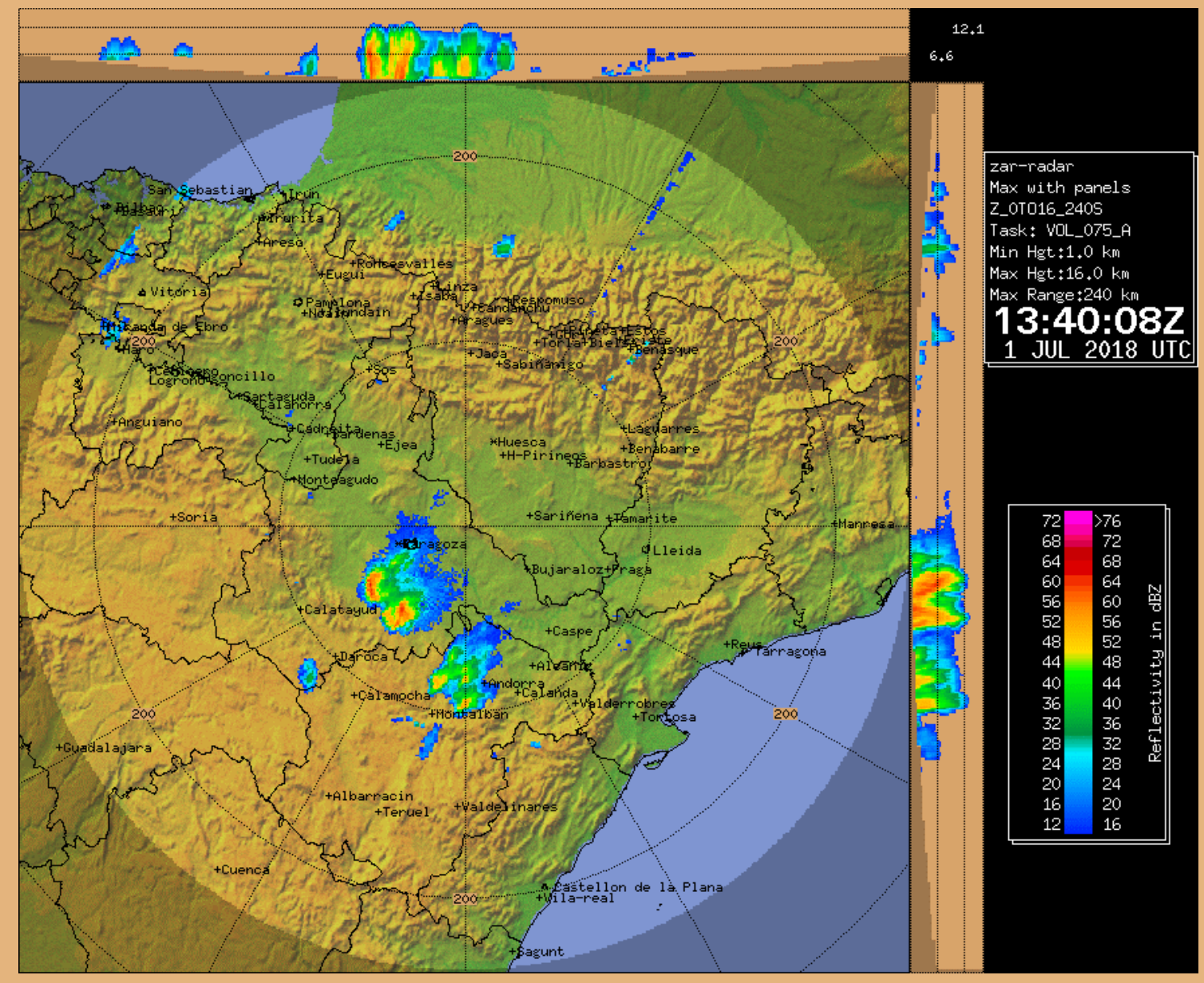

Ismael Sanambrosio Beirán Samuel Tomás Buisán Sanz Tomás José Gutiérrez Cobo José Manuel López Pérez Ramón Pascual Berghaenel

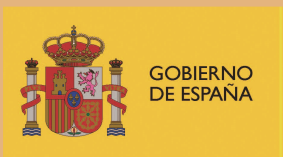

MINISTERIO

PARA LATRANSICIÓN ECOLÓGICA

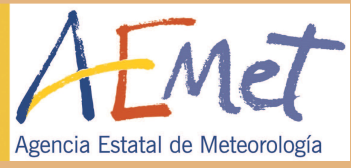





\title{
Informe sobre la convección muy organizada y de tipo supercelular del día 1 de julio de 2018 en la provincia de Zaragoza
}

\author{
Nota técnica 29 de AEMET
}

Ismael Sanambrosio Beirán

Jefe de la Unidad de Estudios y Desarrollos Delegación Territorial de AEMET en Aragón

Samuel Tomás Buisán Sanz

Jefe de la Unidad de Sistemas Básicos

Delegación Territorial de AEMET en Aragón

Tomás José Gutiérrez Cobo

Técnico Superior de Estudios y Desarrollos

Delegación Territorial de AEMET en Aragón

José Manuel López Pérez

Jefe del G. P. V.

Delegación Territorial de AEMET en Valencia

Ramón Pascual Berghaenel

Jefe del G. P. V.

Delegación Territorial de AEMET en Cataluña

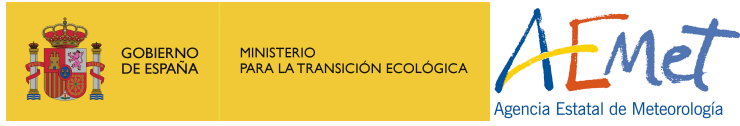


datos Aviso Legal: los contenidos de esta publicación podrán ser reutilizados,

abiertos citando la fuente y la fecha, en su caso, de la última actualización

\section{Edita:}

(C) Ministerio para la Transición Ecológica

Agencia Estatal de Meteorología

Madrid, 2019

Catálogo de Publicaciones de

la Administración General del Estado:

https://cpage.mpr.gob.es

NIPO: 639-19-017-9

https://doi.org/10.31978/639-19-017-9

Agencia Estatal de Meteorología (AEMET)

C/ Leonardo Prieto Castro, 8

28040 Madrid

http://www.aemet.es/

@Aemet_Esp

f https://www.facebook.com/AgenciaEstatalMeteorologia 


\section{AgRAdECIMIENTOS}

Los autores de este informe quieren agradecer la amable colaboración de María Gotor Forcén que nos mostró los desperfectos causados en su finca situada en Osera de Ebro (Zaragoza) y nos detalló cómo se desarrollaron los acontecimientos asociados al paso de la tormenta.

Mencionaremos también al colaborador en esa misma localidad, D. Juan Andrés Prades Carrera, que nos facilitó los datos de precipitación registrados en la estación de la red secundaria de AEMET, y que además nos informó y confirmó los diferentes daños acontecidos en esta misma localidad y alrededores.

Finalmente, nuestro agradecimiento a Elena Sánchez Domingo (jefa de la OMA del aeropuerto de Zaragoza, AEMET) y a Juan Iglesias Gómez (Departamento de Infraestructuras y Sistemas) por las aportaciones e información en relación con las características técnicas de los sistemas de medición ubicados en las instalaciones del aeropuerto de Zaragoza. 



\section{Introducción,}

por Tomás José Gutiérrez Cobo .....

\section{Situación sinóptica}

por Tomás José Gutiérrez Cobo ....

3. Análisis mesoescalar y preconvectivo por Tomás José Gutiérrez Cobo

4. Análisis de las predicciones y avisos por Ramón Pascual Berghaenel .

5. Repercusiones aeronáutivas operativas en LEZG

por José Manuel López Pérez

6. Caracterización de las estructuras convectivas

por Ismael Sanambrosio Beirán

\section{Análisis de los datos de observación}

por Samuel Tomás Buisán Sanz

8. Visita de campo

por Tomás José Gutiérrez Cobo

9. Conclusiones

por Ismael Sanambrosio Beirán

10. Bibliografía 



\section{INTRODUCCIÓN}

Durante la tarde del domingo 1 de julio de 2018 tuvo lugar en la provincia de Zaragoza un episodio complejo de tiempo adverso asociado a la aparición de varias células convectivas que provocaron incidencias a su paso por diversos puntos de la geografía zaragozana.

Dicho episodio ha dado lugar a la solicitud por parte de particulares y empresas de informes meteorológicos relativos a la situación atmosférica que se vivió.

Tanto los medios de comunicación locales como las redes sociales se hicieron eco de los sucesos acontecidos con mayor o menor rigurosidad.

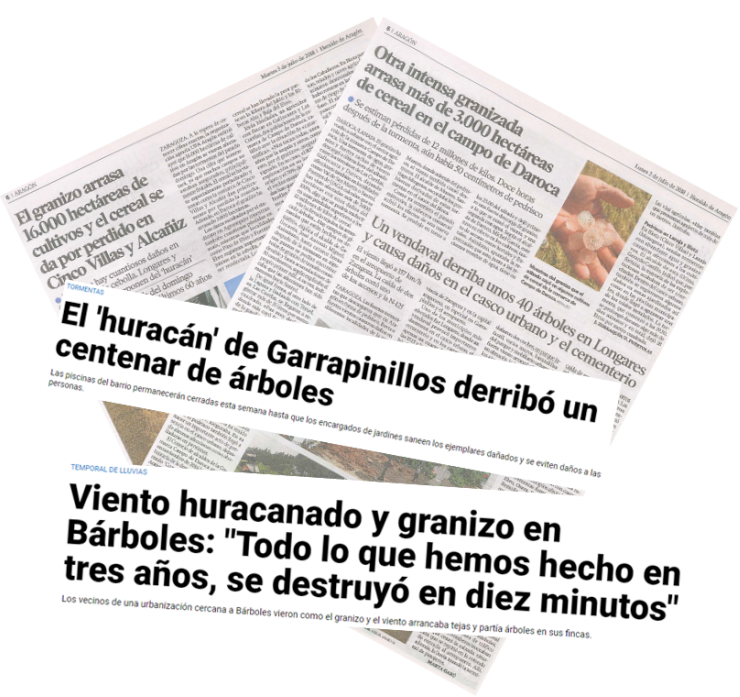

Figura 1. Noticias en prensa escrita y digital.

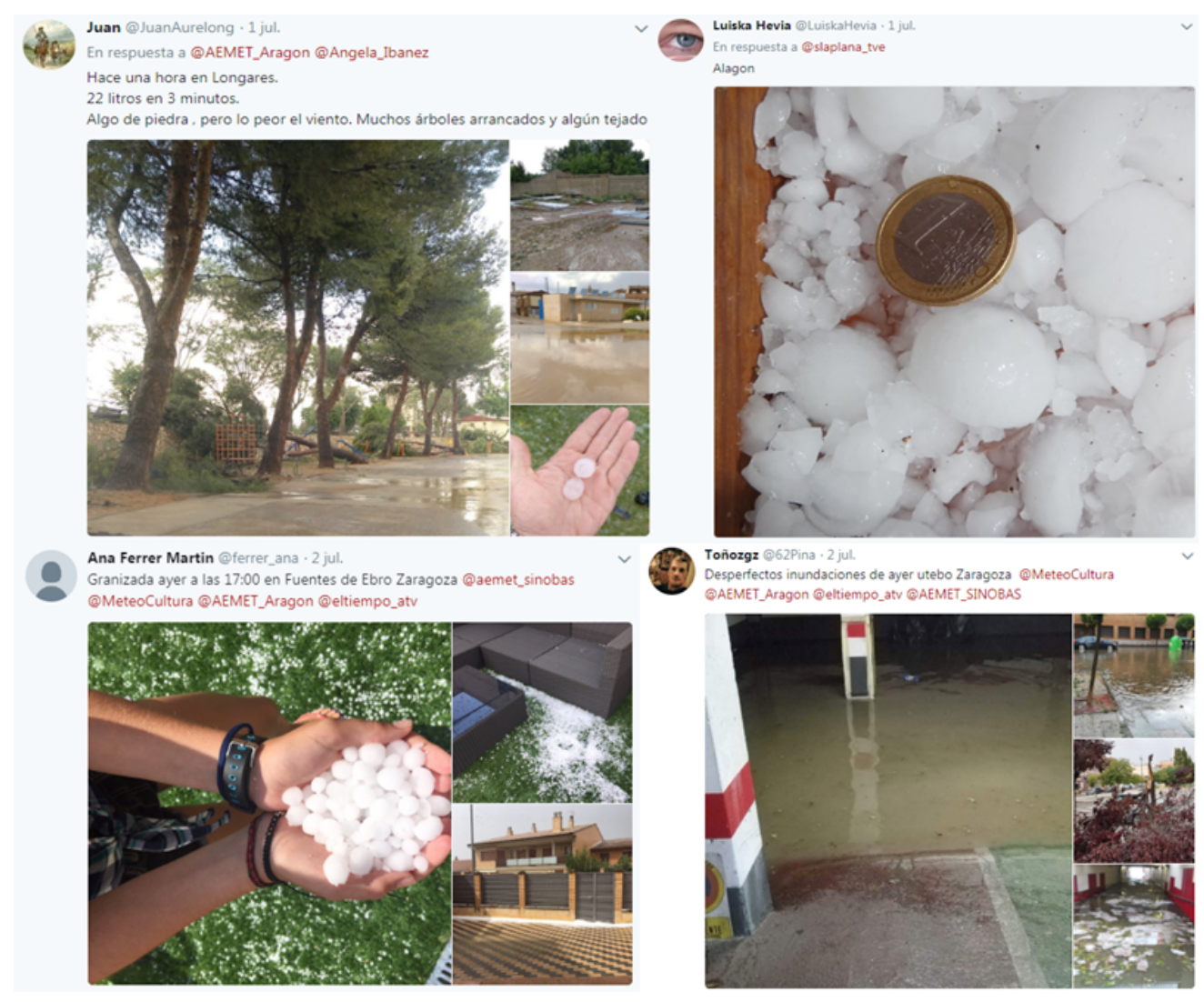

Figura 2. Episodio convectivo del 1 de julio de la provincia de Zaragoza en Twitter.

En las figuras 3 y 4 se presentan algunas de las zonas afectadas que se han podido ver tanto en medios de comunicación como en la visita de campo que los autores de este trabajo realizaron a Osera de Ebro. 


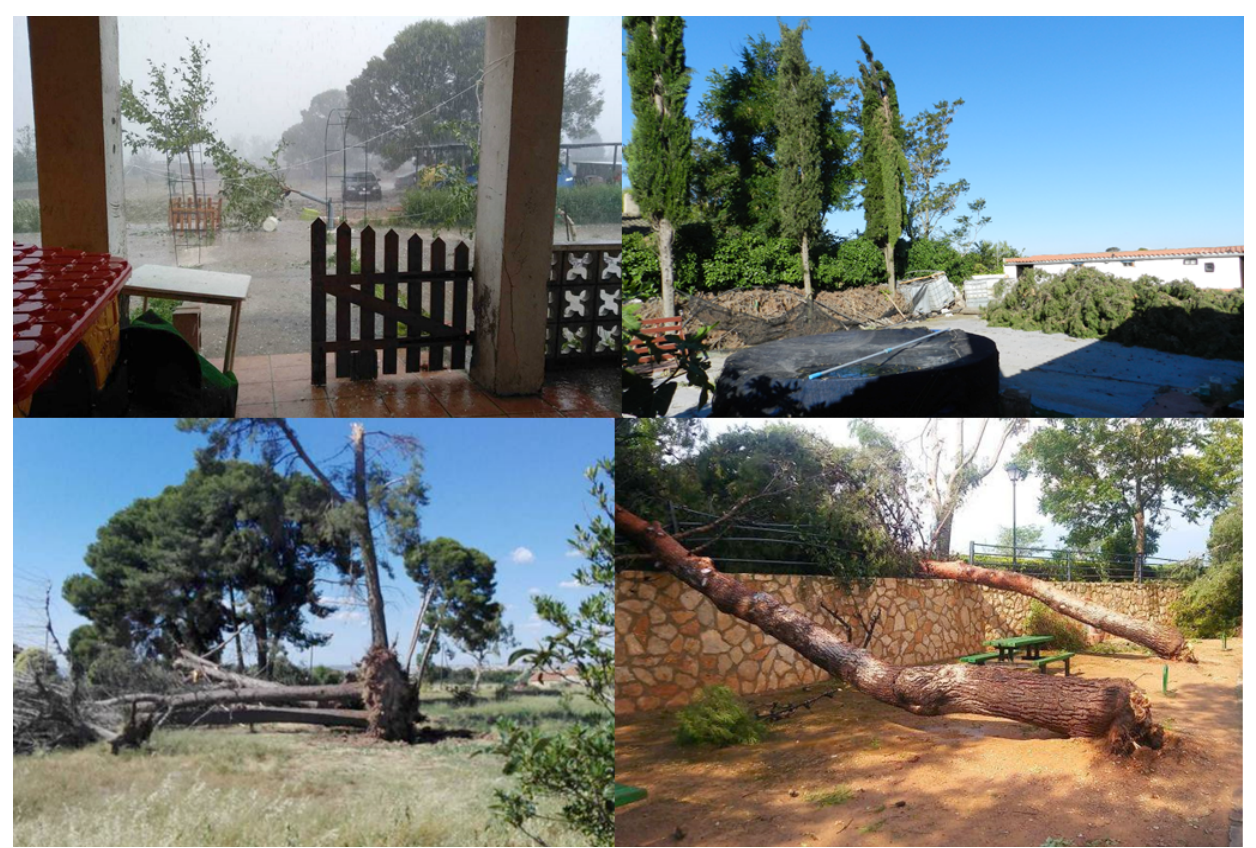

Figura 3. De izquierda a derecha y de arriba abajo: destrozos en Bárboles, Osera de Ebro, Garrapinillos y Longares.

Fuente: Heraldo de Aragón (Bárboles y Garrapinillos), El Periódico de Aragón (Longares) y los autores de este informe (Osera de Ebro).
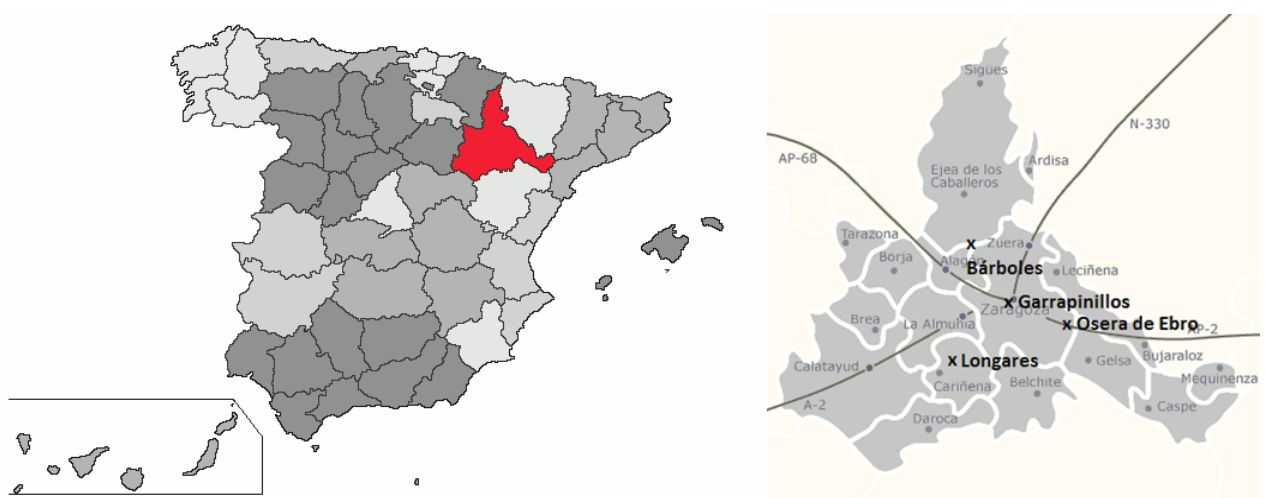

Figura 4. Situación de la provincia de Zaragoza y de los puntos de las fotografías de la figura 3.

Fuentes: https://es.wikipedia.org la imagen de la izquierda, y www.idealista.es el mapa base (

Ante esta excepcional situación, se decide elaborar un informe de lo sucedido durante la jornada del 1 de julio en la provincia de Zaragoza desde las delegaciones territoriales de AEMET en Aragón, Cataluña y Comunidad Valenciana. Este documento pretende caracterizar la situación que aconteció para poder dar respuesta a las solicitudes de informes por desperfectos, así como poder documentar de manera adecuada un episodio singular que provocó, entre otros efectos, la observación de una racha similar a la más intensa de viento registrada hasta entonces en el aeropuerto de Zaragoza, uno de los puntos más afectados por el paso de una potente célula convectiva.

En el aeropuerto de Zaragoza se dispone de anemómetros y veletas situados en varios puntos y todos funcionaron correctamente durante el evento. Estos instrumentos nos servirán para caracterizar la variabilidad espacial y la magnitud de los efectos adversos asociados a los fenómenos convectivos. A modo de ejemplo, la racha máxima medida en la ESOS (estación semiautomática de observación en superficie, la estación del aeropuerto válida para el registro de efemérides) alcanzó los $135 \mathrm{~km} / \mathrm{h}$, igualando la efeméride de racha máxima. A este respecto, hay que señalar que la otra vez en la que se midieron $135 \mathrm{~km} / \mathrm{h}$ en el aeropuerto de Zaragoza el anemómetro se situaba a mayor altura, en una azotea, que los 10 metros del actual. Además, en una de las cabeceras aeronáuticas se midieron $157 \mathrm{~km} / \mathrm{h}$, aunque a efectos de registro de efemérides es la cabecera sinóptica donde se encuentra la ESOS la que se tiene en cuenta. 


\section{SITUACIÓN SINÓPTICA}

En las figuras 5 y 6 se muestran los análisis de temperatura y altura geopotencial del modelo determinista de alta resolución (HRES-IFS) del Centro Europeo de Predicción a Plazo Medio (ECMWF) de las 12 UTC y de las 18 UTC del día 1 en el nivel de 500 hPa.

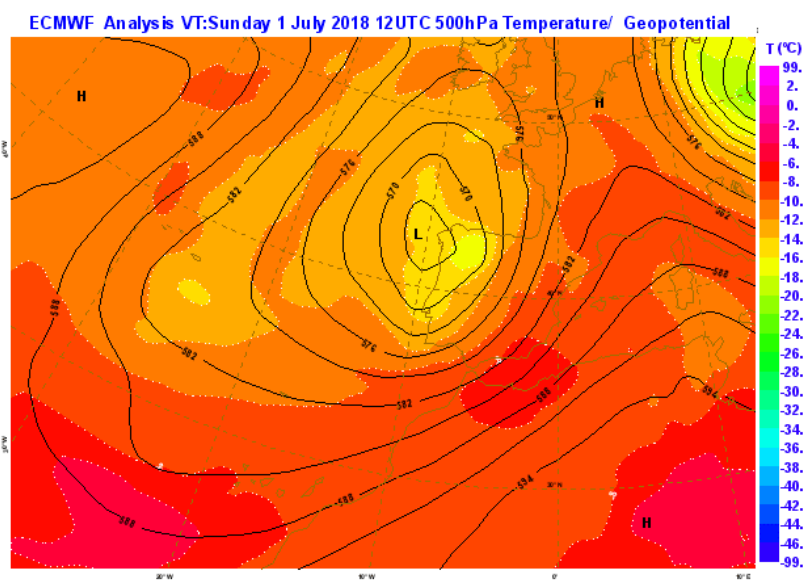

Figura 5. Análisis del HRES-IFS de la temperatura y la altura geopotencial en $500 \mathrm{hPa}$ a las $12 \mathrm{UTC}$.

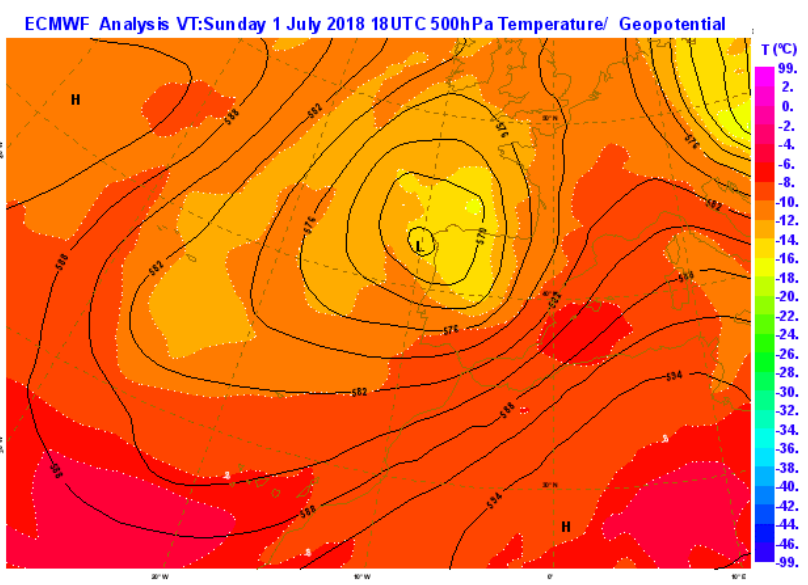

Figura 6. Análisis del HRES-IFS de la temperatura y la altura geopotencial en $500 \mathrm{hPa}$ a las $18 \mathrm{UTC}$.

La situación a escala sinóptica estaba definida por una baja con núcleo frío de unos $-16{ }^{\circ} \mathrm{C}$ centrada en la costa occidental gallega que provocó circulación ciclónica en toda la Península, con un flujo del SW difluente sobre la zona de interés. Había además una posible pequeña onda secundaria que se distingue levemente en la figura 6.

Se aprecia en la figura 7 un máximo de viento al sur de la zona de interés, con un ramal cruzando el centro de la Península y apuntando a Aragón con una velocidad máxima de unos 50 kt en su centro según la Guía técnica de diagnóstico del Centro Nacional de Predicción (no mostrada aquí) que se debilita ligeramente en la zona de difluencia. A las 18 UTC la zona de estudio se sitúa a la izquierda

ECMWF Analysis VT:Sunday 1 July 2018 18UTC 300hPa Strmln / Wind Speed

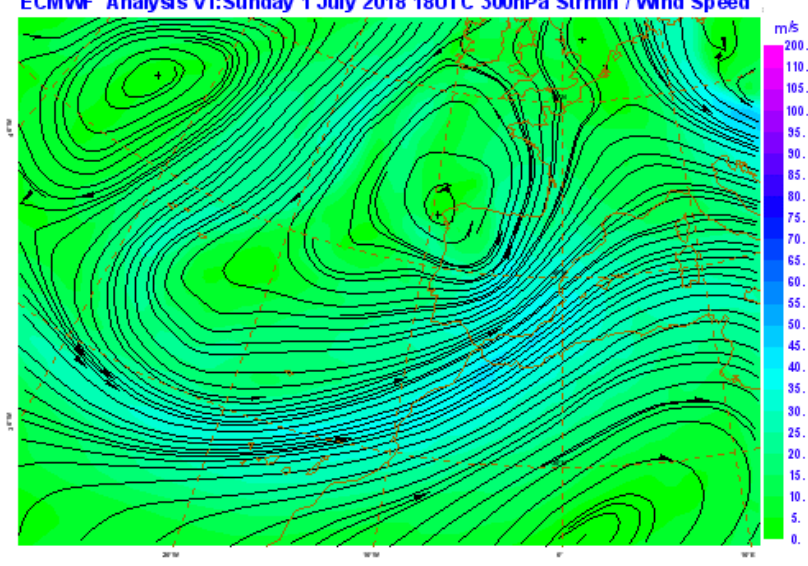
de la salida del máximo de viento, área que según el conocido esquema de los cuatro cuadrantes (BLUESTEIN, 1993) sería favorable a los movimientos ascendentes a mesoescala.

Figura 7. Análisis del HRES-IFS del viento en $300 \mathrm{hPa}$ a las 18 UTC. 
En el análisis del campo de presión en superficie, figura 8, se aprecia la presencia de un mínimo de presión de origen térmico sobre Aragón que modifica el flujo mesoescalar, favoreciendo la entrada de aire húmedo de origen mediterráneo y las convergencias en superficie con los vientos de componente suroeste que predominan al oeste de la comunidad. Esta convergencia, unida a las elevadas temperaturas de la zona, podría haber actuado como mecanismo de disparo.

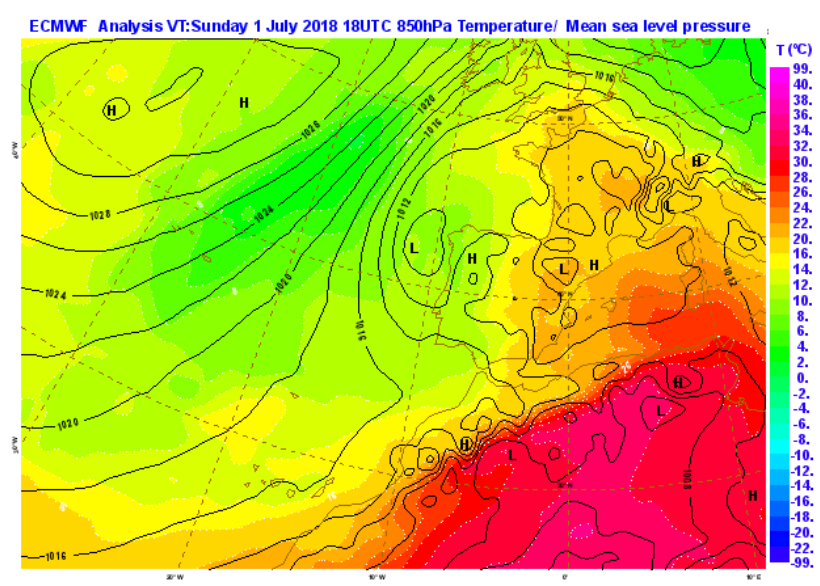

Figura 8. Análisis del HRES-IFS de la temperatura en 850 hPa y la presión a nivel del mar a las 18 UTC. 


\section{ANÁLISIS MESOESCALAR Y PRECONVECTIVO}

\section{SITUACIÓN MESOESCALAR}

Comenzamos el estudio de la situación mesoescalar mostrando el análisis de temperatura y altura geopotencial en $500 \mathrm{hPa}$ del HIRLAM $0.48^{\circ}$, figura 9. Se observa claramente el mínimo térmico de $-16{ }^{\circ} \mathrm{C}$ desplazado hacia el este del mínimo de altura geopotencial, tal como ya se apreciaba en la figura 5. Asimismo, aparece una onda térmica de $-10^{\circ} \mathrm{C}$ sobre el nordeste peninsular que también se intuía en la figura 5.

En la figura 10 se muestra el análisis de las 18 UTC donde se percibe que esta onda térmica ha contribuido a la formación de los desarrollos convectivos de nuestro interés.

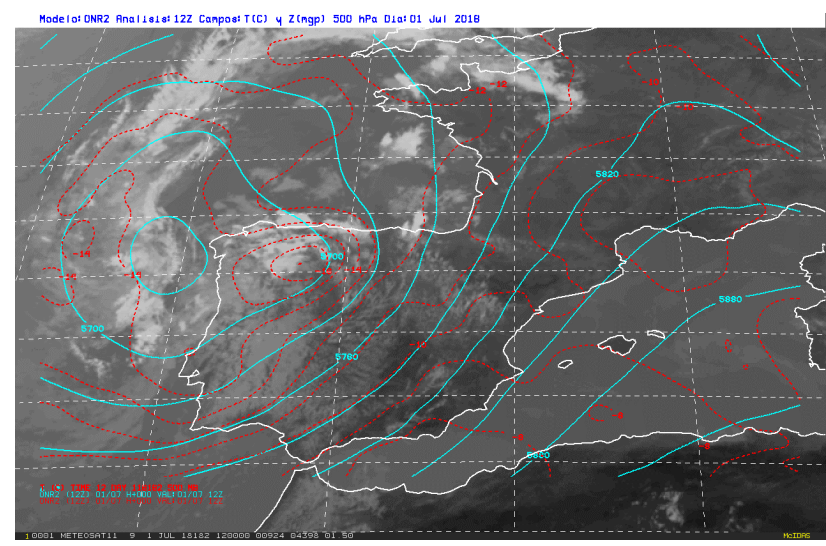

Figura 9. Análisis del HIRLAM $0.48^{\circ}$ de la temperatura y la altura geopotencial en $500 \mathrm{hPa}$ a las $12 \mathrm{UTC}$ superpuesta a la imagen del canal IR108 del Meteosat11.

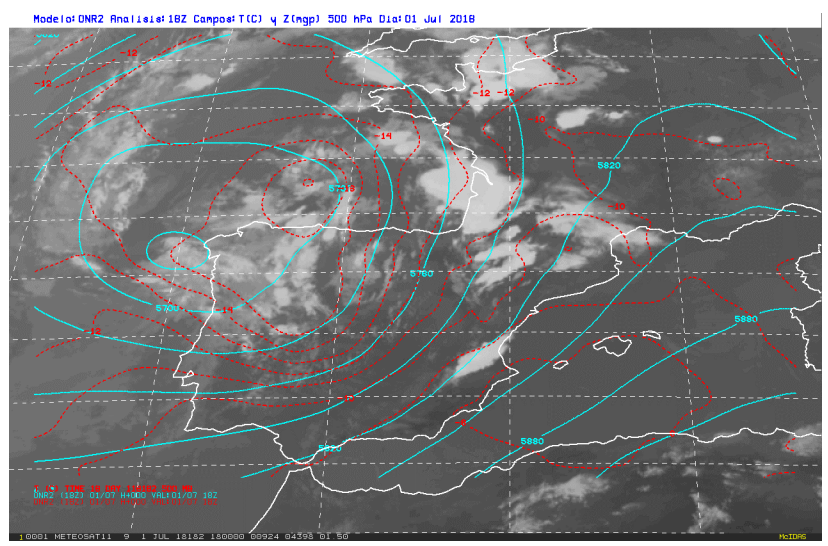

Figura 10. Análisis del HIRLAM $0.48^{\circ}$ de la temperatura y la altura geopotencial en $500 \mathrm{hPa}$ a las $18 \mathrm{UTC}$

superpuesta a la imagen del canal IR108 del Meteosat11.

En la figura 11 se muestra el análisis del HIRLAM $0.05^{\circ}$ a las 12 UTC de la presión a nivel del mar y del viento en superficie en el cuadrante nororiental peninsular. En ella se aprecia el área de relativa baja presión que abarca gran parte del valle del Ebro y que intensifica el flujo de origen marítimo procedente del Mediterráneo, dando lugar a convergencias principalmente al suroeste de la provincia

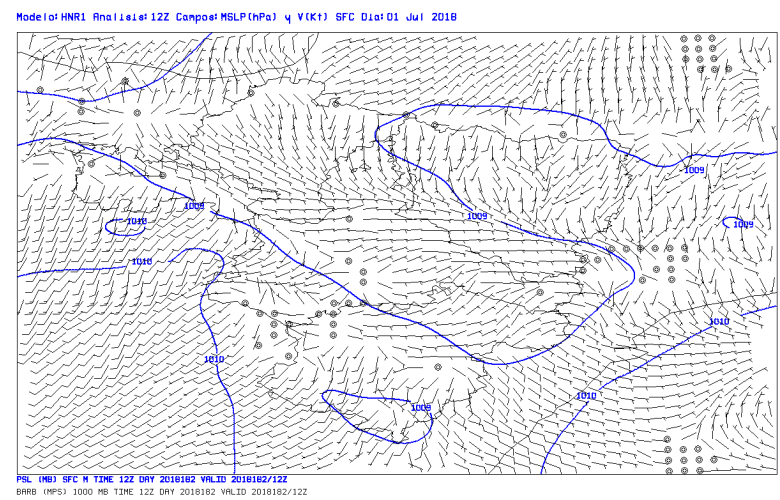

Figura 11. Análisis del HIRLAM $0.05^{\circ}$ de la presión a nivel del mar y del viento en superficie a las 12 UTC.

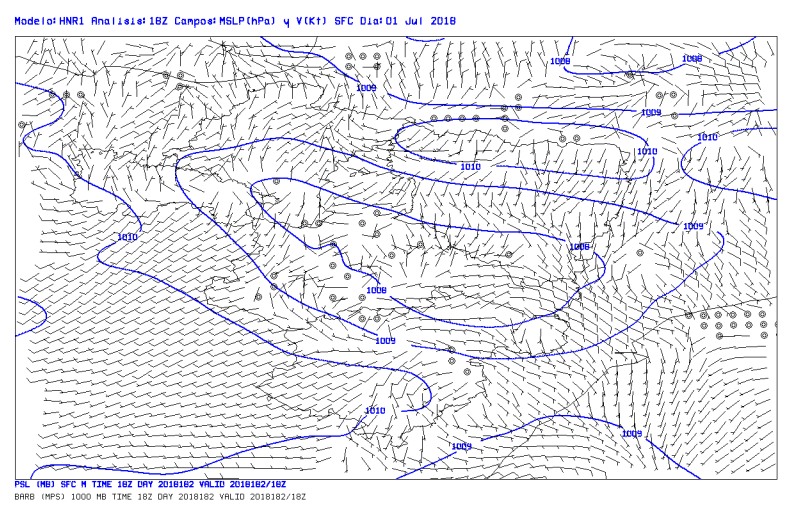

Figura 12. Análisis del HIRLAM $0.05^{\circ}$ de la presión a nivel del mar y del viento en superficie a las 18 UTC. 


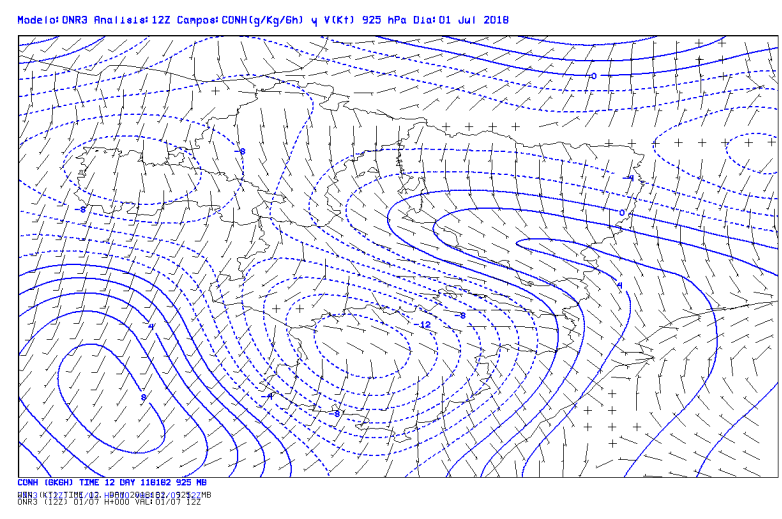

Figura 13. Análisis del HIRLAM $0.16^{\circ}$ del viento y de la convergencia del flujo de humedad en $925 \mathrm{hPa}$ a las 12 UTC.

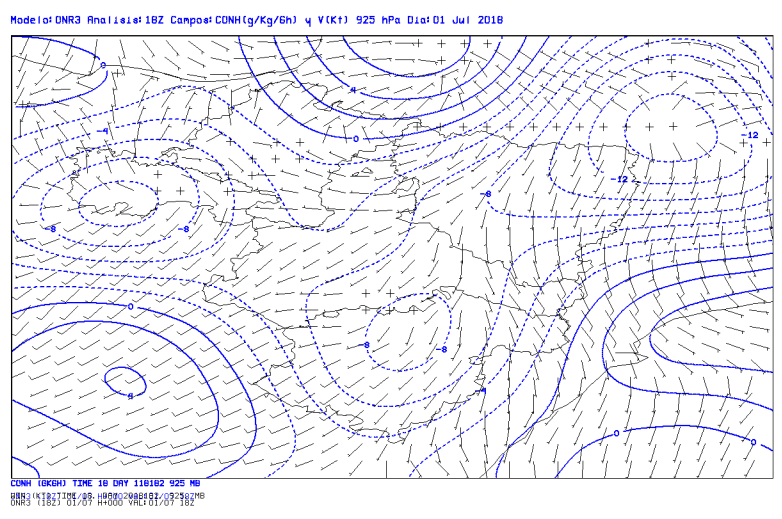

Figura 14. Análisis del HIRLAM $0.16^{\circ}$ del viento y de la convergencia del flujo de humedad en $925 \mathrm{hPa}$ a las $18 \mathrm{UTC}$.

de Zaragoza entre los flujos secos predominantes del suroeste y los flujos húmedos del sudeste. En el análisis de las 18 UTC, figura 12, estas convergencias abarcan gran parte de la frontera entre Zaragoza y Teruel.

La convergencia del flujo de humedad se muestra explícitamente en las figuras 13 y 14 , en los análisis del HIRLAM $0.16^{\circ}$ de viento y convergencia de humedad en $925 \mathrm{hPa}$. Los valores de esta convergencia en las salidas del ECMWF $0.125^{\circ}$ son ligeramente inferiores a los del HIRLAM $0.16^{\circ}$. En 850 hPa también se aprecia esta convergencia de humedad, aunque de menor intensidad (no se muestran las imágenes), alcanzándose los valores máximos a las 15 UTC (predicción $\mathrm{H}+03$ ), y siendo estos de $-8 \mathrm{~g} / \mathrm{kg} / 6 \mathrm{~h}$ según el ECMWF $0.125^{\circ}$ y de $-6 \mathrm{~g} / \mathrm{kg} / 6 \mathrm{~h}$ según el HIRLAM $0.16^{\circ}$.

En $700 \mathrm{hPa}$, figura 15, el viento es del SW y en la altura geopotencial a este nivel se aprecia una posible pequeña onda (señalada en rojo en la figura) que puede también ayudar a que se produzcan desarrollos convectivos.

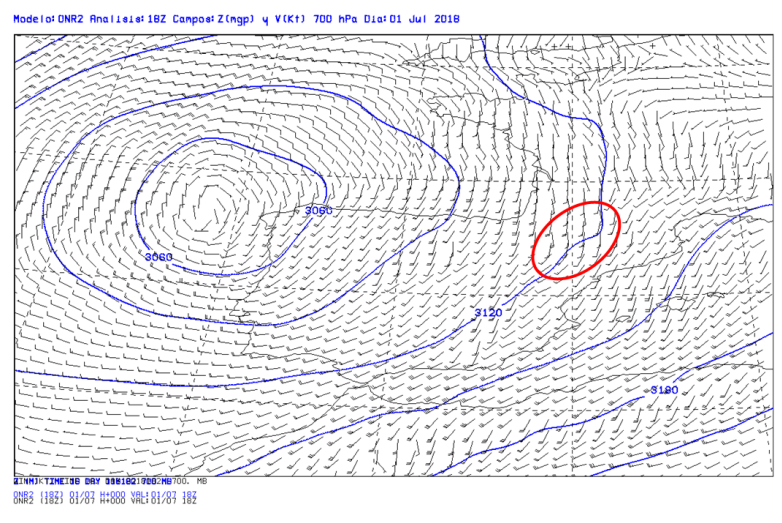

Figura 15. Análisis del HIRLAM $0.48^{\circ}$ de la altura geopotencial y el viento en $700 \mathrm{hPa}$ a las 18 UTC.

\section{ENTORNO PRECONVECTIVO}

EI CAPE (Convective Available Potential Energy) indica la cantidad de energía potencial disponible cuando una burbuja de aire asciende libremente a partir del NCL (nivel de convección libre, nivel a partir del cual está más caliente que el aire ambiente que la rodea). En contraposición, el CIN (Convective INhibition) es la energía que hay que suministrar a una burbuja de aire (por ejemplo, mediante calentamiento o energía cinética cuando el flujo de aire incide contra una barrera orográfica) para alcanzar el NCL. Estos parámetros considerados a partir de una evolución que parte exactamente desde superficie se denominan SBCAPE (Surface Based CAPE) y SBCIN (Surface Based CIN).

Los parámetros CIZ3 y ClZ6 nos indican la cizalladura vertical del viento en los primeros 3 y 6 kilómetros, respectivamente, de atmósfera junto al suelo. En la figura 16 se muestra la salida del HRES-IFS del ECMWF $0.125^{\circ}$ de CAPE, SBCAPE, CIZ3 y CIZ6 a las 15 UTC. Los valores proporcionados por este modelo son sensiblemente inferiores a los pronosticados por el HIRLAM $0.16^{\circ}$, figura 17 . Vemos, en todo caso, valores de SBCAPE por encima, en general, de $500 \mathrm{~J} / \mathrm{kg}$, que en Teruel llegan a superar los $1000 \mathrm{~J} / \mathrm{kg}$ (según el HIRLAM, supera los $1500 \mathrm{~J} / \mathrm{kg}$ en prácticamente toda la provincia de Zaragoza), lo que es indicativo del potencial convectivo que hay en la región. 
Respecto a la cizalladura vertical del viento, cabe destacar que en los primeros 6 kilómetros alcanza, en la predicción de los dos modelos, los $12 \mathrm{~m} / \mathrm{s}$ en la provincia de Zaragoza. Según QuiRANTES ET AL. (2014), estos valores de cizalladura y SBCAPE son lo suficientemente elevados para generar supercélulas.
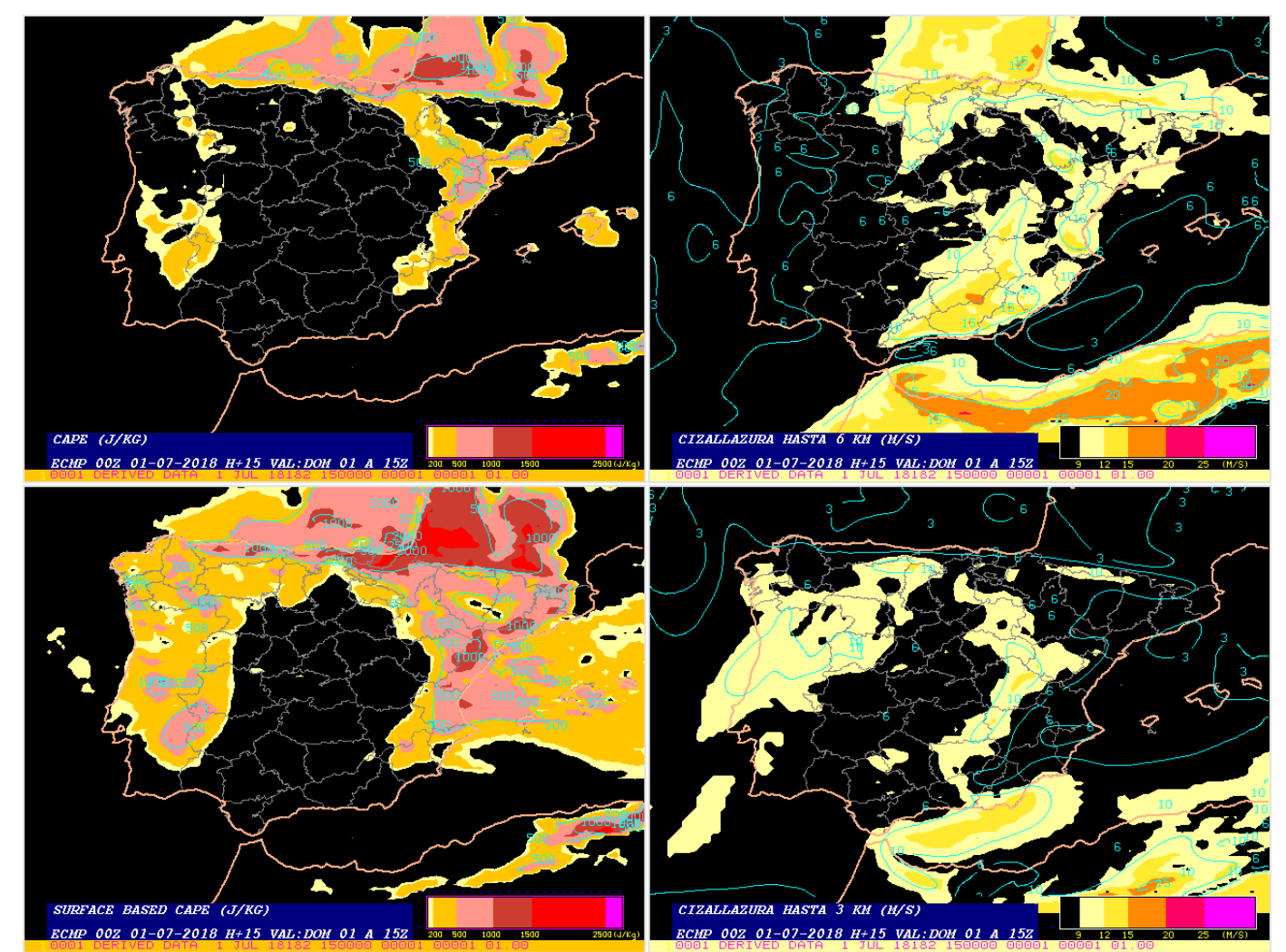

Figura 16. CAPE y cizalladura H+15 según el HRES-IFS del ECMWF $0.125^{\circ}$ a las 15 UTC.
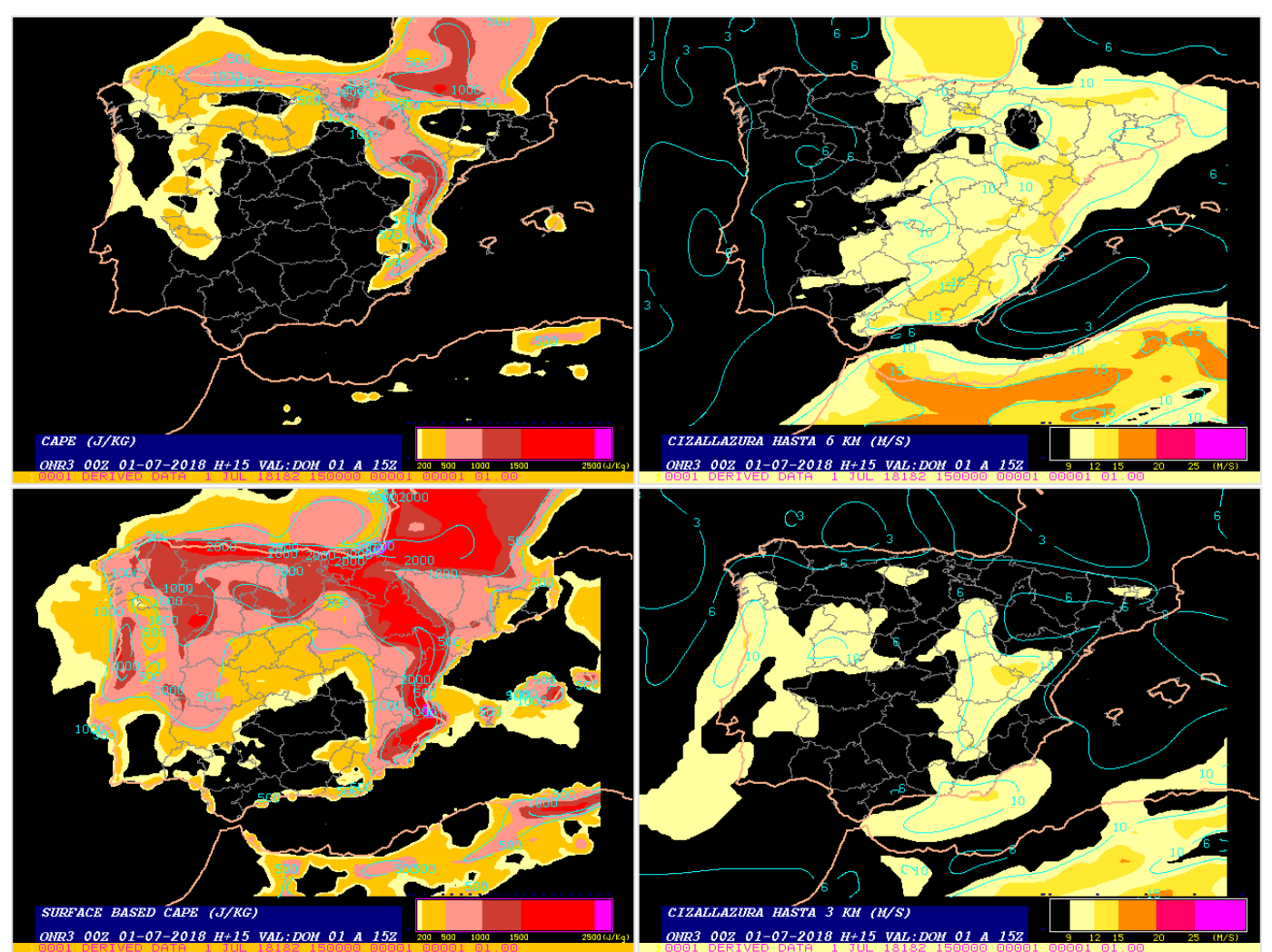

Figura 17. CAPE y cizalladura H+15 según HIRLAM $0.16^{\circ}$ a las 15 UTC. 
EI CAPE en niveles bajos (hasta $3 \mathrm{~km}$ ) previstos por el HIRLAM $0.16^{\circ}$, figura 18 , alcanza los $100 \mathrm{~J} / \mathrm{kg}$ al sur de Zaragoza, lo que podría favorecer el aprovechamiento de la cizalladura vertical de niveles bajos para generar rotación en las células convectivas (GUTIÉRREZ RUBIO ET AL., 2017). Los valores previstos por el ECMWF son bastante inferiores y los máximos están desplazados al sudeste.

La helicidad relativa a la tormenta, que cuantifica la superposición de vorticidad horizontal paralela al flujo horizontal de la tormenta, pronosticada por el HIRLAM $0.16^{\circ}$, figura 19, alcanza valores comprendidos entre los 100 y los $150 \mathrm{~m}^{2} / \mathrm{s}^{2}$ (valores solo ligeramente superiores a los pronosticados por el ECMWF $0.125^{\circ}$ ), compatibles con la formación de células convectivas con rotación en su seno.

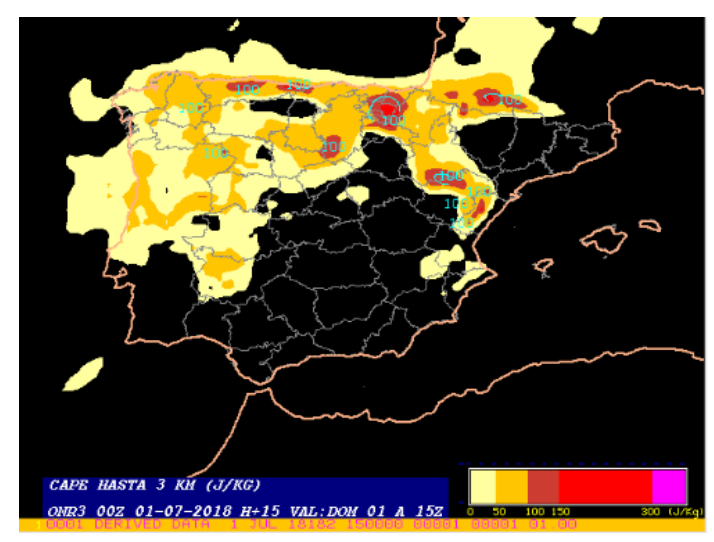

Figura 18. CAPE hasta $3 \mathrm{~km} \mathrm{H}+15$ según HIRLAM $0.16^{\circ}$ a las 15 UTC.
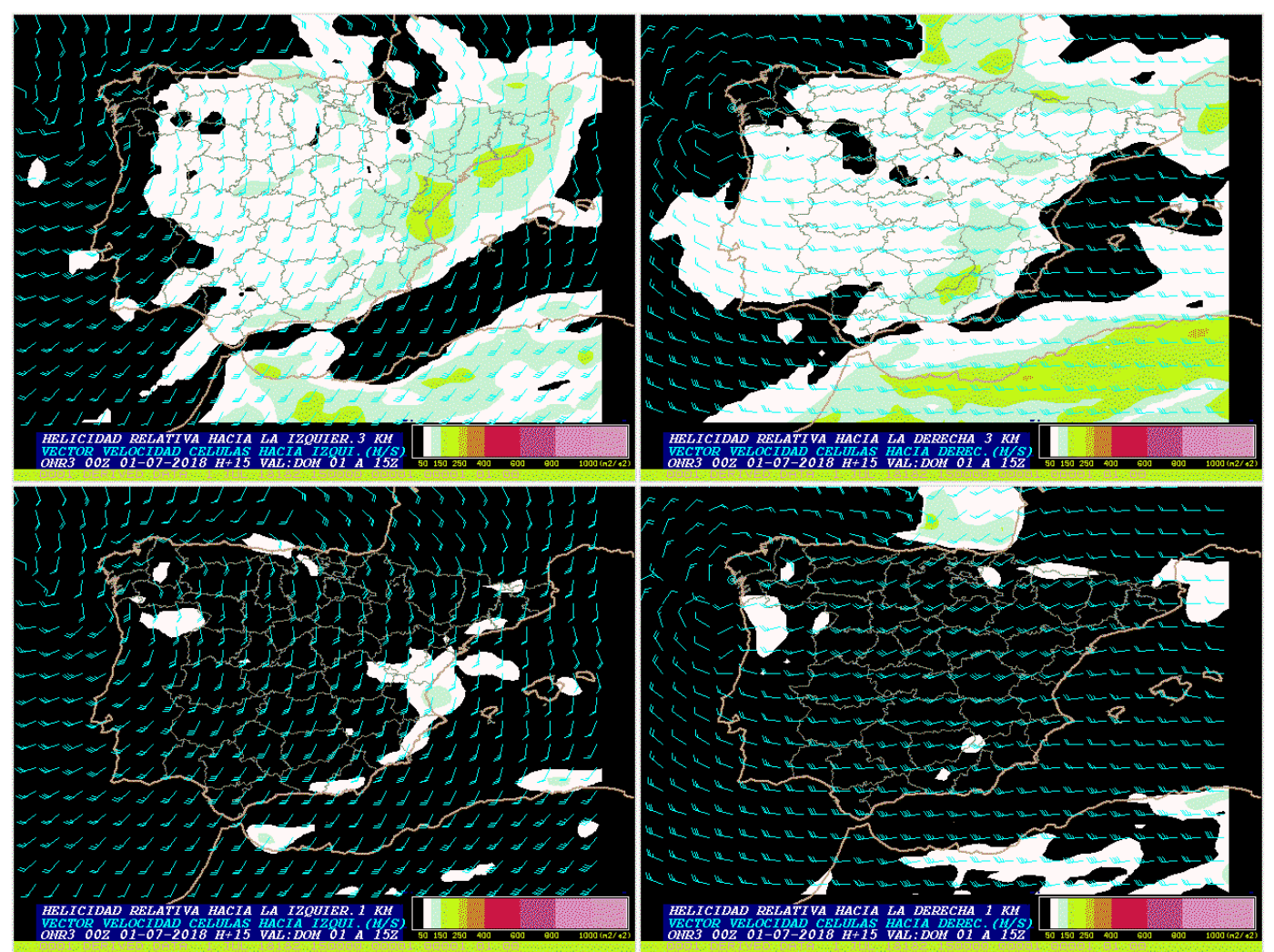

Figura 19. Helicidad relativa a la tormenta H+15 según HIRLAM $0.16^{\circ}$ a las 15 UTC.

En la figura 20 se presentan otros índices de convección pronosticados por el HIRLAM $0.16^{\circ}$ para las 15 UTC. EI LI (Lifted Index) nos da idea de la flotabilidad de las burbujas de aire y se calcula como la diferencia entre la temperatura observada en $500 \mathrm{hPa}$ y la temperatura de una parcela de aire que se elevase hasta $500 \mathrm{hPa}$ desde la superficie (el LI7 es similar al LI pero tomando como nivel los $700 \mathrm{hPa}$ ). Hay valores por debajo de $-4{ }^{\circ} \mathrm{C}$ (en general, entre $-2{ }^{\circ} \mathrm{C} y-4{ }^{\circ} \mathrm{C}$ ), lo que indica un ambiente bastante inestable. Los valores pronosticados por el HRES-IFS del ECMWF $0.125^{\circ}$ son bastante inferiores. EI TT (Total Totals Index) se calcula utilizando la temperatura y el punto de rocío en $850 \mathrm{hPa}$ y la temperatura en $500 \mathrm{hPa}$. Se tienen valores por encima de $50{ }^{\circ} \mathrm{C}$ (ligeramente superiores a los pronosticados por el HRES-IFS $0.125^{\circ}$ ), lo que da idea de la posibilidad de aparición de tormentas severas. Por último, el índice $\mathrm{K}$ ( $K$ index) es útil para identificar ambientes favorables a la convección y la producción de precipitaciones intensas y tiene en cuenta la distribución de humedad y temperatura. Alcanza 


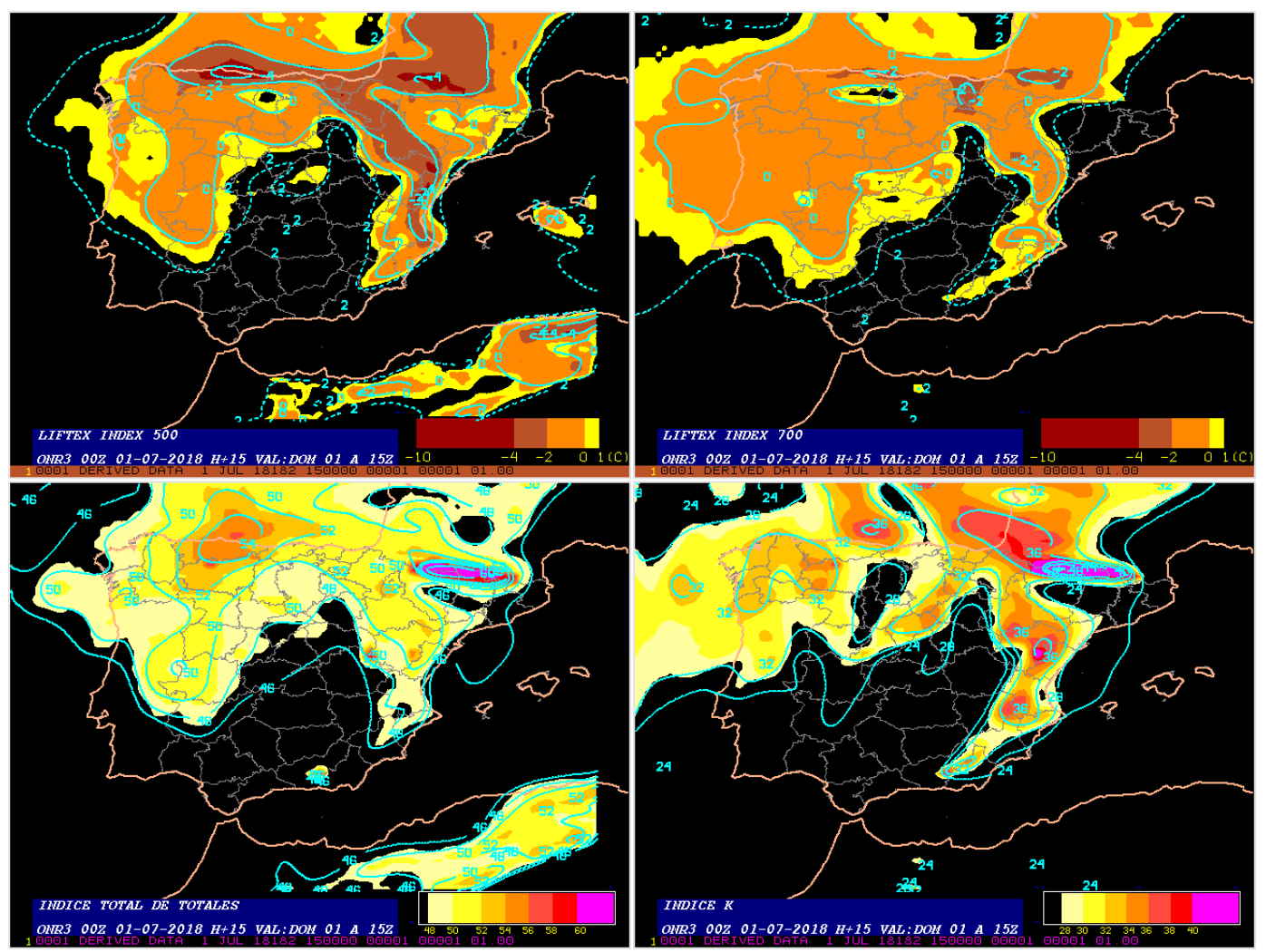

Figura 20. LI, TT y K H+15 según HIRLAM 0.16ª a las 15 UTC.

valores de $36^{\circ} \mathrm{C}$ (en este caso, el HRES-IFS $0.125^{\circ}$ da valores superiores, aunque coincide en la intensidad y colocación del máximo turolense), que nos indica que la probabilidad de que se desarrollen tormentas es alta.

Los valores de SBCIN pronosticados por el HIRLAM $0.16^{\circ}$ para las 15 UTC no son altos, encontrándose por debajo de $50 \mathrm{~J} / \mathrm{kg}$ en toda la zona de interés, figura 21, siendo significativamente más elevados a partir de las 21 UTC y similares a los pronosticados por el HRES-IFS del ECMWF $0.125^{\circ}$.

El agua precipitable según el HIRLAM $0.16^{\circ}$ a las 15 UTC, figura 22, marca un máximo puntual de unos $35 \mathrm{~mm}$ y, de manera más generalizada, unos $30 \mathrm{~mm}$, valores que se mantienen en la siguiente salida del modelo, 3 horas más tarde, y sensiblemente mayores que la salida anterior, a las 12 UTC. Los valores son similares a los previstos por el ECMWF $0.125^{\circ}$.

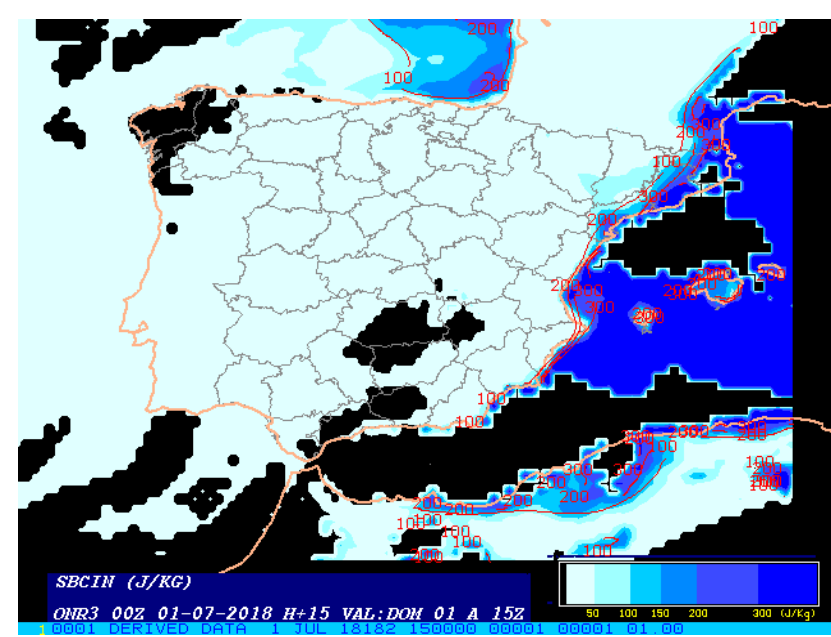

Figura 21. SBCIN H+15 según HIRLAM $0.16^{\circ}$ a las 15 UTC.

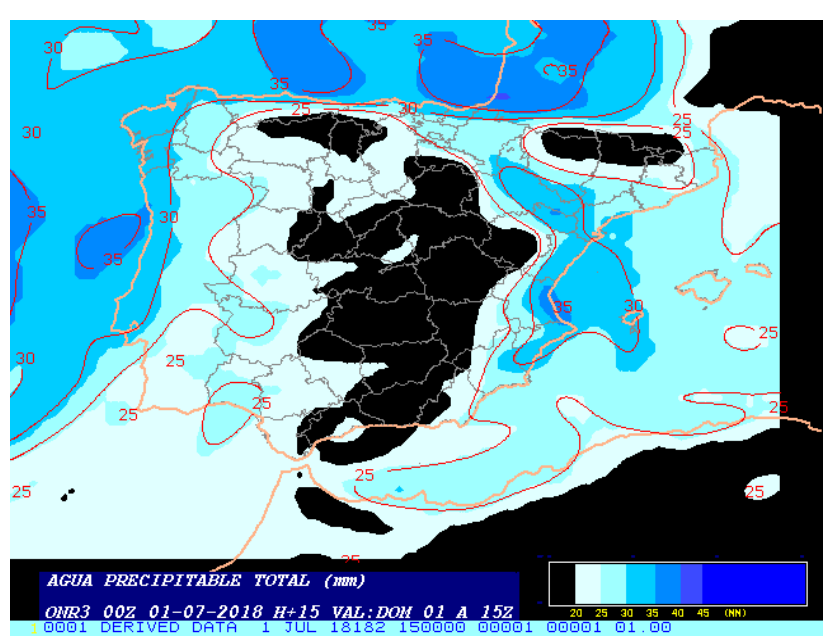

Figura 22. Agua precipitable H+15 según HIRLAM 0.16º a las 15 UTC. 


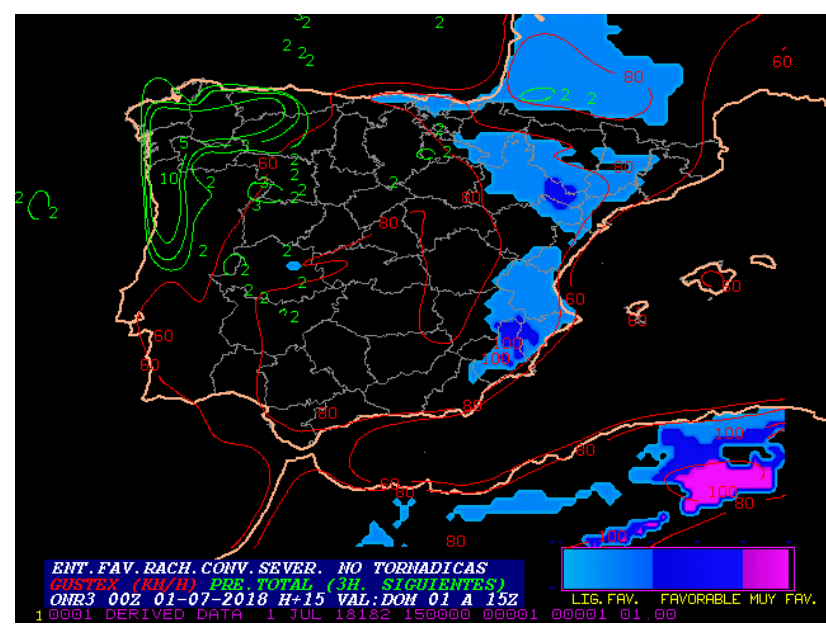

Figura 23. Entornos favorables a rachas severas no tornádicas y GUSTEX. H+15 según HIRLAM 0.16 a las 15 UTC.

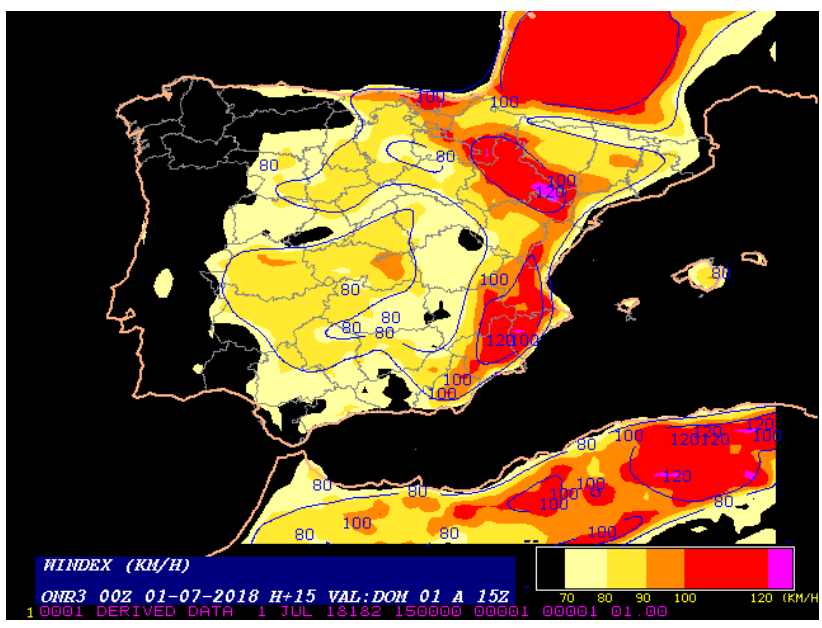

Figura 24. WINDEX H+15 según HIRLAM $0.16^{\circ}$ a las 15 UTC.

EI GUSTEX (GU) es un índice relacionado con la racha máxima de viento de origen convectivo esperada y es mayor cuanto mayor es el WINDEX y el módulo del viento medio en $500 \mathrm{hPa}$. El WINDEX a su vez es una estimación de la hipotética racha máxima en superficie. Este índice fue el resultado de una investigación sobre microbursts realizada por la US Air Force y para su cálculo se usa la altura de la isocero, la proporción de mezcla del primer kilómetro, la proporción de mezcla en la isocero (único parámetro cuyo aumento hace que disminuya esta estimación del viento) y el gradiente térmico vertical desde la isocero hasta la superficie (Perea Hitos et al., 2014). El estudio de entornos favorables a rachas convectivas severas no tornádicas usa un algoritmo que tiene en cuenta los índices de inestabilidad LI y LI7 y el DCAPE (Downdraft CAPE), así como el índice GUSTEX para estimación de rachas convectivas. En la figura 23 se muestra el GUSTEX y los entornos favorables a rachas convectivas severas no tornádicas según el HIRLAM $0.16^{\circ}$ a las 15 UTC. La salida es similar a la del HRES-IFS $0.125^{\circ}$ (no mostrada). Destaca la posibilidad de vientos superiores a $80 \mathrm{~km} / \mathrm{h}$.

Señalar que el WINDEX prevé rachas superiores a los $100 \mathrm{~km} / \mathrm{h}$ entre las 12 UTC y las 18 UTC, pudiendo llegar incluso a superar los $120 \mathrm{~km} / \mathrm{h}$, figura 24.

Se presentan en las figuras 25, 26, 27 y 28 los sondeos y hodógrafas de HARMONIE-AROME, los previstos para las 15 UTC y los analizados a las 18 UTC en el aeropuerto de Zaragoza. Los índices convectivos tienen magnitudes significativas. EI LI, algo inferior que el que se preveía en la figura 20, pero variando de $-2{ }^{\circ} \mathrm{Ca}-4{ }^{\circ} \mathrm{C}$ entre los dos sondeos. El TT y el $\mathrm{K}$ también aumentan entre las 15 UTC

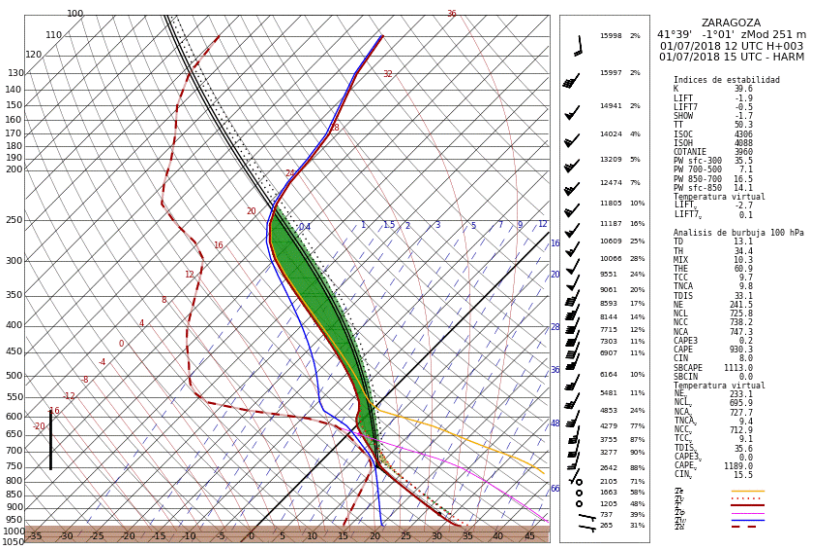

Figura 25. Sondeo H+03 en el aeropuerto de Zaragoza previsto por HARMONIE-AROME a las 15 UTC.

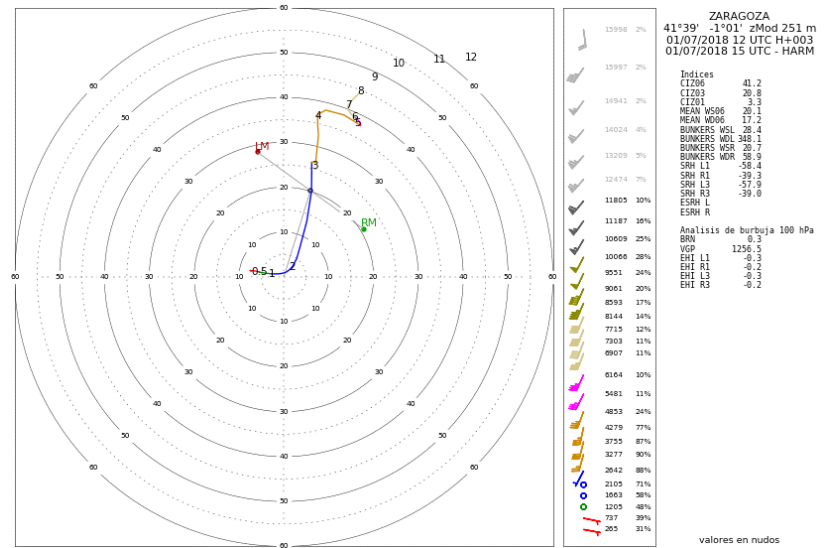

Figura 26. Hodógrafa H+03 en el aeropuerto de Zaragoza previsto por HARMONIE-AROME a las 15 UTC. 


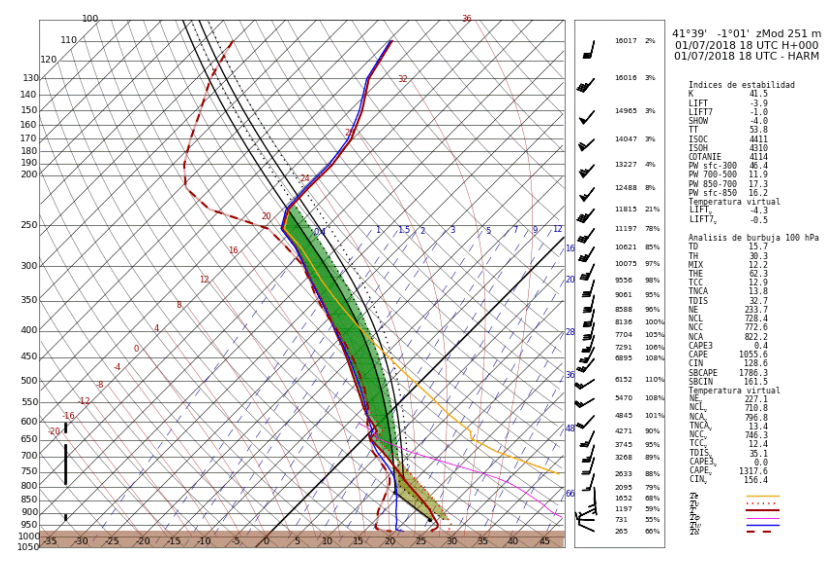

Figura 27. Sondeo en el aeropuerto de Zaragoza. Análisis del HARMONIE-AROME a las 18 UTC.

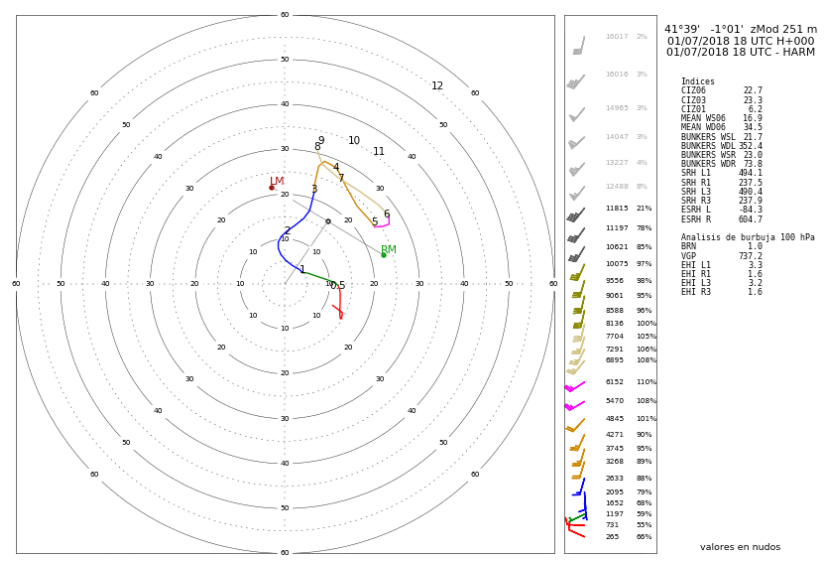

Figura 28. Hodógrafa en el aeropuerto de Zaragoza. Análisis del HARMONIE-AROME a las 18 UTC.

y las 18 UTC, con valores superiores a los previstos en la figura 20 . El índice $\mathrm{K}$ supera los $40^{\circ} \mathrm{C}$ y el TT alcanza un valor de $54^{\circ} \mathrm{C}$. El SBCIN también aumenta, adquiriendo a las 18 UTC un valor de 161,5 J/kg. Pero lo más significativo es el SBCAPE, que ya a las 15 UTC presenta un valor alto, de $1100 \mathrm{~J} / \mathrm{kg}$, pero que a las 18 UTC ha aumentado sustancialmente hasta superar los $1700 \mathrm{~J} / \mathrm{kg}$. El CAPE en los tres primeros kilómetros es despreciable en los dos sondeos y el NCL está bastante alto.

Por el contrario, la cizalladura en los 6 primeros kilómetros es mayor en la hodógrafa de las 15 UTC, alcanzando los $20 \mathrm{~m} / \mathrm{s}$. A las 18 UTC ha bajado hasta situarse en torno a los $10 \mathrm{~m} / \mathrm{s}$. En la hodógrafa de las 15 UTC se aprecia viento de componente este en superficie y hasta una altitud de unos $2 \mathrm{~km}$ no empieza a ser significativa la velocidad del viento de dirección suroeste, a partir de este punto se aprecia una hodógrafa recta. El perfil de viento en la hodógrafa de las 18 UTC es diferente. Ya no se aprecian vientos de componente este en superficie, presentando la cizalladura un giro en el sentido contrario a las agujas del reloj hasta el primer o segundo kilómetro, y siendo a partir de ahí unidireccional hasta aproximadamente el cuarto kilómetro. A partir de ahí, la hodógrafa adquiere diferentes curvaturas.

En el sondeo de las 15 UTC se aprecia una capa húmeda entre 650 y $750 \mathrm{hPa}$ y, por debajo, una capa bastante seca que podría realzar la intensidad de las corrientes descendentes. A las 18 UTC, la capa húmeda comienza también en torno a unos $750 \mathrm{hPa}$, pero se extiende hacia arriba, hasta la tropopausa, indicativo de la condensación por ascenso convectivo que ha tenido lugar en este periodo. Asimismo, por debajo de $750 \mathrm{hPa}$ la capa es mucho más seca a las 15 UTC que las 18 UTC.

Se comparan ahora los sondeos anteriores con otros obtenidos con el HIRLAM $0.16^{\circ}$ en dos puntos de la provincia de Zaragoza (no se dispone de estos sondeos ni de la hodógrafa del HARMONIE-AROME). En primer lugar, en La Almunia, figura 29, no se aprecian los vientos de componente este que sí se veían en Zaragoza a las 15 UTC. La cizalladura es unidireccional y también parece adquirir valores importantes.

En la figura 30 se muestra el sondeo previsto a las 18 UTC en La Almunia. Los parámetros significativos para la convección alcanzan valores inferiores, aunque siguen siendo importantes. En el perfil de viento no se aprecia cambio significativo en la dirección aunque sí en la velocidad del mismo, como sí ocurría en los sondeos y hodógrafas del aeropuerto de Zaragoza, figuras 25-28. En las figuras 31 y 32 se muestran sondeos previstos para Alcañiz por el HIRLAM $0.16^{\circ}$ con validez a las 15 UTC y a las 18 UTC. Los parámetros convectivos como el LI, el TT o el CAPE son más elevados en este punto que en La Almunia. La cizalladura también es importante, y el viento en niveles bajos adquiere componente este tanto a las 15 UTC como a las 18 UTC. A las 15 UTC, en niveles bajos, aproximadamente hasta los $800 \mathrm{hPa}$, se aprecia cómo el viento gira con la altura en el sentido de las agujas del 


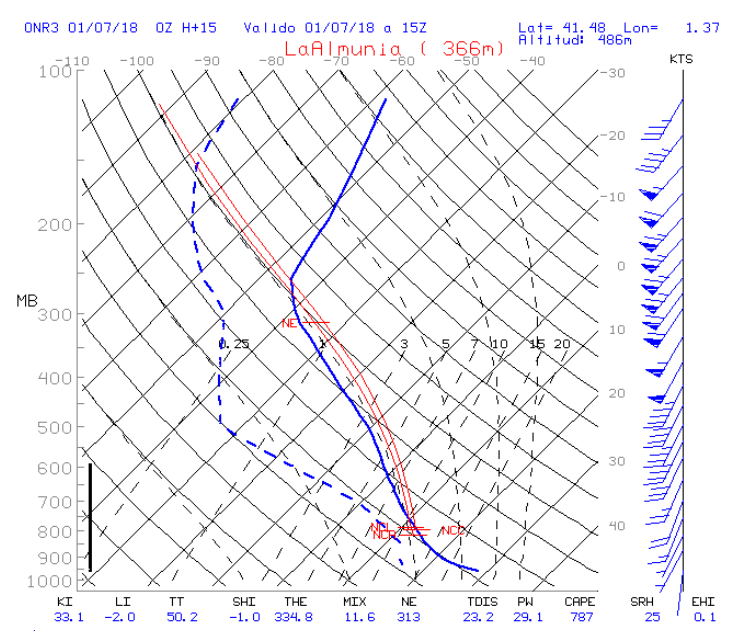

Figura 29. Sondeo $\mathrm{H}+15$ en La Almunia previsto por el HIRLAM $0.16^{\circ}$ a las 15 UTC.

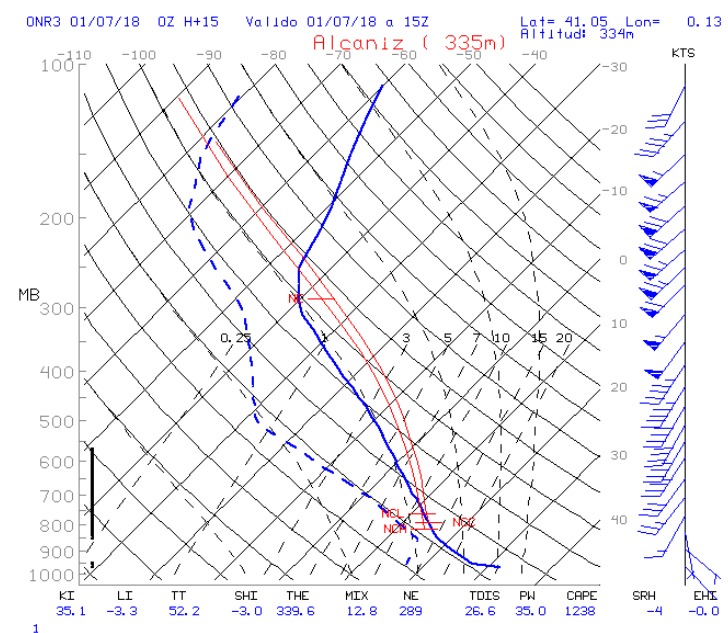

Figura 31. Sondeo $\mathrm{H}+15$ en Alcañiz previsto por el HIRLAM $0.16^{\circ}$ a las 15 UTC.

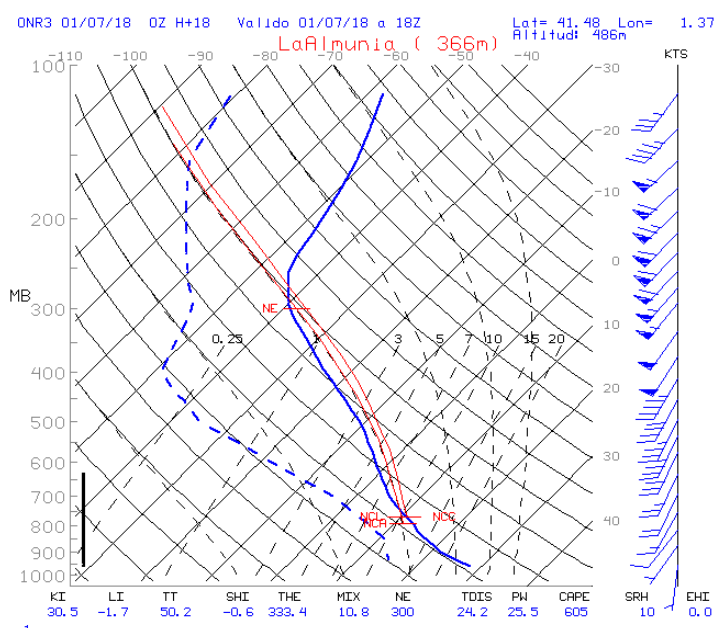

Figura 30. Sondeo $\mathrm{H}+18$ en La Almunia previsto por el HIRLAM $0.16^{\circ}$ a las 18 UTC.

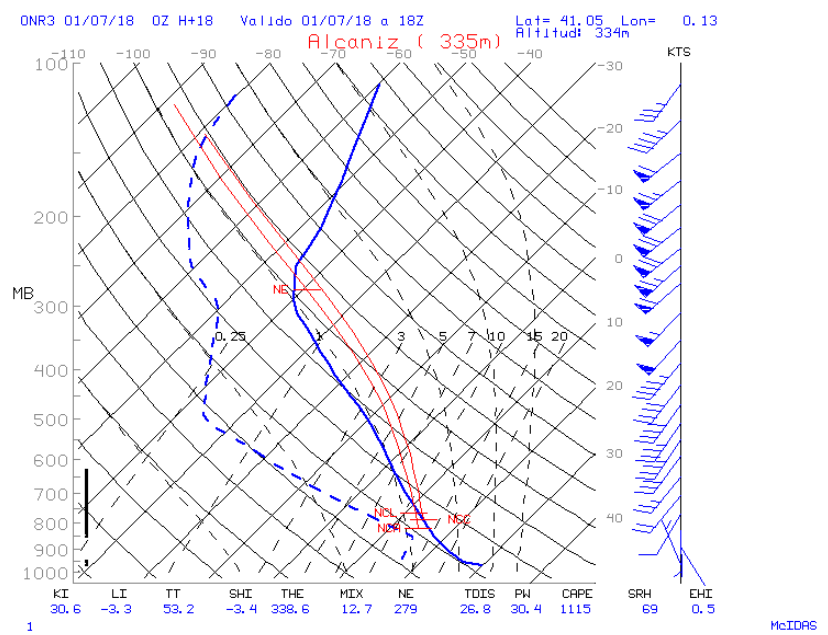

Figura 32. Sondeo $\mathrm{H}+18$ en Alcañiz previsto por el HIRLAM $0.16^{\circ}$ a las 18 UTC.

reloj, para ser a partir de ahí de dirección suroeste y aumentar de intensidad con la altura. A las 18 UTC continúa habiendo cizalladura direccional en niveles bajos aunque el viento de componente suroeste queda ya constituido en niveles más bajos que a las 15 UTC.

Destacar que en los sondeos del aeropuerto la capa seca comienza a mayor altura que en los sondeos de La Almunia y Alcañiz, y sobre todo el de las 15 UTC del aeropuerto parece tener más diferencia entre el perfil del termómetro seco y el del punto de rocío. Asimismo, no muestran los sondeos de La Almunia y de Alcañiz una extensión de la capa húmeda hasta la tropopausa como sí ocurría en el sondeo de las 18 UTC del aeropuerto. Aquí, y durante toda la discusión, se debe insistir en la precaución que hay que tener al llevar a cabo estas comparaciones ya que los modelos son diferentes, la resolución es diferente y las pasadas son diferentes.

Tal como se ha mostrado en este apartado y el anterior, la zona de interés se halla en un entorno favorable a la convección organizada dada la presencia de:

- Inestabilidad generalizada como muestran los valores significativos de LI (por debajo de $-2{ }^{\circ} \mathrm{C}$ ), $\mathrm{TT}$ (por encima de $50{ }^{\circ} \mathrm{C}$ ) y $\mathrm{K}$ (en torno a $35^{\circ} \mathrm{C}$, llegando a superar los $40{ }^{\circ} \mathrm{C}$ ).

- Difluencia en altura a escala sinóptica (figuras 5 y 6 ). 
- Convergencia de vientos (figuras 11 y 12) y aporte de humedad entre la superficie y $850 \mathrm{hPa}$ (figuras 13 y 14), con valores que alcanzan los $-14 \mathrm{~g} / \mathrm{kg} / 6 \mathrm{~h}$ en $925 \mathrm{hPa}$ y los $-8 \mathrm{~g} / \mathrm{kg} / 6 \mathrm{~h}$ en $850 \mathrm{hPa}$. La convergencia actúa como mecanismo de disparo.

- Valores de cizalladura del viento en los primeros $6 \mathrm{~km}$ y SBCAPE suficientes, por encima de $12 \mathrm{~m} / \mathrm{s}$ y de $500 \mathrm{~J} / \mathrm{kg}$ respectivamente (según el sondeo de Zaragoza superan, respectivamente, $20 \mathrm{~m} / \mathrm{s} \mathrm{a}$ las 15 UTC y $1700 \mathrm{~J} / \mathrm{kg}$ a las 18 UTC), compatibles con el desarrollo de supercélulas.

- Valores de helicidad relativa a la tormenta comprendidos entre 100 y $150 \mathrm{~m}^{2} / \mathrm{s}^{2}$ (figura 19), que unido a los más de $100 \mathrm{~J} / \mathrm{kg}$ de CAPE en los 3 primeros kilómetros podrían generar rotación en las células convectivas, aunque no se aprecia CAPE en niveles bajos en los sondeos.

- EISBCIN pronosticado para la zona y las horas de interés está en torno a $50 \mathrm{~J} / \mathrm{kg}$, lo que no supone una gran dificultad para el desarrollo de la convección. Es más elevado al final de la tarde. 


\section{ANÁLISIS DE LAS PREDICCIONES Y AVISOS}

Se ha llevado a cabo un análisis de las predicciones y avisos de fenómenos meteorológicos adversos (FMA) emitidos por el GPV de Barcelona durante los días anteriores al 1 de julio y durante el propio día. Como única referencia de las distintas herramientas usadas para la predicción se muestran los campos de precipitación prevista por el modelo HRES-IFS del ECMWF y por el modelo HARMONIEAROME ciclo 40, que son los dos modelos de uso operativo en predicción general y emisión de avisos en AEMET.

En situaciones meteorológicas como la descrita en los apartados correspondientes de este informe, la precipitación prevista por los modelos está fundamentalmente asociada a fenómenos convectivos (chubascos y tormentas) y su presencia o ausencia se puede explicar en términos de los ingredientes básicos para la convección (humedad atmosférica, inestabilidad en la estratificación y elemento de disparo) (DosweLL ET AL., 1996). La generación de precipitación convectiva por los modelos está asociada a la presencia de estos tres ingredientes y su ausencia normalmente está ligada a la falta de un mecanismo de disparo eficaz. Por lo tanto, el análisis que se hace en esta parte del informe es sobre la capacidad predictiva en este episodio de la precipitación convectiva por los dos modelos usados operativamente.

\section{PREDICCIÓN GENERAL}

En el boletín de medio plazo para la comunidad autónoma de Aragón emitido el 28 de junio y válido para el día 1 de julio se señalaba lo siguiente:

«Cielo poco nuboso o despejado, con intervalos nubosos de evolución diurna en zonas de montaña, sin descartar algún chubasco por la tarde en el Pirineo, localmente fuerte».

Esta predicción no se ajustó bien a lo posteriormente observado ya que los chubascos y las tormentas aparecieron en zonas Ilanas del centro de Huesca, la Ribera del Ebro y el Bajo Aragón aunque también se observaron en el Pirineo y las Cinco Villas.

En el boletín de corto plazo extendido, emitido el día 29 y válido para el día 1, se mantuvo la misma predicción. En la figura 33 se muestran campos de precipitación prevista por las dos pasadas del día 29 de HRES-IFS del ECMWF para el día 1.

El boletín para el D+1 emitido el día 30 ya introducía algunos cambios:

«Cielo poco nuboso o despejado con nubosidad de evolución diurna, con probabilidad de chubascos y tormentas dispersos por la tarde, más probables en áreas de montaña.»

Respecto a la predicción de medio plazo emitida el día 28 se había incrementado la probabilidad, por la tarde, de chubascos y tormentas, aunque dispersos, en cualquier parte del territorio aragonés, aunque especialmente en áreas de montaña. 

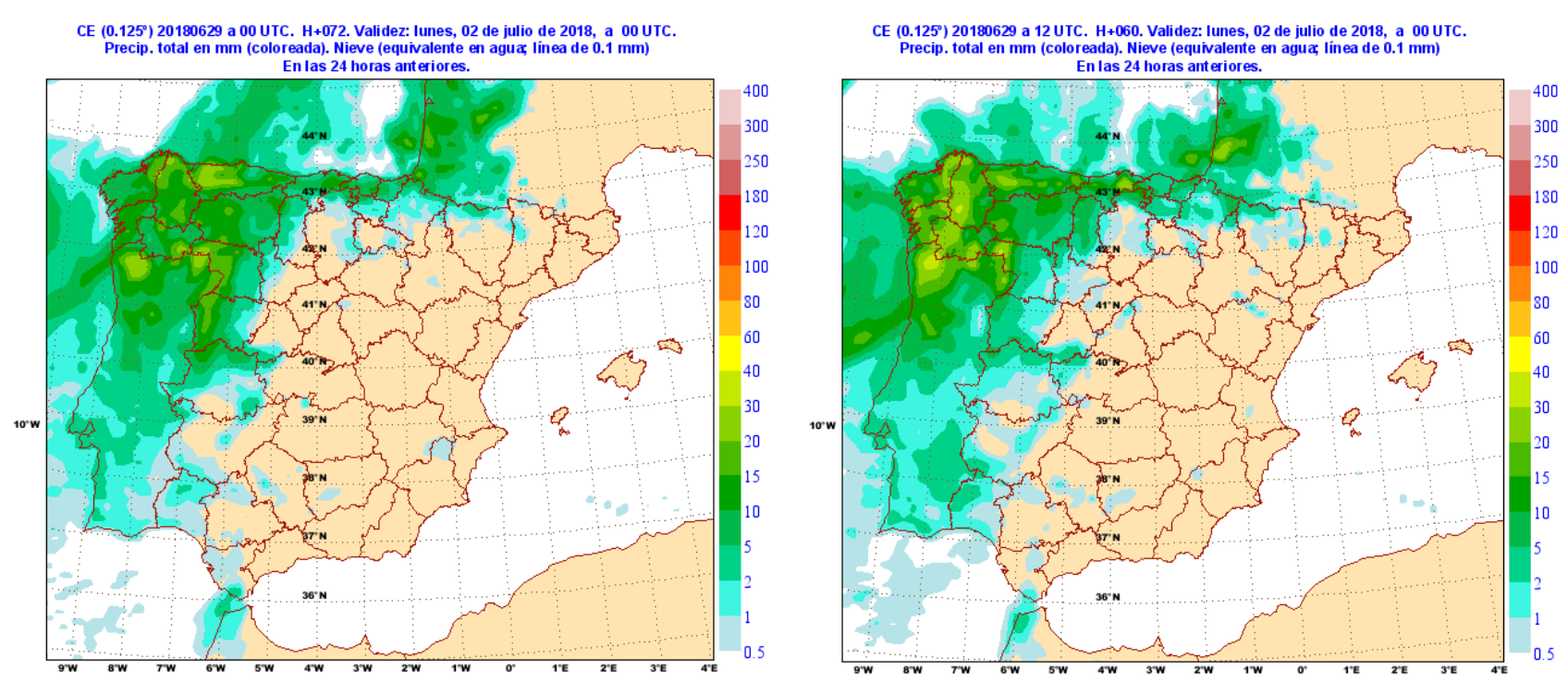

Figura 33. Izquierda: 2018062900 UTC H+072, validez $24 \mathrm{~h}$ anteriores a 2018070200 UTC; derecha: 2018062912 UTC H+060, validez $24 \mathrm{~h}$ anteriores a 2018070200 UTC.
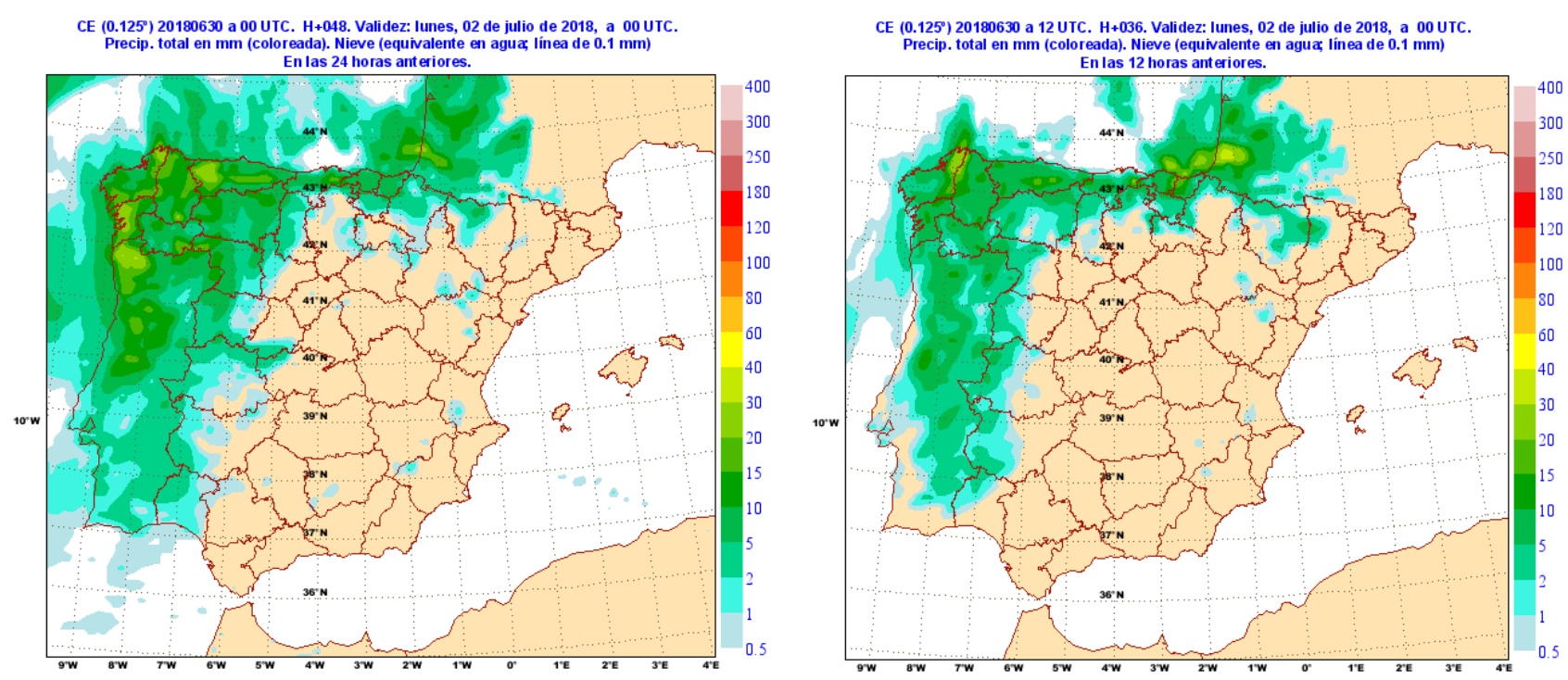

Figura 34. Izquierda: 2018063000 UTC H+048, validez 24 h anteriores a 2018070200 UTC; derecha: 2018063012 UTC H+036, validez $24 \mathrm{~h}$ anteriores a 2018070200 UTC.
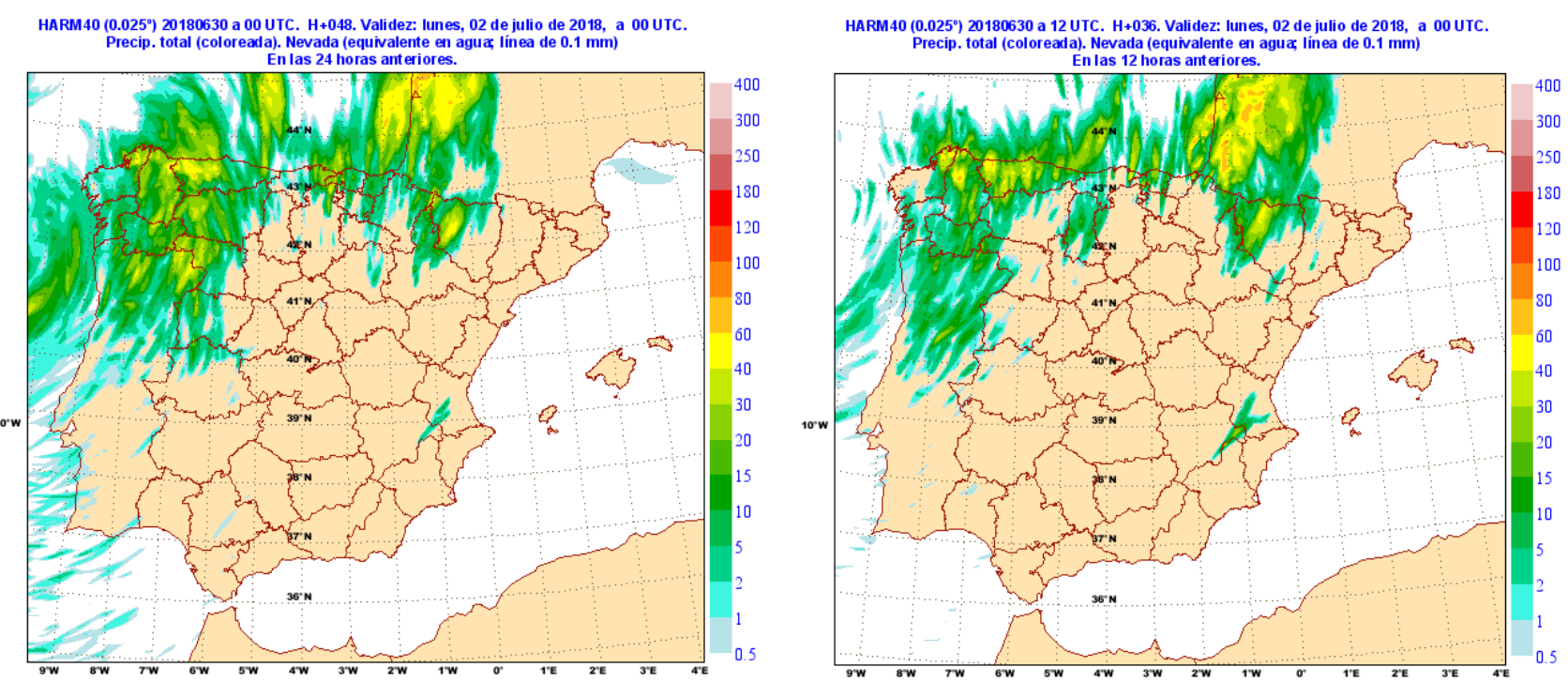

Figura 35. Izquierda: 2018063000 UTC H+048, validez 24 h anteriores a 2018070200 UTC; derecha: 2018063012 UTC H+036, validez 24 h anteriores a 2018070200 UTC. 
En la predicción para la provincia de Zaragoza emitida el día 30 y válida para el día 1, se incluía la misma predicción. Por lo tanto, se consideraba probable la ocurrencia de alguna tormenta que afectara a Zaragoza capital, si bien las tormentas previstas no se calificaron como fuertes. En la figura 34 se muestran campos de precipitación prevista por las dos pasadas del día 30 de HRES-IFS del ECMWF para el día 1 y en la figura 35 los correspondientes a HARMONIE-AROME (40).

A primera hora del día 1 se cambió la predicción para el día en curso, modificando el correspondiente boletín autonómico, para introducir el calificativo de fuertes a los chubascos que se podrían producir durante el día en el tercio norte, no incluyendo, por lo tanto, el área de Zaragoza capital. En la figura 36 se muestran campos de precipitación prevista por las dos pasadas del día 1 de HRES-IFS del ECMWF para el día 1 y en la figura 37 los correspondientes a HARMONIE-AROME (40).

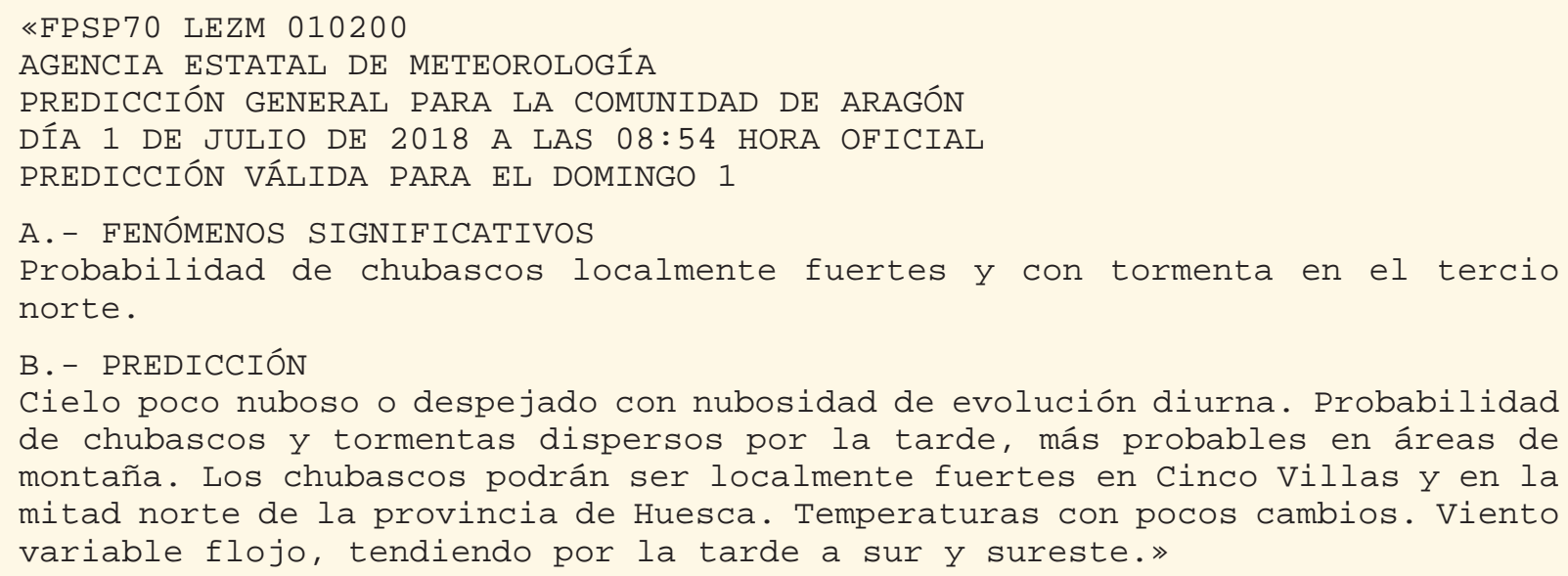

Del análisis y comparación de los campos de precipitación previstos por los dos modelos se puede concluir que: 1) la precipitación para el tercio norte de Aragón fue insistentemente prevista por las diferentes pasadas del HRES-IFS, 2) la precipitación prevista por HARMONIE-AROME (40) fue superior (como es habitual en situaciones convectivas) a la prevista por HRES-IFS y 3) HARMONIE-AROME (40) extendió la precipitación prevista hacia el sur, hasta abarcar puntos de la Ribera del Ebro. En resumen, y en base exclusivamente al análisis de estos campos previstos, se puede concluir que ambos modelos, y especialmente HRES-IFS, subestimaron la extensión e intensidad de los fenómenos convectivos.
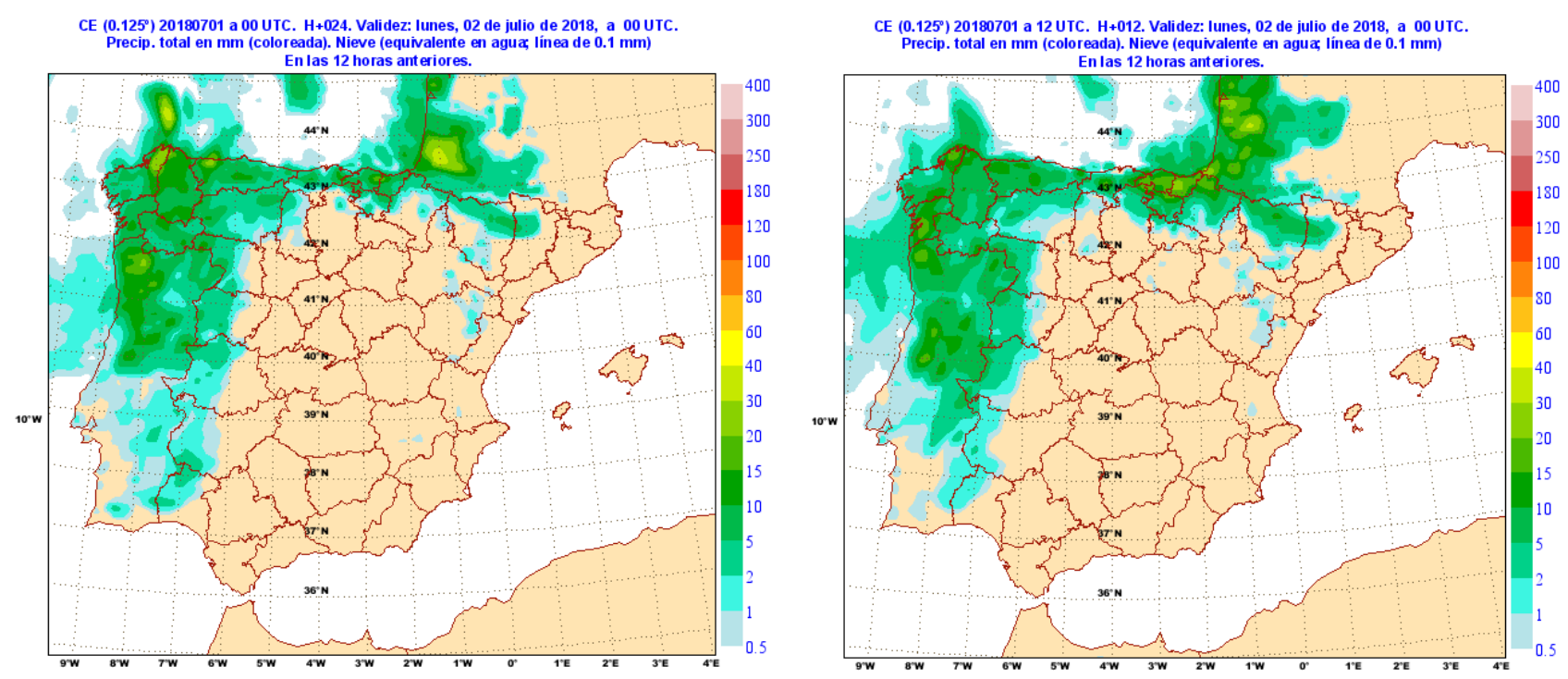

Figura 36. Izquierda: 2018070100 UTC H+024, validez $24 \mathrm{~h}$ anteriores a 2018070200 UTC; derecha: 2018070112 UTC H+012, validez $12 \mathrm{~h}$ anteriores a 2018070200 UTC. 

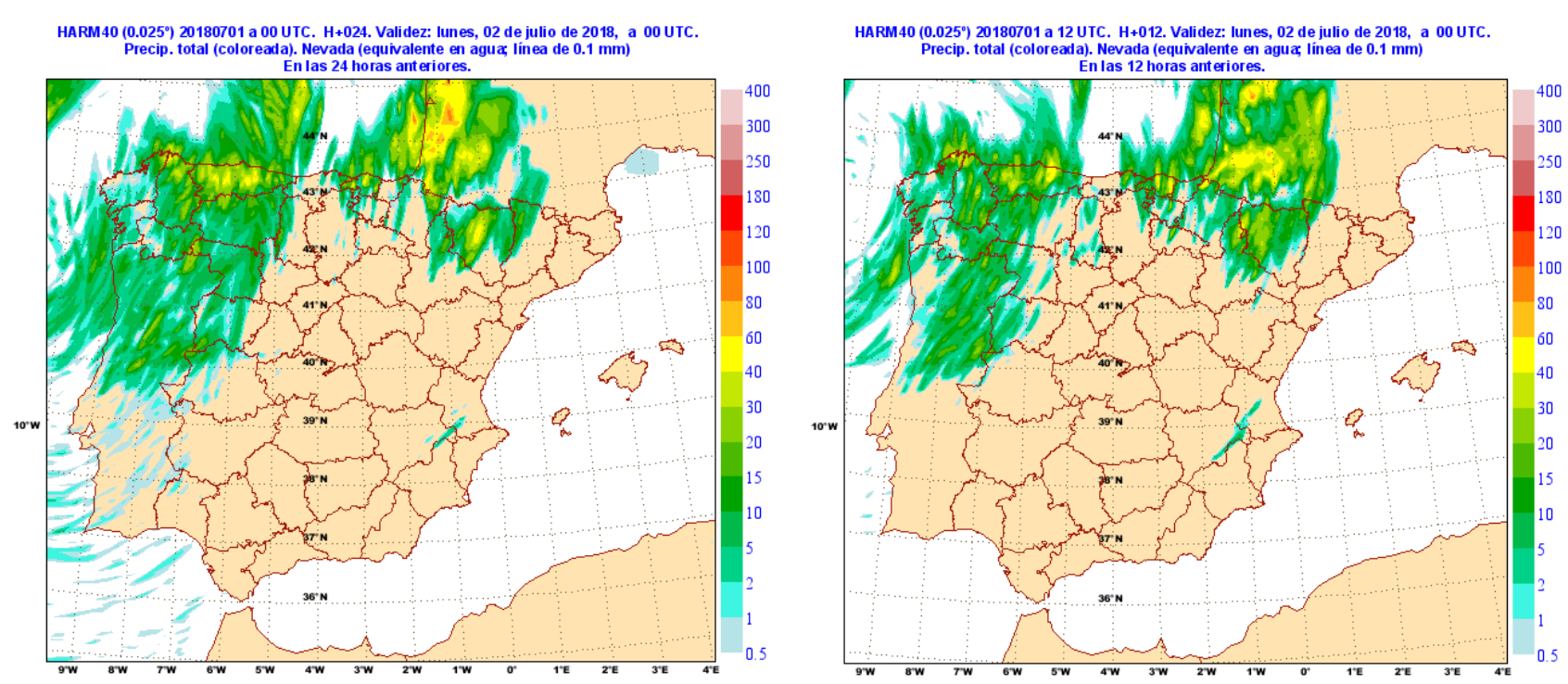

Figura 37. Izquierda: 2018070100 UTC H+024, validez 24 h anteriores a 2018070200 UTC; derecha: 2018070112 UTC H+012, validez 12 h anteriores a 2018070200 UTC.

\section{AVISOS DE FENÓMENOS METEOROLÓGICOS ADVERSOS}

Los primeros avisos válidos para el día 1 se emitieron en el ciclo de las 23 H.O. del día 30:

\section{AGENCIA ESTATAL DE METEOROLOGÍA}

BOLETÍN DE FENÓMENOS ADVERSOS DE NIVEL AMARILLO

C. AUTÓNOMA: ARAGÓN

BOLETÍN NÚMERO 206/62ARA_C_C_AM_TT

EMITIDO A LAS 22:44 HORA OFICIAL DEL 30/06/2018

VÁLIDO HASTA LAS 00:00 HORA OFICIAL DEL 02/07/2018

FENÓMENOS PREVISTOS

Fenómeno(1) - Lluvias. Precipitación acumulada en una hora: $20 \mathrm{~mm}$.

Nivel: amarillo.

Ámbito geográfico: Huesca (Pirineo oscense, Centro); Zaragoza (Cinco Villas). Hora de comienzo: 17:00 hora oficial del 01/07/2018. Hora de finalización: 00:00 hora oficial del 02/07/2018. Probabilidad: $40 \%-70 \%$

Fenómeno(2) - Tormentas.

Nivel: amarillo.

Ámbito geográfico: Huesca (Pirineo oscense, Centro); Zaragoza (Cinco Villas). Hora de comienzo: 17:00 hora oficial del 01/07/2018. Hora de finalización: 00:00 hora oficial del 02/07/2018. Probabilidad: $40 \%-70 \%$.

Fueron avisos de nivel amarillo, tanto de tormenta como de precipitaciones fuertes, válidos para tres zonas de aviso del tercio norte de la comunidad y para la tarde del día 1. 
A las 16 H.O., como resultado de la vigilancia y la observación de tormentas en la provincia de Zaragoza se abrieron avisos de nivel amarillo de lluvias fuertes y tormentas para la zona de Ribera del Ebro, que incluye la ciudad de Zaragoza:

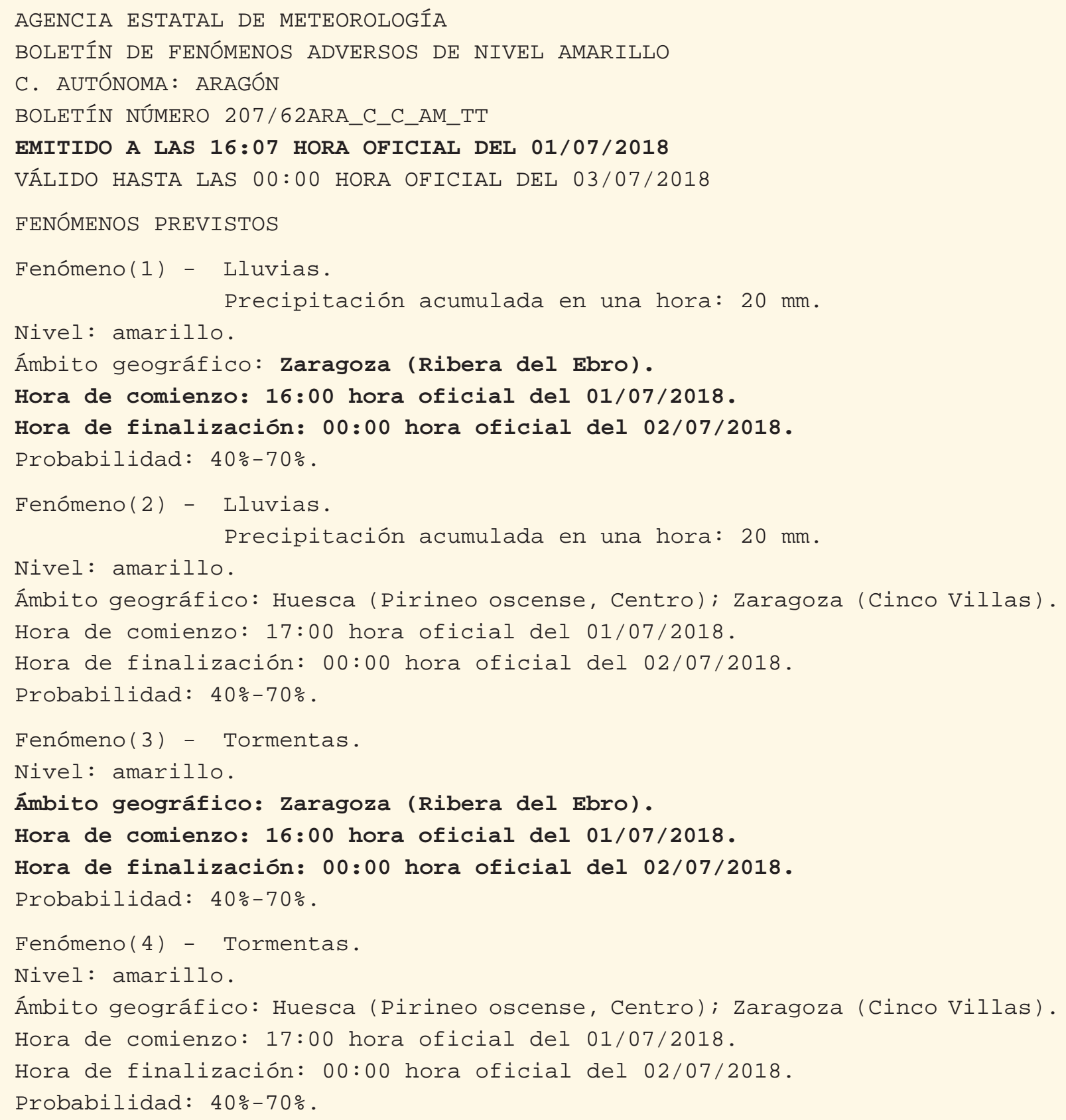

Este aviso infravaloró la intensidad de las tormentas en el área de Zaragoza capital, y también en el medio y el corto plazo los dos modelos usados operativamente en las tareas de predicción (HRES-IFS del ECMWF y HARMONIE-AROME) infravaloraron en algunas áreas de Aragón la precipitación convectiva lo cual condicionó, a su vez, la predicción de tiempo sensible y la emisión de avisos de chubascos intensos y tormentas.

En resumen, se puede considerar que las diferentes predicciones se fueron ajustando cada vez mejor a lo observado, desde el medio plazo, en el que apenas se hacía referencia a las tormentas, hasta el nowcasting y la emisión de avisos para la Ribera del Ebro, con algo de retraso en la emisión de los avisos respecto a lo óptimo y con infravaloración del fenómeno en el caso concreto de la tormenta de Zaragoza y otros puntos de la Ribera del Ebro y la Ibérica zaragozana. 


\section{REPERCUSIONES AERONÁUTICAS OPERATIVAS EN LEZG}

Aunque sea una situación compleja para ser recogida de forma adecuada por los modelos, puede ser interesante analizar algunos de los campos, más directamente relacionados con la convección, de los dos modelos operativos de que disponían los predictores en aquel momento. En ambos casos se van a analizar las pasadas de las 00 UTC del día 1 de julio. A continuación se hará un análisis de los productos realizados por el GPV de Valencia el día 1 de julio de 2018 para el aeropuerto de Zaragoza (TAFy avisos de aeródromo) así como los boletines de área (mapas de baja cota) y avisos aeronáuticos (SIGMET y AIRMET) para ver hasta qué punto se adecuaron a la predicción y vigilancia de las tormentas en el valle del Ebro, en general, y del aeropuerto de Zaragoza en particular.

\section{MODELO HRES-IFS DEL ECMWF}

La previsión de rachas de viento en superficie del HRES-IFS no muestra nada relevante (figura 38). Se muestran a continuación las rachas previstas para las 17-18 UTC.

La previsión de rayos, del mismo modelo, sí prevé una alta densidad de rayos en la zona (en las proximidades del límite provincial entre Teruel y Zaragoza) a las horas 13 y a las 14 UTC (figuras 39 y 40) en que

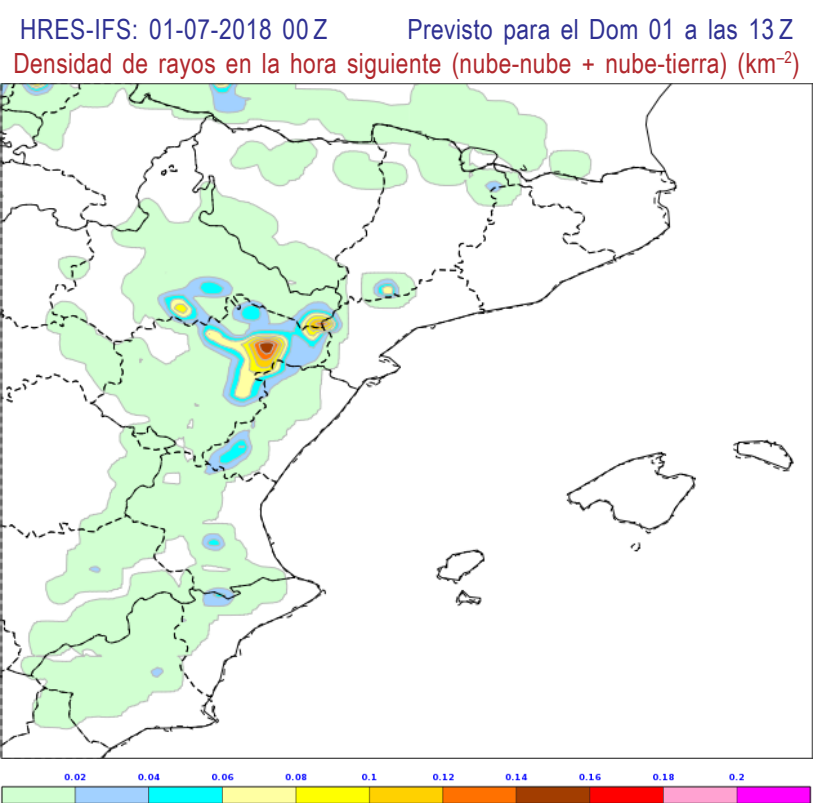

Figura 39. Densidad de rayos según HRES-IFS del día 1 de julio de 2018 a las 00 UTC, prevista para las 13 UTC.
HRES-IFS: 01-07-2018 $00 \mathrm{Z}$ Previsto para el Dom 01 a las $17 \mathrm{Z}$ Racha instantánea de viento en superficie (a la hora nominal) $(\mathrm{km} / \mathrm{h})$

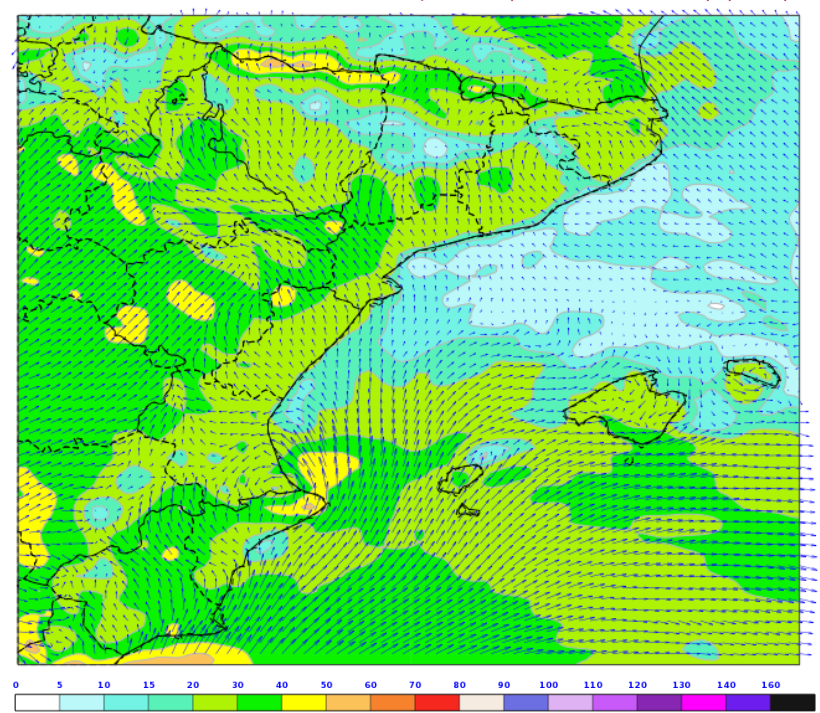

Figura 38. Rachas de viento instantáneo según HRES-IFS del 1 de julio de 2018 a las 00 UTC, previstas para las 17 UTC. 
HRES-IFS: 01-07-2018 $00 \mathrm{Z} \quad$ Previsto para el Dom 01 a las $15 \mathrm{Z}$ Densidad de rayos en la hora siguiente (nube-nube + nube-tierra) $\left(\mathrm{km}^{-2}\right)$

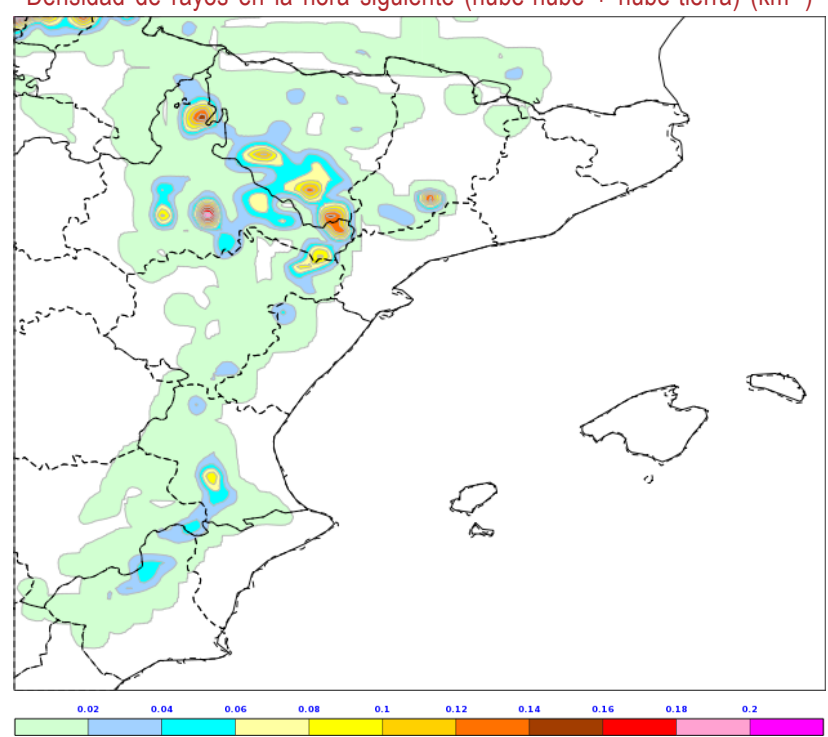

Figura 41. Densidad de rayos según HRES-IFS del día 1 de julio de 2018 a las 00 UTC, prevista para las 15 UTC.
HRES-IFS: 01-07-2018 $00 \mathrm{Z} \quad$ Previsto para el Dom 01 a las $17 \mathrm{Z}$ Densidad de rayos en la hora siguiente (nube-nube + nube-tierra) $\left(\mathrm{km}^{-2}\right)$

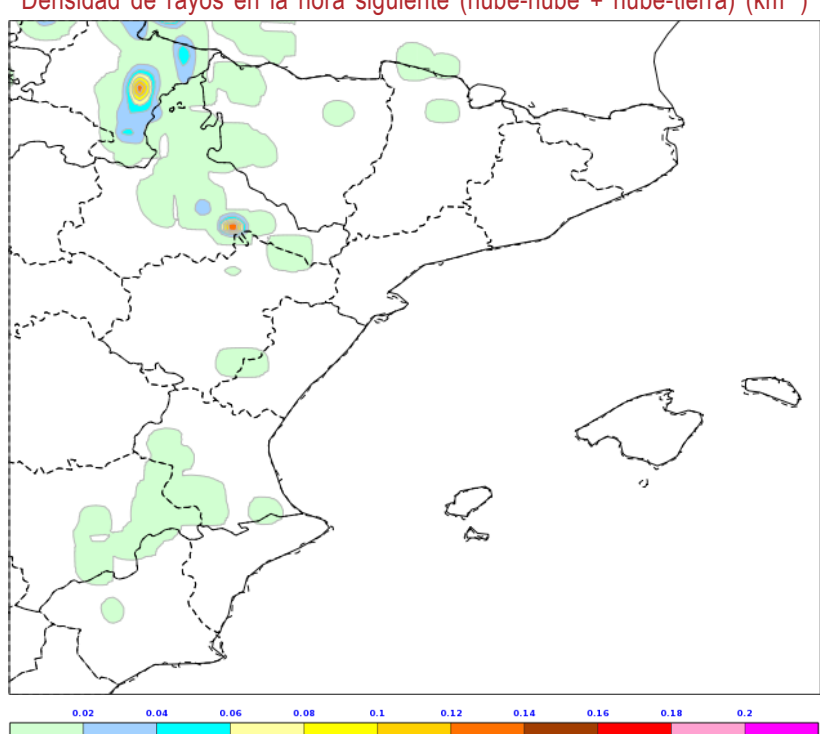

Figura 42. Densidad de rayos según HRES-IFS del día 1 de julio de 2018 a las 00 UTC, prevista para las 17 UTC.

posteriormente se iniciará la convección significativa. A las 15 UTC (figura 41) se desplaza la densidad de rayos hacia el norte (sur de la provincia de Zaragoza) y a las 17 UTC (figura 42) aún mantiene un máximo de densidad al sur de Zaragoza donde se forma la segunda célula que afectará posteriormente al aeropuerto.

\section{MODELO HARMONIE-AROME}

Este modelo pronostica bastante bien la intensidad del viento y además sitúa correctamente la convergencia de vientos del este, procedentes del Mediterráneo, y vientos del suroeste en el límite provincial entre Teruel y Zaragoza y su evolución con el tiempo entre 12 y las 18 UTC (figura 43), con un aumento de la velocidad del viento y su extensión tanto en los vientos del este como en los del suroeste. Se ve además cómo se refuerza la convergencia en el extremo sudoriental de la provincia de Zaragoza y el norte de la provincia de Teruel.

HARMONIE-AROME 01-07-2018 $00 \mathrm{Z}$ Previsto para el Dom 01 a las $13 \mathrm{Z}$ Viento en superficie

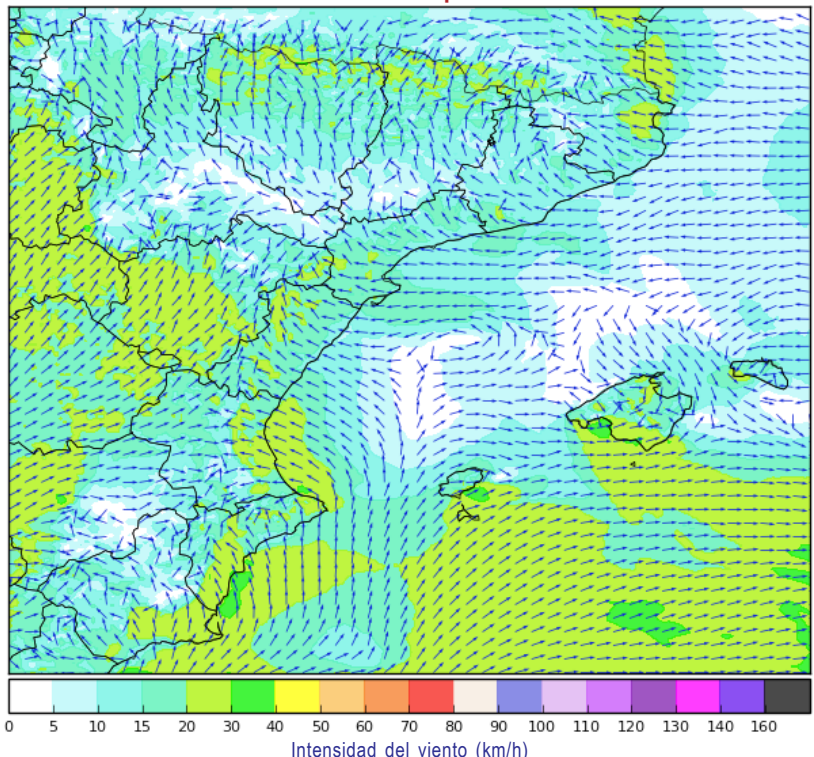

HARMONIE-AROME 01-07-2018 00 Z Previsto para el Dom 01 a las 17 Z Viento en superficie

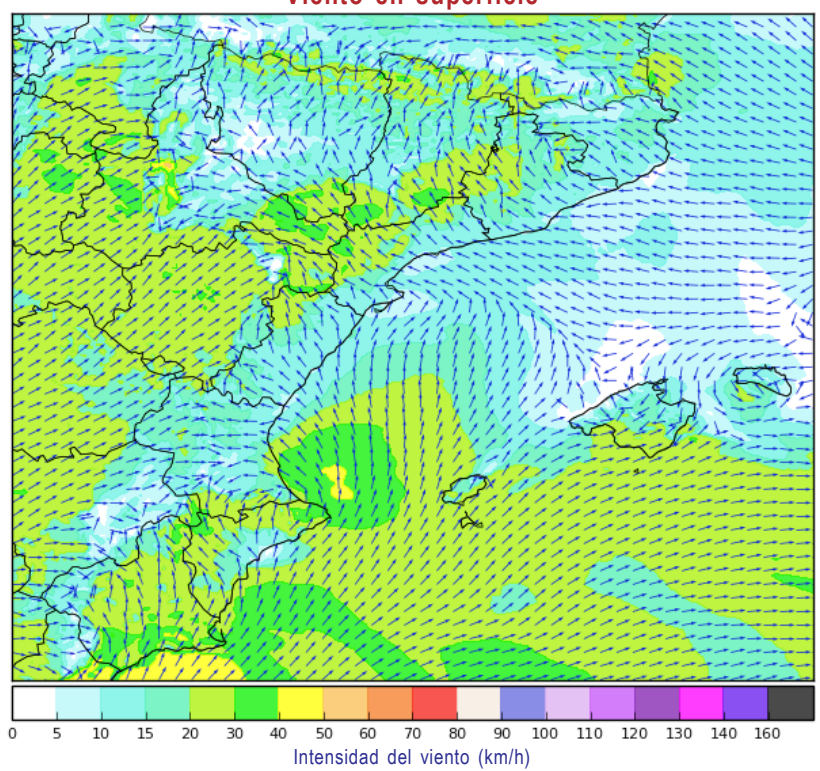

Figura 43. Intensidad del viento en superficie del modelo HARMONIE-AROME el día 1 de julio de 2018 a las 00 UTC, prevista para las 13 UTC (izquierda) y para las 17 UTC (derecha). 
HARMONIE-AROME 01-07-2018 00Z Previsto para el Dom 01 a las $18 \mathrm{Z}$ Rachas de viento en superficie

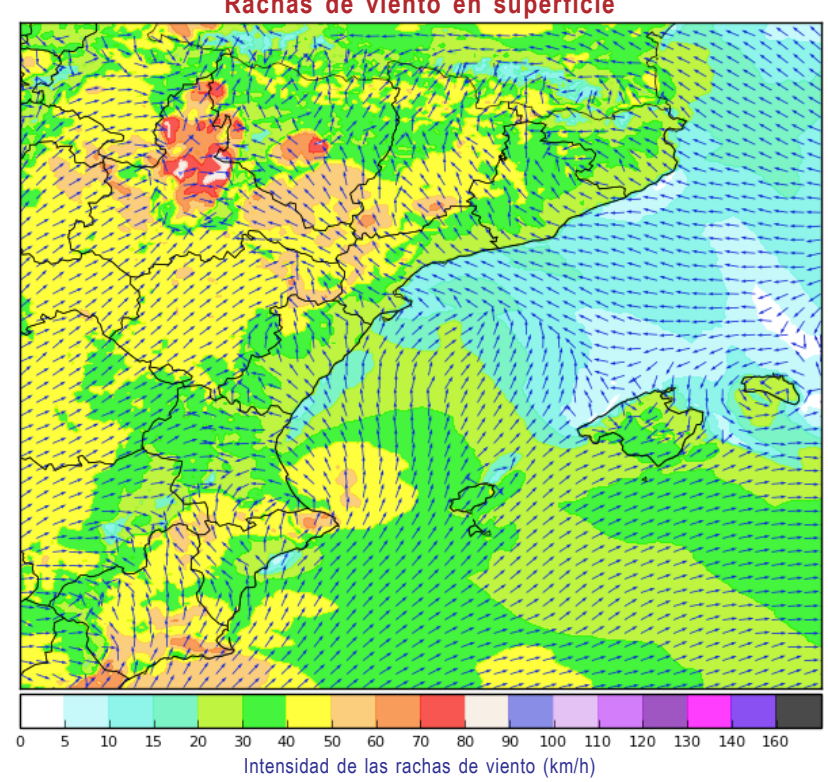

HARMONIE-AROME 01-07-2018 00Z Previsto para el Dom 01 a las $20 Z$ Rachas de viento en superficie

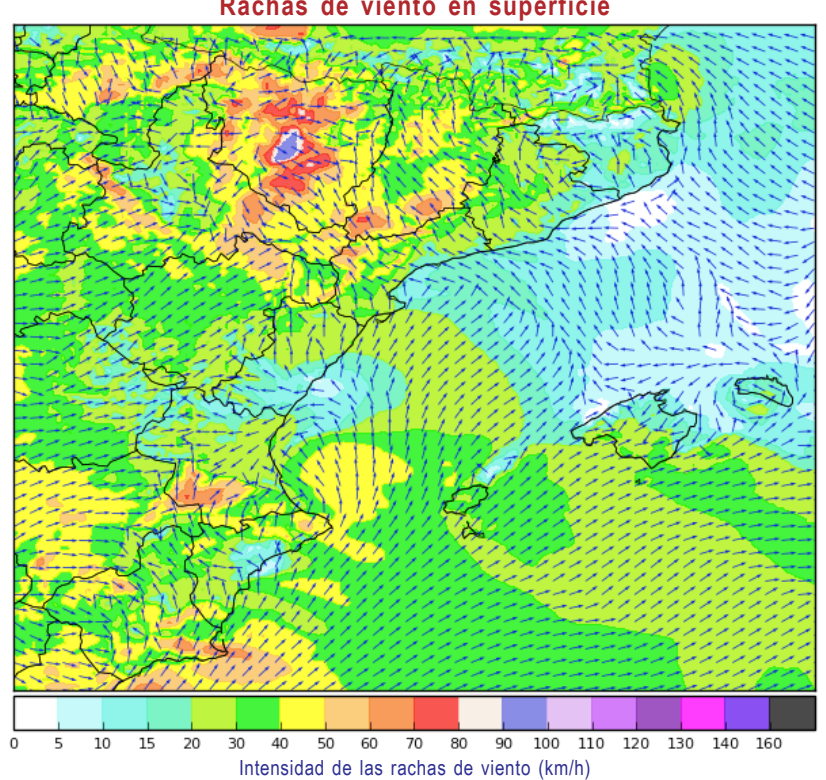

Figura 44. Rachas máximas de viento en superficie del modelo HARMONIE-AROME el día 1 de julio de 2018 a las 00 UTC, previstas para las 18 UTC (izquierda) y para las 20 UTC (derecha).

Por otro lado, al no recoger este modelo correctamente el desarrollo de la convección, no sitúa de manera adecuada las rachas máximas en superficie (figura 44, previstas para las 18 UTC a la izquierda y previstas para las 20 UTC a la derecha), y las sitúa fundamentalmente en la comarca de las Cinco Villas y en la provincia de Huesca, y algo más tarde en el tiempo.

\section{PREDICCIONES DE AERÓDROMO}

En el briefing que la OMPA de Valencia realiza con las OMA de su demarcación, a las 9 de la mañana hora local, se comentó, para la OMA de Zaragoza, la probabilidad de que hubiera tormentas por la tarde, y la posibilidad de que fueran fuertes teniendo en cuenta el entorno meteorológico y las rachas convectivas que predecía el modelo HARMONIE-AROME. Se avisó de que probablemente se emitiría un aviso de aeródromo a lo largo de la mañana.

Los primeros desarrollos convectivos aparecen en torno a las 13:00 UTC en el norte de la provincia de Teruel y al sur de la provincia de Zaragoza. Los METAR y SPECI (en amarillo) de ese período en el aeropuerto de Zaragoza son los siguientes:

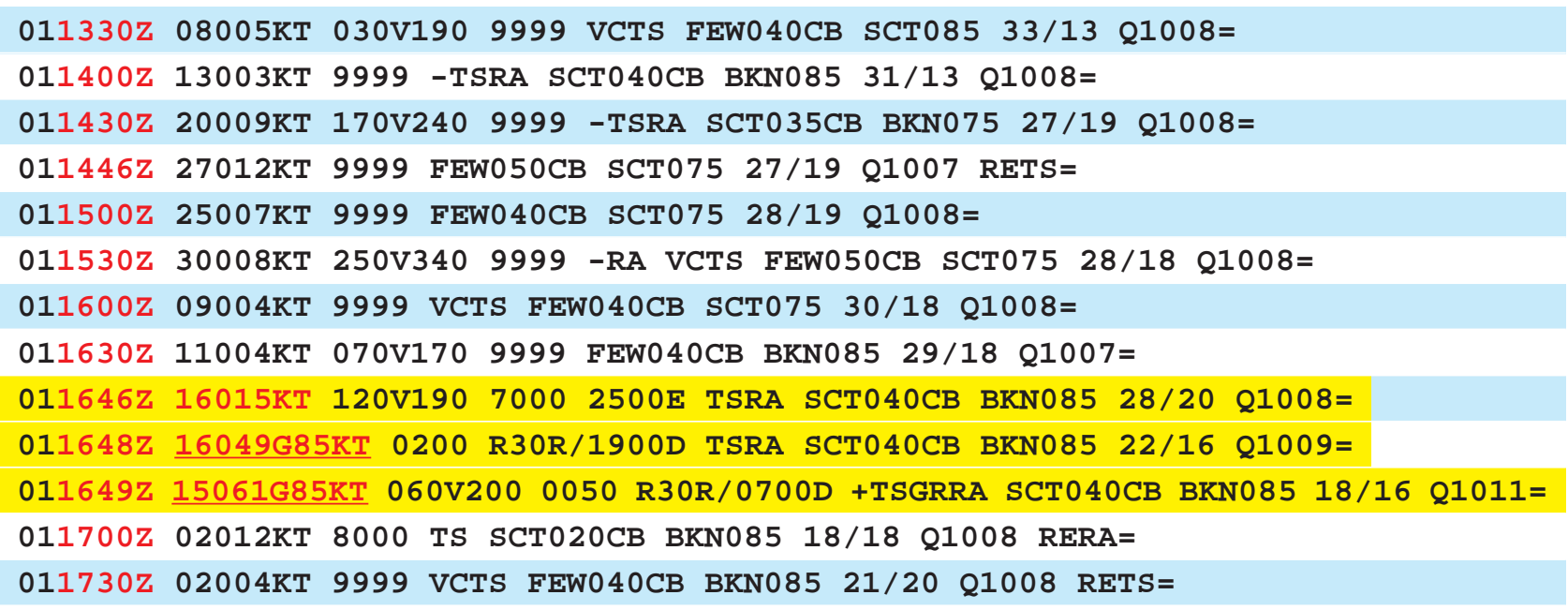


Así mismo a las 11:00 y 17:00 UTC se emitieron los siguientes TAF:

TAF LEZG $011100 \mathrm{0}$ 0112/0212 VRB04KT 9999 FEW050 TX34/0114Z TN20/0205Z TEMPO 0113/0120 13010KT PROB40 TEMPO 0112/0120 FEW040CB SCT050 PROB30 TEMPO 0112/0120 33015G25KT TSRA FEW040CB SCT050 BECMG 0200/0202 28005KT=

TAF LEZG $011700 \mathrm{Z}$ 0118/0218 VRB04KT 9999 FEW050 TX36/0214Z TN21/0205Z TEMPO 0118/0120 13010KT PROB40 TEMPO 0118/0120 FEW040CB SCT050 PROB30 TEMPO 0118/0120 33015G25KT TSRA FEWO4OCB SCT050 BECMG 0200/0202 28007KT=

En ambos TAF se predicen tormentas con rachas de viento fuertes en el período de 12 a 20 UTC con una probabilidad entre el 30 y el $39 \%$. Esta asignación de probabilidad probablemente debería haber sido superior en el TAF de las 11 (teniendo en cuenta los análisis y predicciones de niveles altos y bajos y el sondeo previsto por los modelos para la zona).

\section{AVISOS DE AERÓDROMO}

El primer aviso de aeródromo se emite a las 13:24 UTC, poco después del inicio de la convección cerca del límite provincial. Se mantiene hasta las 18:00 UTC, pero al debilitarse la convección a partir de las 16:00 UTC se deja expirar y no se renueva hasta las 18:42 UTC.

\footnotetext{
WW 01/07/2018 13:24-> LEZG AD WRNG 1 VALID 011324/011500 TS FCST NC=

WW 01/07/2018 14:43-> LEZG AD WRNG 2 VALID 011500/011800 TS FCST NC= WW 01/07/2018 18:42-> LEZG AD WRNG 3 VALID 011842/012000 TS FCST NC=
}

\section{MAPAS DE BAJA COTA}

Las predicciones de área consisten en los boletines GAMET y los mapas de baja cota. La predicción meteorológica es la misma para los dos productos. La diferencia entre ambos consiste en que el primero es alfanumérico y el segundo es un producto gráfico. Utilizaremos por tanto el segundo para evaluar la bondad de la predicción.

La previsión para las 12:00 UTC de ese día en la parte central del valle del Ebro, marcada con un 2 en el mapa (figura 45), indica cumulonimbos aislados entre las 12 y las 15 UTC y chubascos locales que reducirían la visibilidad a menos de $5000 \mathrm{~m}$. En el mapa previsto para las 18:00 UTC, y por tanto válido desde las 15 a las 21 UTC (figura 46) se mantiene la predicción de los cumulonimbos y tormentas para la parte central del valle del Ebro, norte de Aragón, Navarra y golfo de Vizcaya. La predicción para las 12:00 UTC se quedó claramente por debajo de lo que realmente ocurrió.

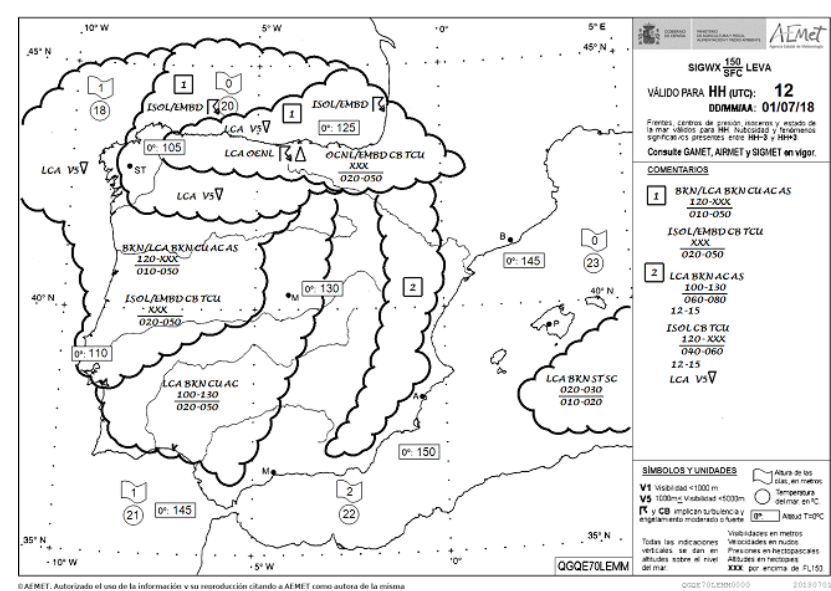

Figura 45. Mapa de baja cota previsto para el día 1 de julio de 2018 a las 12 UTC.

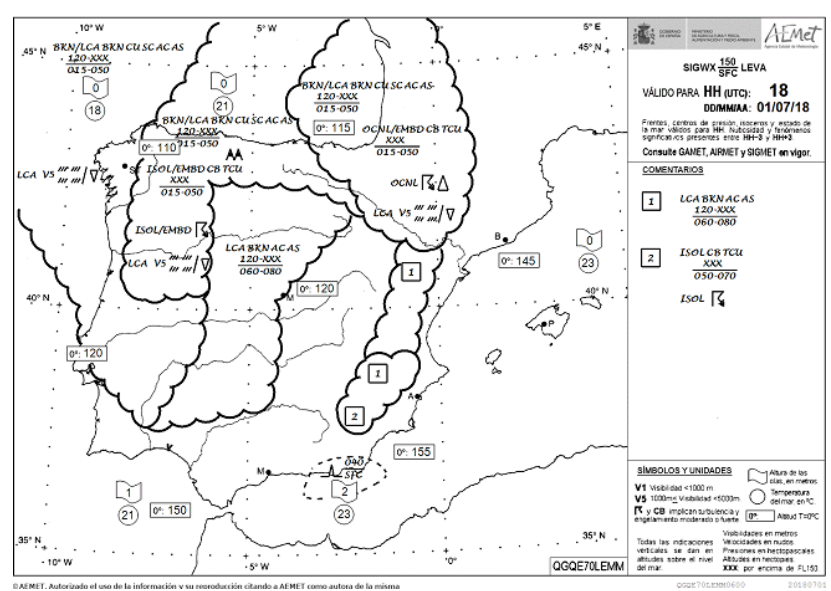

Figura 46. Mapa de baja cota previsto para el día 1 de julio de 2018 a las 18 UTC. 


\section{VIGILANCIA Y AVISOS: SIGMET}

Se emitieron cuatro avisos SIGMET para el FIR de Barcelona y once para el FIR de Madrid ese día. La división entre los FIR pasa, de norte a sur, por el extremo oriental de la provincia de Zaragoza. La mayoría de las tormentas se formaron en el FIR de Madrid y el aeropuerto de Zaragoza pertenece a este FIR.

Se emite el primer aviso a las 13:44 UTC para el FIR de Madrid con previsión de tormentas, embebidas en nubosidad, entre las 14:00 y las 16:00 UTC. Al poco tiempo (14:00 y 14:01 UTC) se emiten sendos avisos de tormentas observadas para el FIR de Madrid y el FIR de Barcelona. Ambos avisos son de dos horas de duración y se renuevan poco antes de que expire su vigencia (16:00 UTC). La segunda serie de avisos finaliza a las 18:00 UTC y no se renuevan. Probablemente porque el predictor considera que, de acuerdo con lo previsto en el mapa de baja cota, y el seguimiento de las tormentas en la vigilancia no hay riesgo significativo de tormentas. Entre las 18:44 y las 18:54 UTC se emiten 3 SIGMET de tormentas observadas para el FIR de Madrid y 2 para el FIR de Barcelona.

Por otro lado, a las 13:28 UTC se emite un AIRMET para el FIR de Barcelona para corregir el hecho de que el mapa de baja cota no previera el desarrollo de tormentas en la zona de Baleares. No hubo emisión de AIRMET para la zona de Aragón objeto de este estudio.

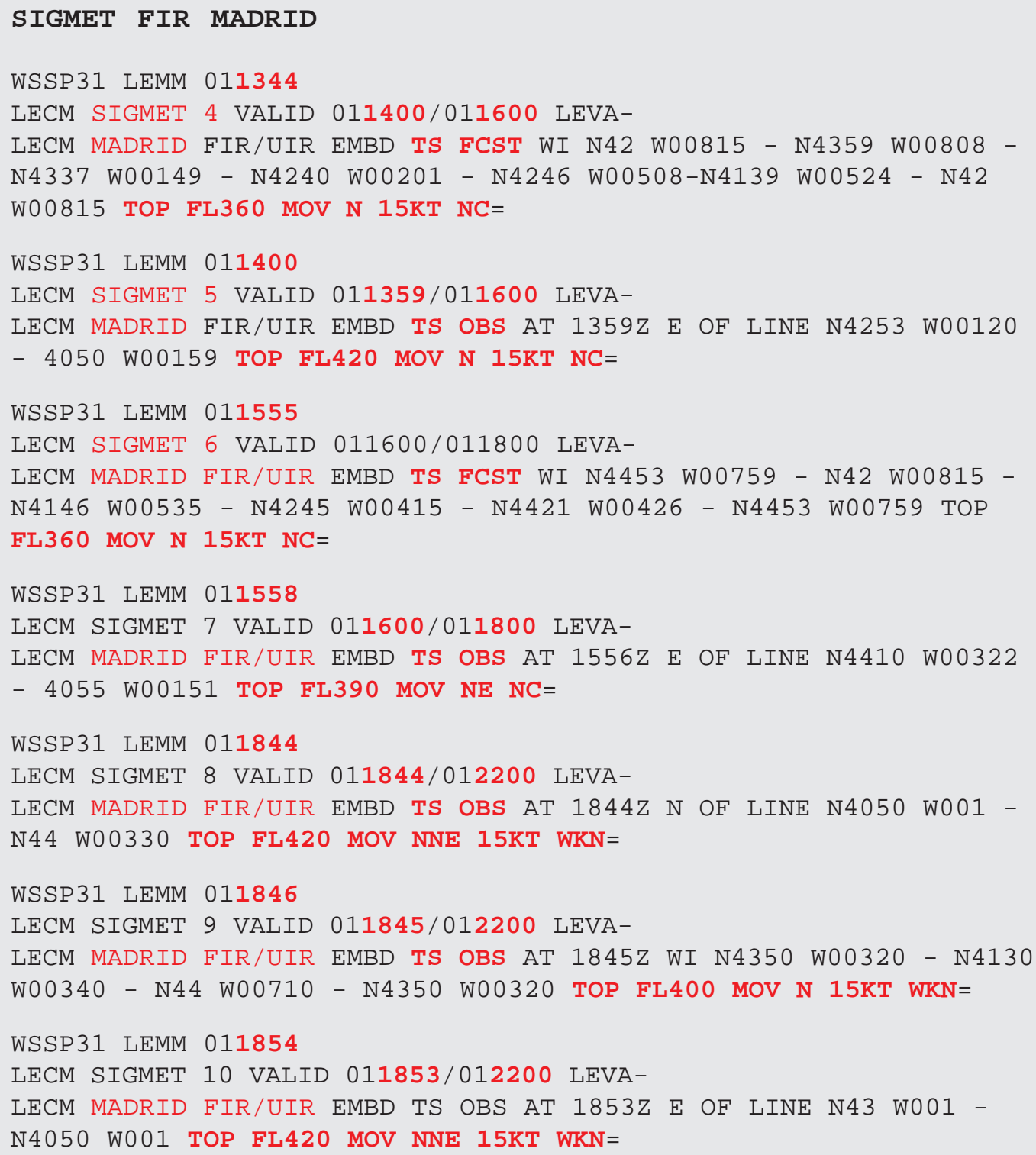




\section{SIGMET FIR BARCELONA}

WSSP 32 LEMM 011401

LECB SIGMET 1 VALID 011400/011600 LEVA-

LECB BARCELONA FIR/UIR EMBD TS OBS AT $1400 Z$ W OF LINE N4241

E00058 - N4020 W00001 TOP FL420 MOV N NC=

WSSP 32 LEMM 011559

LECB SIGMET 2 VALID 011600/011800 LEVA-

LECB BARCELONA FIR/UIR EMBD TS OBS AT 1558Z W OF LINE N4044

E00017 - N4237 E00157 TOP FL420 MOV N WKN=

WSSP 32 LEMM 011848

LECB SIGMET 3 VALID 011847/012200 LEVA-

LECB BARCELONA FIR/UIR EMBD TS OBS AT $1847 \mathrm{Z}$ OF LINE N4110

W00050 - N4240 E001 TOP FL420 MOV NNE 15KT NC=

WSSP 32 LEMM 011849

LECB SIGMET 4 VALID 011848/012200 LEVA-

LECB BARCELONA FIR/UIR EMBD TS OBS AT $1848 \mathrm{Z}$ W OF LINE N3830

W00050 - N4030 E00030 TOP FL420 MOV NE 20KT WKN=

\section{AIRMET}

WASP 42 LEMM 011328

LECB BARCELONA FIR ISOL TS OBS AT 1328Z WI N3942 E00242 - N3951

E00301 - N3936 - N3931 E00259 - N3942 E00242 TOP ABV FL150 STNR

$\mathrm{NC}=$ 


\section{CaRACTERIZACIÓN DE LAS ESTRUCTURAS CONVECTIVAS}

\section{IMÁGENES DE SATÉLITE}

Por medio de las imágenes del satélite Meteosat Segunda Generación (MSG-4), se puede apreciar que a lo largo de la tarde de este día, 1 de julio de 2018, y sobre las zonas centrales de Aragón, tiene lugar la formación de varias estructuras nubosas convectivas con un marcado desarrollo vertical y una larga persistencia, que evolucionan y se desplazan hacia el N y NE.
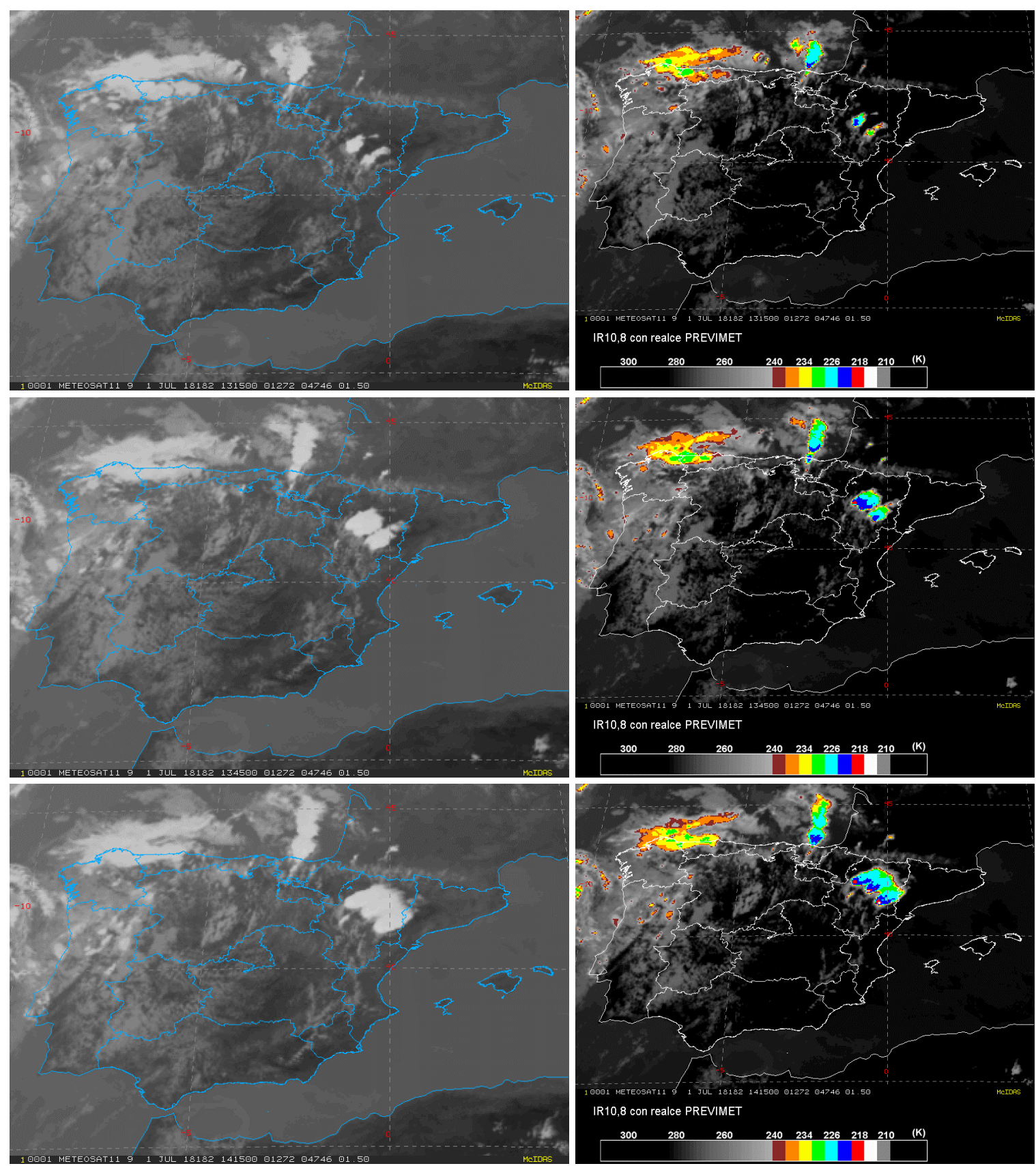

Figura 47. Imágenes del canal IR108 del satélite MSG-4 (imágenes de la izquierda) y con realce PREVIMET (imágenes de la derecha), de las 13:15 UTC (arriba), de las 13:45 UTC (fila central), y de las 14:15 UTC (fila de abajo). 
Los primeros desarrollos convectivos aparecen en torno a las 13:00 UTC al S de la provincia de Zaragoza, en su límite con la de Teruel, y en el $\mathrm{N}$ de Teruel. Se puede apreciar el desarrollo de dos primeras estructuras en las imágenes de las 13:15, 13:45 y 14:15 UTC, y la manera en que se van dividiendo en un claro proceso de storm splitting a la vez que adquieren un marcado desarrollo vertical alcanzando sus topes nubosos temperaturas muy frías, por debajo de $-60^{\circ} \mathrm{C}$, según las imágenes con realce PREVIMET (figura 47).

Estas se empiezan a debilitar a partir de las 15:30 o 16:00 UTC, momento en el cual empiezan a aparecer otras nuevas en la misma zona que se van desplazando de la misma manera. No llegan a tener un tamaño tan grande como las anteriores, pero sí un carácter altamente organizado. La de mayor desarrollo, con topes nubosos también por debajo de los $-60^{\circ} \mathrm{C}$ de temperatura de brillo, es la que afectó al aeropuerto de Zaragoza con rachas que alcanzaron los $157 \mathrm{~km} / \mathrm{h}$, y proviene también de un proceso de storm splitting (figura 48).
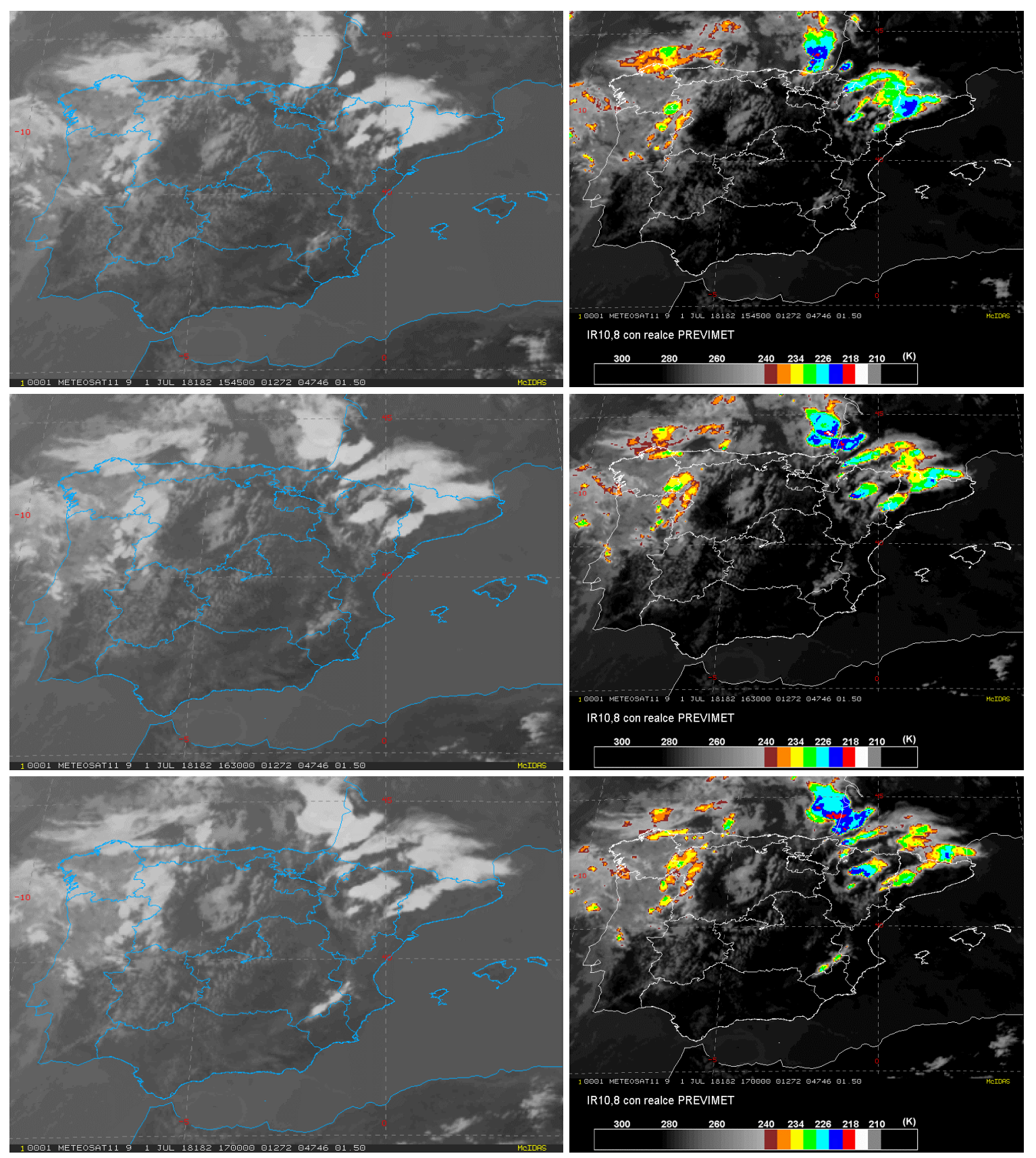

Figura 48. Imágenes del canal IR108 del satélite MSG-4 (imágenes de la izquierda) y con realce PREVIMET (imágenes de la derecha), de las 15:45 UTC (arriba), de las 16:30 UTC (fila central), y de las 17:00 UTC (fila de abajo). 
En las imágenes del canal HRVIS se puede ver cómo estas dos estructuras convectivas iniciales tienen un fuerte desarrollo vertical, con presencia de overshootings, y cómo están sufriendo el proceso de división que se ha comentado. Así en la figura 49 se aprecia que a las 13:45 UTC las dos estructuras nubosas están empezando a dividirse, mientras en la figura 50 se puede ver cómo a las 14:30 UTC la que está situada al NW ha sufrido un proceso de storm splitting simétrico son similar desarrollo de las dos posibles supercélulas (círculos de color rojo y naranja en la figura), mientras que en la estructuras situada al SE este proceso ha supuesto el debilitamiento de la supercélulas anticiclónica (la de la izquierda), reforzándose la ciclónica (la de la derecha, círculo amarillo).

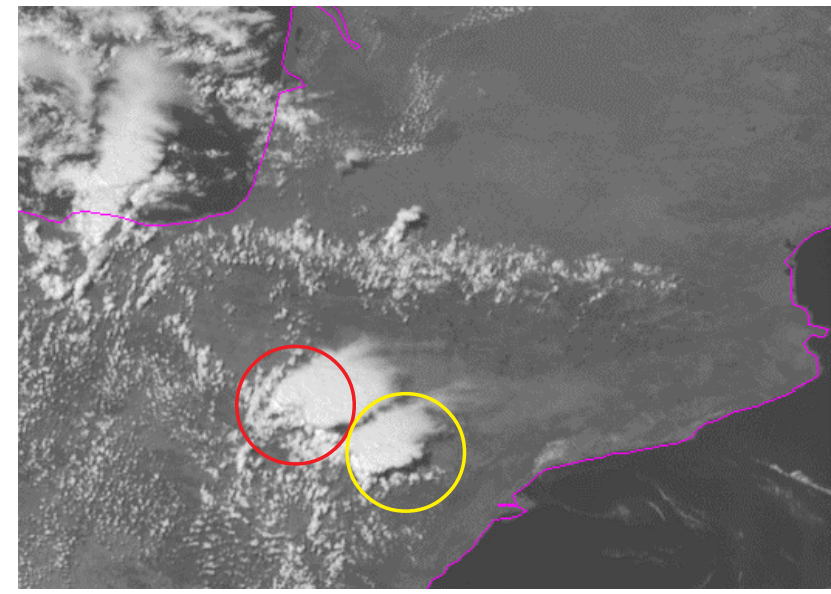

Figura 49. Imagen del satélite MSG-4, canal HRVIS de las 13:45 UTC, en la que se aprecian las dos primeras estructuras nubosas convectivas sobre el centro de Aragón (círculos rojo y amarillo). Se aprecia el marcado desarrollo vertical de la nubosidad y el proceso de storm splitting.

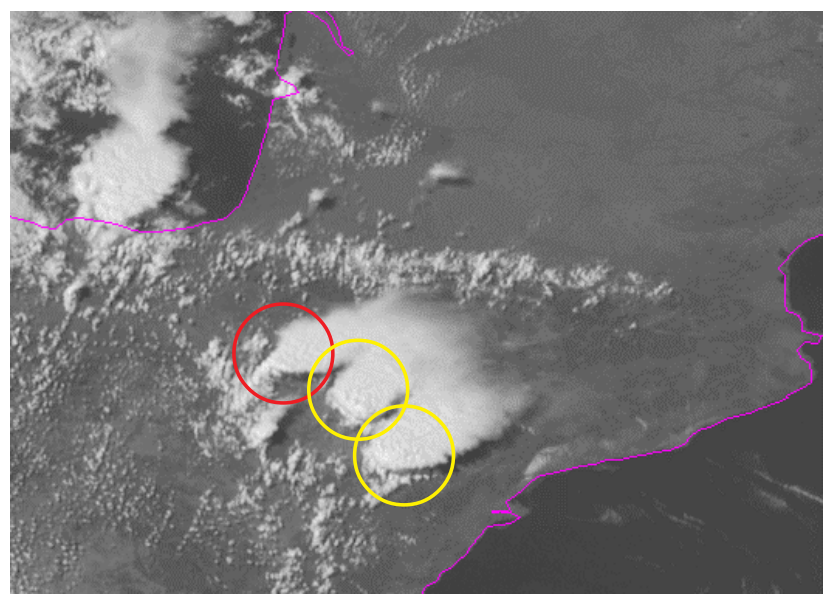

Figura 50. Imagen del satélite MSG-4, canal HRVIS de las 14:30 UTC, en la que se aprecian las dos estructuras nubosas convectivas sobre el centro de Aragón. Se mantiene el marcado desarrollo vertical de la nubosidad y el proceso de storm splitting que ha seguido progresando.

En la imagen del canal HRVIS de las 17:00 UTC (figura 51) se puede ver cómo los dos desarrollos convectivos iniciales se están debilitando a la vez que se han desplazado hacia el N. Pero a la vez han ido apareciendo nuevas estructuras convectivas, de las cuales destaca la que hay en esta imagen y que es la que afectó al aeropuerto de Zaragoza (círculo de color rojo en la figura), y que se ha intensificado como célula anticiclónica después de sufrir un proceso de storm splitting en el cual parece debilitarse la célula ciclónica (círculo de color amarillo en la figura), aunque luego se reactiva. En estas tres imágenes del canal HRVIS se pueden apreciar en las estructuras nubosas principales la presencia de lo que podrían ser flanking lines, característicos de las tormentas supercelulares.

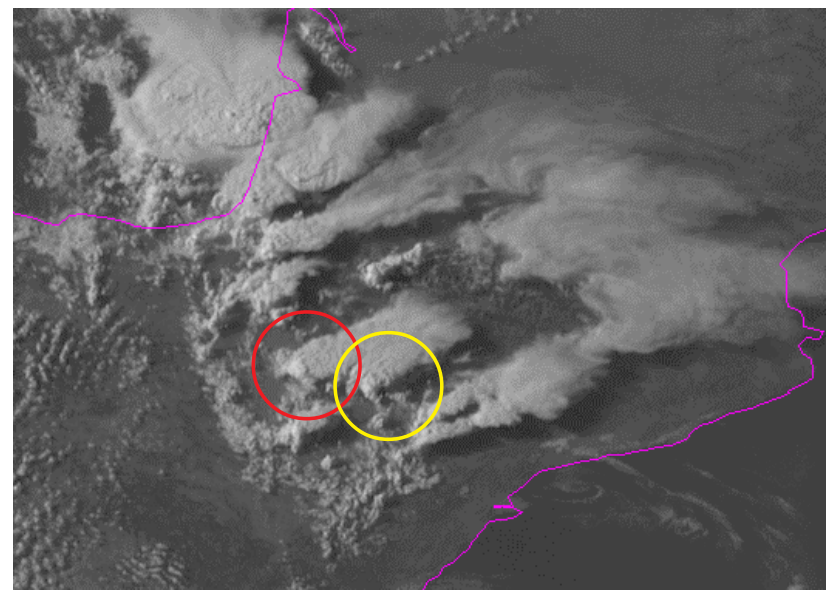

Figura 51. Imagen del satélite MSG-4, canal HRVIS de las 17:00 UTC, en la que se aprecia la estructura nubosas convectivas que afectó al aeropuerto de Zaragoza (círculo rojo). Se puede ver su marcado desarrollo vertical y el proceso de storm splitting que también tuvo lugar. 

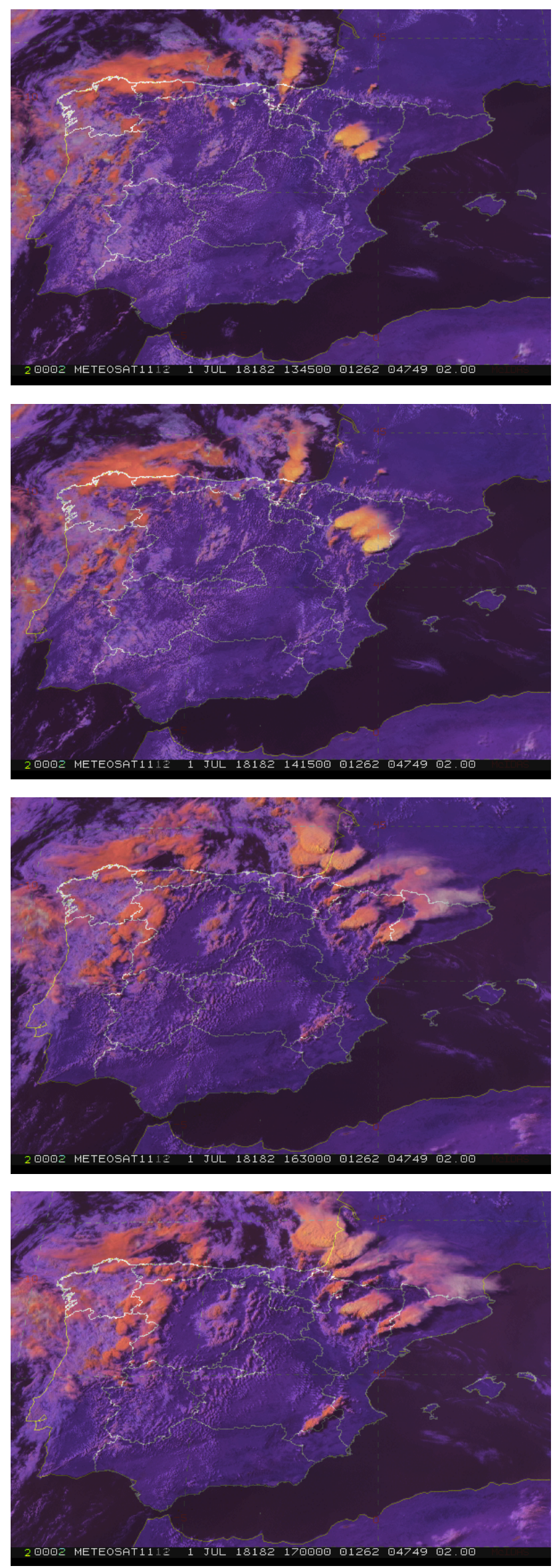

Algunas imágenes y productos del SAF de Nowcasting, permiten destacar mejor determinadas características de la nubosidad asociada a estos procesos convectivos. Las imágenes SANDWICH, que combinan el canal HRVIS con el RGB de convección permiten destacar la nubosidad convectiva (colores naranja) y, de esta manera, en la figura 52, vemos las diferentes estructuras que fueron apareciendo en la región, cómo se fueron dividiendo y el fuerte desarrollo vertical que llegaron a tener. En la figura 53 vemos las mismas estructuras nubosas por medio del producto CRPh1, de intensidad de precipitación convectiva $(\mathrm{mm} / \mathrm{h})$ destacando que en todas ellas aparecen colores correspondientes a altas intensidades de precipitación. En las dos primeras imágenes se pueden ver intensidades en torno a los 10 o $16 \mathrm{~mm} / \mathrm{h}, \mathrm{y}$ en las imágenes de las $16: 30$ y 17:00 UTC se llegan a apreciar pixeles con valores de 30 e incluso $50 \mathrm{~mm} / \mathrm{h}$.
Figura 52. Imágenes SANDWICH, combinando el canal HRVIS con el RGB de convección del SAF de Nowcasting. Las dos imágenes superiores muestran las primeras estructuras convectivas en proceso de storm splitting a las 13:45 UTC (arriba) y a las 14:15 UTC (debajo de la anterior). Las dos imágenes inferiores muestran el proceso de storm splitting de la célula convectiva que afectó al aeropuerto de Zaragoza, a las 16:30 UTC (tercera imagen) y a las 17:00 UTC (abajo). 

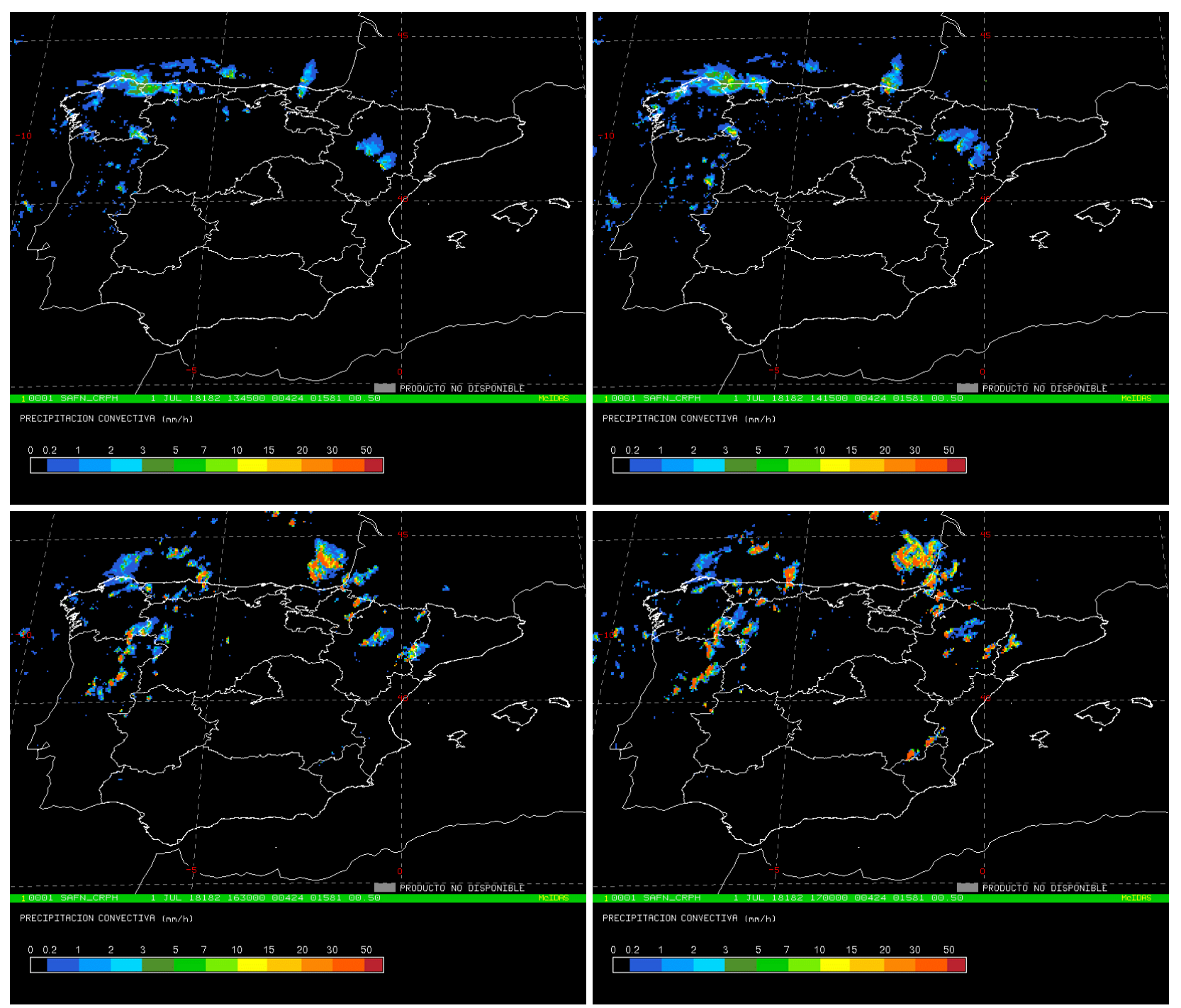

Figura 53. Imágenes de producto CRPh1 (intensidad de precipitación convectiva), del SAF de Nowcasting. Destacan las primeras estructuras convectivas en proceso de storm splitting a las 13:45 UTC (arriba a la izquierda) y a las 14:15 UTC (arriba a la derecha). En la fila de abajo, célula convectiva que afectó al aeropuerto de Zaragoza, a las 16:30 UTC (a la izquierda) y a las 17:00 UTC (a la derecha).

\section{IMÁGENES RADAR Y DESCARGAS ELÉCTRICAS}

Los datos obtenidos por el radar de Zaragoza, tanto en modo normal como en modo Doppler, permiten analizar y describir con bastante detalle el nacimiento, desarrollo y evolución de los diferentes fenómenos convectivos que se generaron durante este evento. Lo primero que se puede destacar se observa en las imágenes del primer PPI de reflectividad. En la figura 54 se pueden ver a las 13:30 UTC las dos primeras estructuras convectivas, perfectamente desarrolladas y en proceso de storm splitting. En la que aparece al $\mathrm{N}$ de la provincia de Teruel, solo se reforzaría la supercélula ciclónica que se desplazó hacia la comarca del Bajo Aragón. La otra estructura se forma al S de la provincia de Zaragoza, en el límite con la de Teruel, y en su proceso de división se puede observar cómo las dos células convectivas «nuevas» van a persistir sin que ninguna de ellas se debilite.

En las imágenes siguientes (figuras 55 a 58) se aprecia la evolución de estos dos procesos de splitting, el de la célula que se dirige hacia el Bajo Aragón y el que da lugar a dos células, una ciclónica que se desplaza al E de la ciudad de Zaragoza, y afectará a poblaciones de la Ribera del Ebro, y otra anticiclónica que se desplaza al W de Zaragoza y se dirige hacia la comarca de las Cinco Villas. 


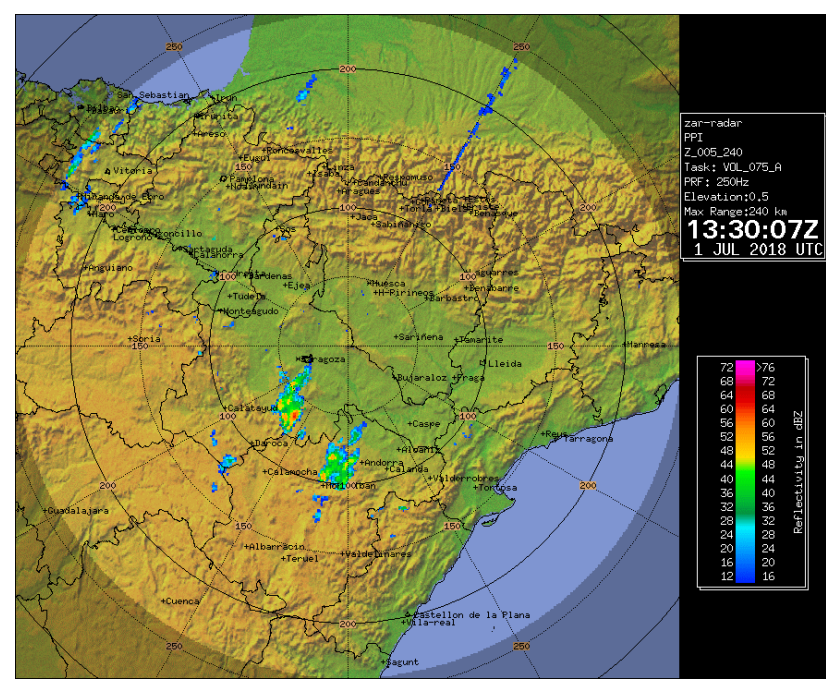

Figura 54. Imagen de reflectividad del radar de Zaragoza correspondiente al primer PPI (primera elevación radar), del día 1 de julio de 2018 a las 13:30 UTC.

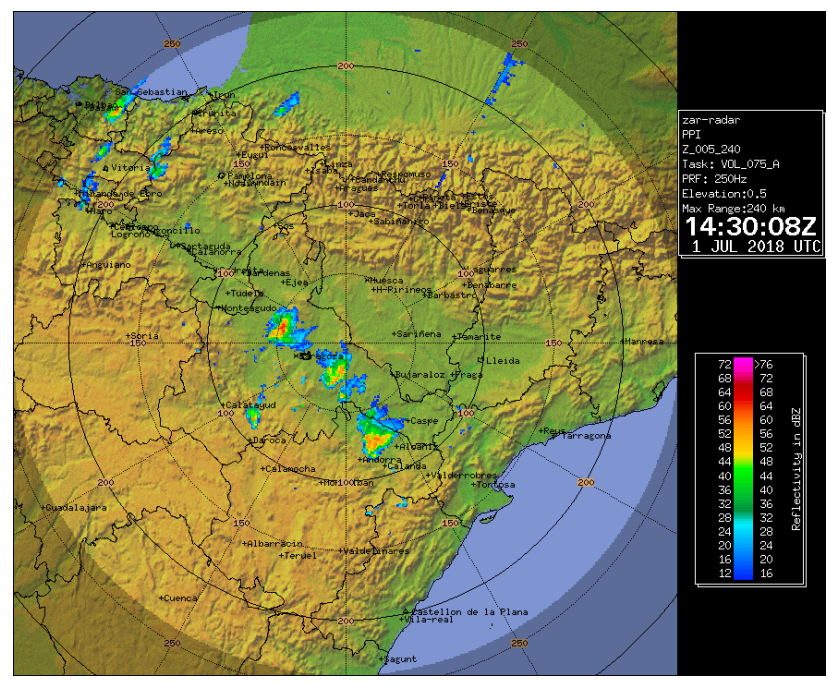

Figura 56. Imagen de reflectividad del radar de Zaragoza correspondiente al primer PPI (primera elevación radar), del día 1 de julio de 2018 a las 14:30 UTC.

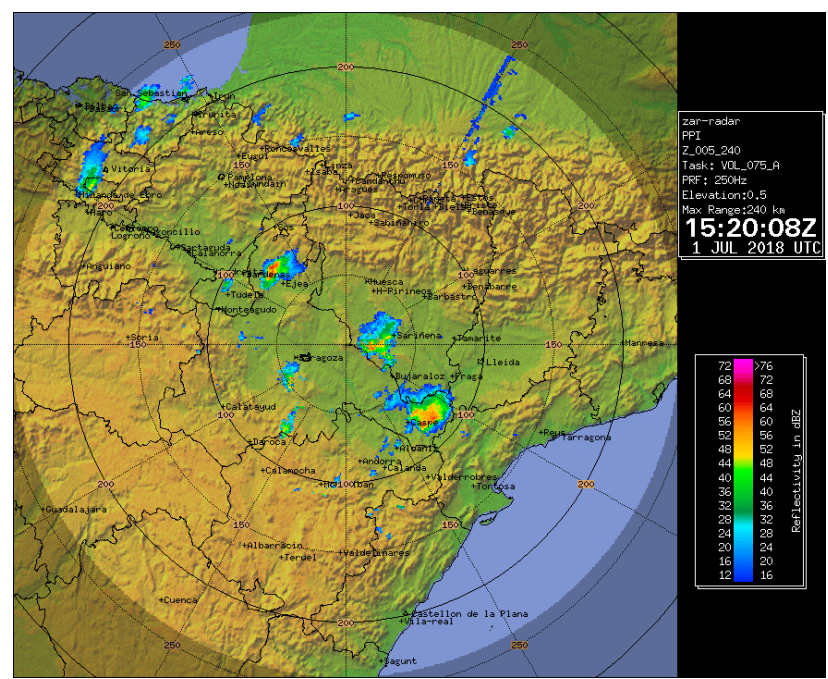

Figura 58. Imagen de reflectividad del radar de Zaragoza correspondiente al primer PPI (primera elevación radar), del día 1 de julio de 2018 a las 15:20 UTC.

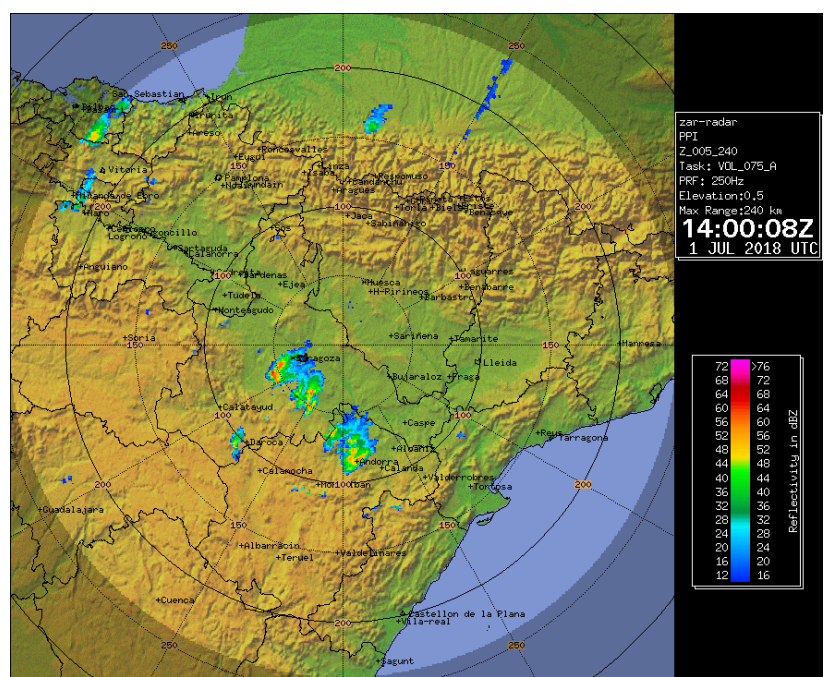

Figura 55. Imagen de reflectividad del radar de Zaragoza correspondiente al primer PPI (primera elevación radar), del día 1 de julio de 2018 a las 14:00 UTC.

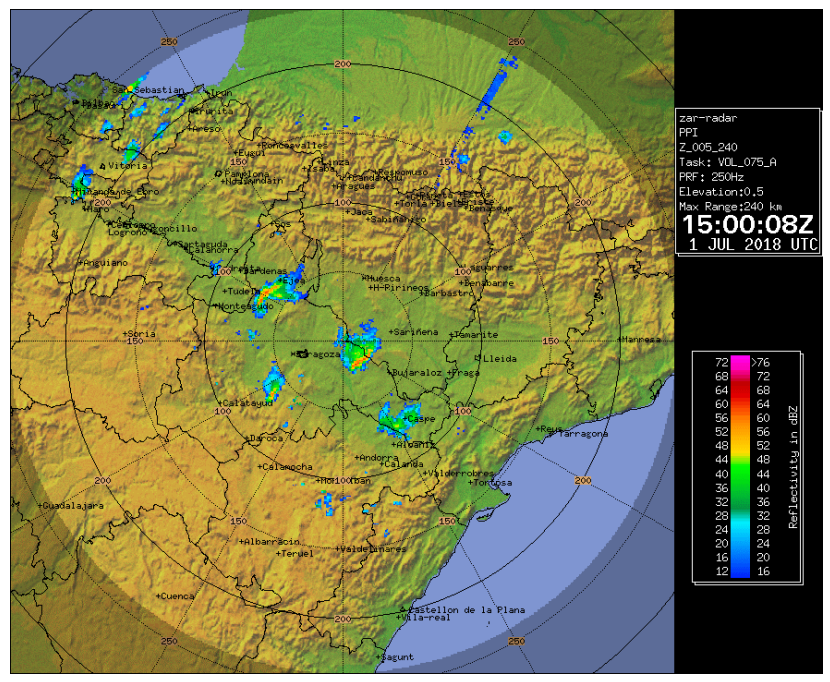

Figura 57. Imagen de reflectividad del radar de Zaragoza correspondiente al primer PPI (primera elevación radar), del día 1 de julio de 2018 a las 15:00 UTC.

En la imagen de las 15:00 UTC (figura 57), la supercélula situada en el Bajo Aragón parece más débil, pero es una impresión debida al apantallamiento que produce la supercélula de la Ribera del Ebro que en este momento se sitúa al SE del radar, muy cerca del mismo. Cuando esta célula se desplaza de esta posición, la anterior vuelve a verse, muy cerca de Caspe, otra vez con reflectividades altas.

A las 15:20 UTC (figura 58), a la vez que las estructuras convectivas anteriores siguen su evolución y desplazamiento podemos observar cómo aparece una nueva célula convectiva prácticamente en el mismo lugar donde se originó una de las anteriores, al S de la provincia de Zaragoza, en el 


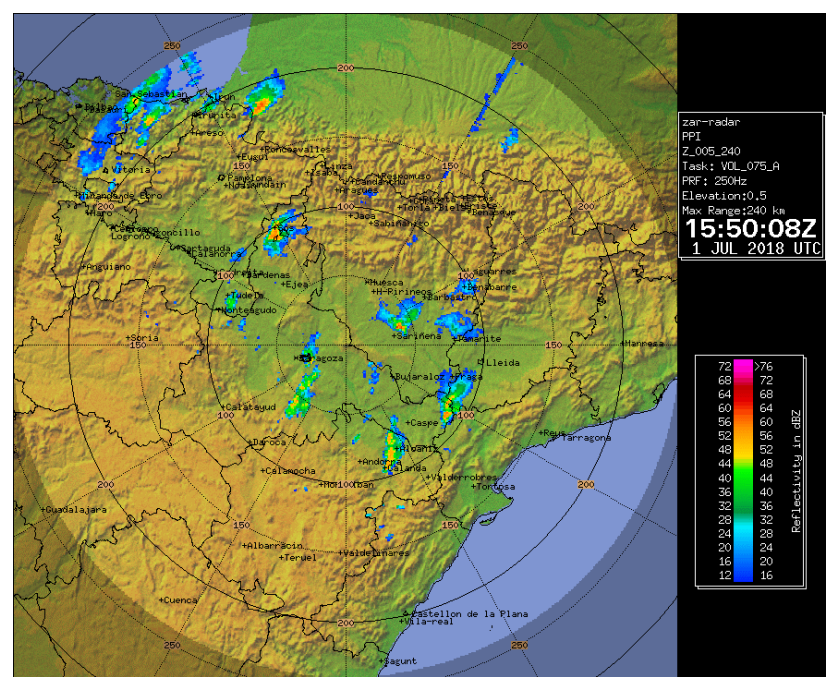

Figura 59. Imagen de reflectividad del radar de Zaragoza correspondiente al primer PPI (primera elevación radar), del día 1 de julio de 2018 a las 15:50 UTC.

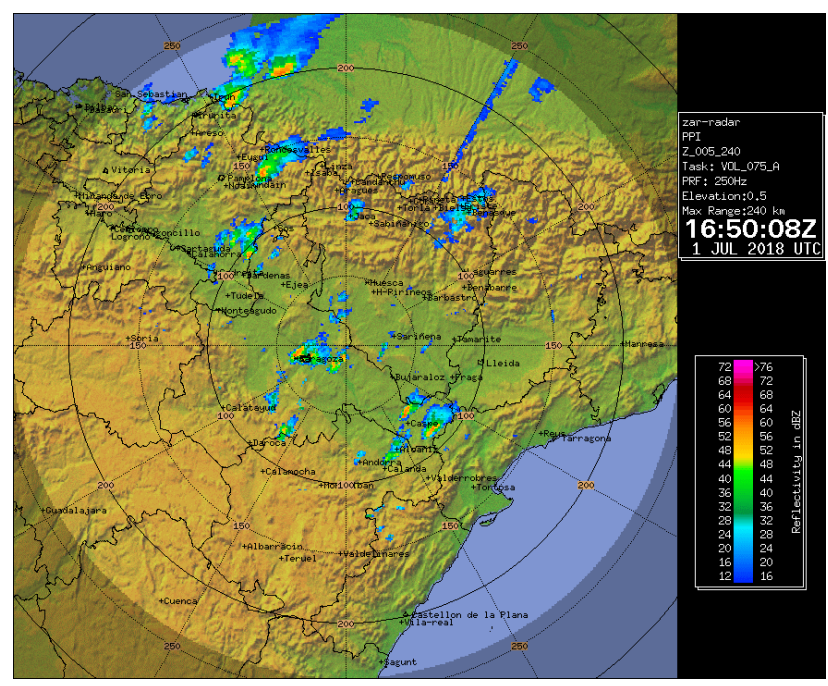

Figura 61. Imagen de reflectividad del radar de Zaragoza correspondiente al primer PPI (primera elevación radar), del día 1 de julio de 2018 a las 16:50 UTC.

límite con la de Teruel. En las imágenes siguientes (figuras 59 a 63), se observa cómo esta estructura convectiva sufre también un proceso de storm splitting, dividiéndose en dos supercélulas que van a mantenerse activas como se ve a lo largo de estas imágenes. La supercélula con giro anticiclónico es la que en su desplazamiento hacia el N afectó, hacia las 16:50 UTC, al aeropuerto de Zaragoza, donde se llegaron a registrar rachas de viento de $157 \mathrm{~km} / \mathrm{h}$. Ambas estructuras se mantuvieron activas, evolucionando y desplazándose, una hacia el N, para llegar a las Cinco Villas, y la célula ciclónica al NE, para cruzar la sierra de Alcubierre y dirigirse a las proximidades de Sariñena.

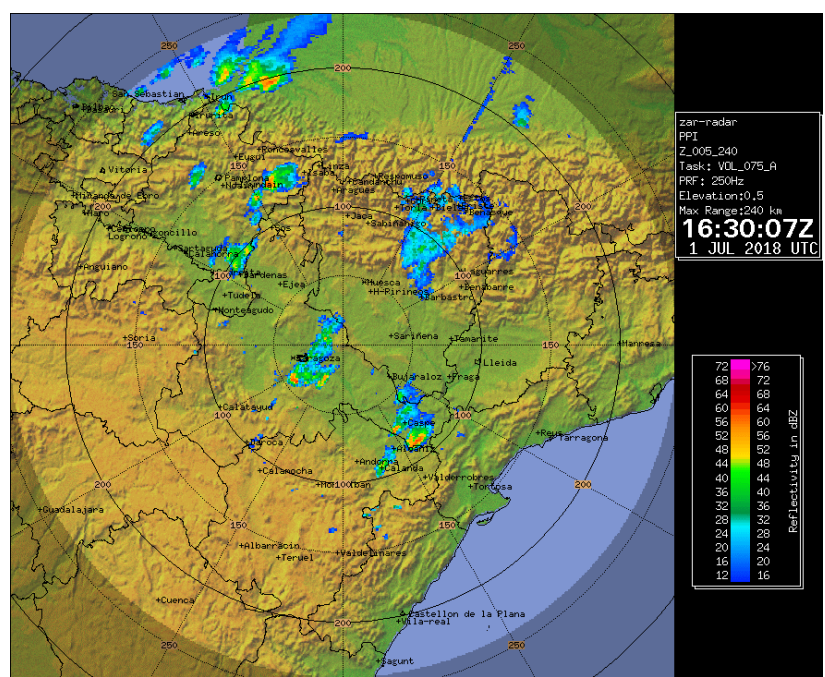

Figura 60. Imagen de reflectividad del radar de Zaragoza correspondiente al primer PPI (primera elevación radar), del día 1 de julio de 2018 a las 16:30 UTC.

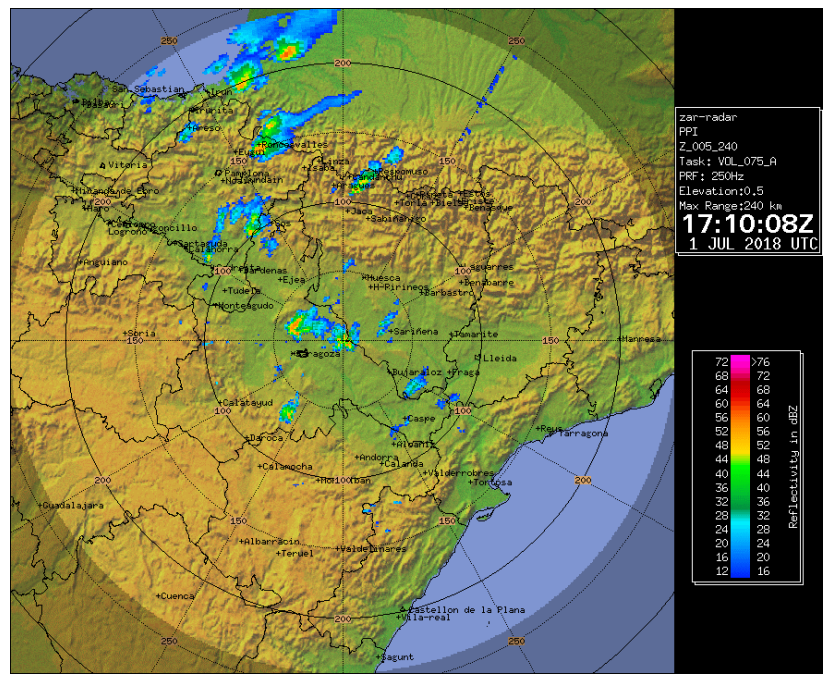

Figura 62. Imagen de reflectividad del radar de Zaragoza correspondiente al primer PPI (primera elevación radar), del día 1 de julio de 2018 a las 17:10 UTC.

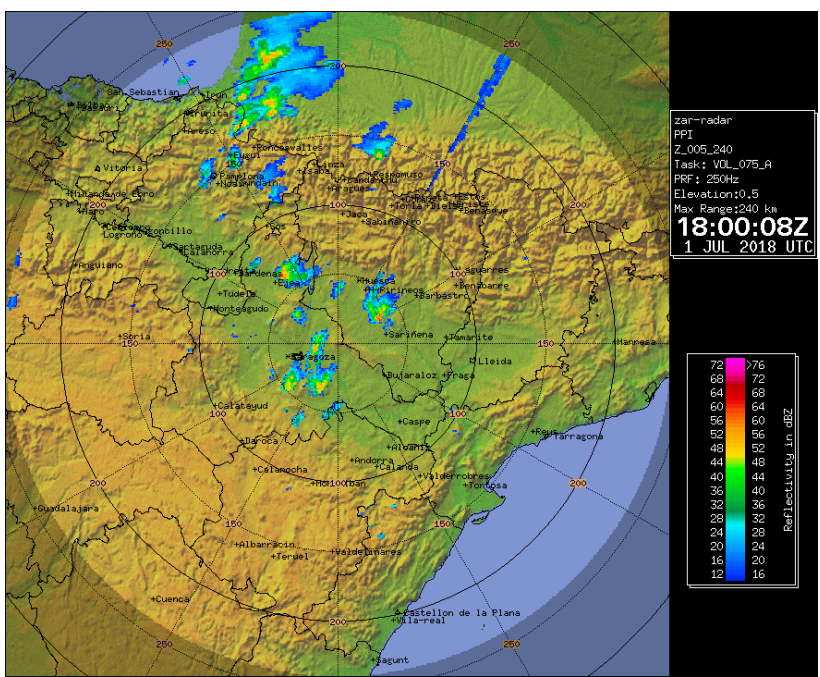

Figura 63. Imagen de reflectividad del radar de Zaragoza correspondiente al primer PPI (primera elevación radar), del día 1 de julio de 2018 a las 18:00 UTC. 
En las figuras 64 a 67 se pueden ver las imágenes de ecotop y en las figuras 68 a 71 las de VIL (vertically integrated liquid) en varios momentos a lo largo del desarrollo y evolución de las células convectivas que se han descrito previamente. Las imágenes de ecotop, que reflejan la mayor altura a que llegan los ecos de $12 \mathrm{dBZ}$, ponen de manifiesto el gran desarrollo vertical de las estructuras convectivas que se formaron durante los procesos de storm splitting que se han identificado, con valores que llegan a los 14, 15 e incluso $16 \mathrm{~km}$ de altura. Por otro lado, durante todo este intervalo de tiempo las imágenes de VIL reflejan un contenido líquido acuoso muy elevado. Se ven valores en todos los casos que llegan a los 25 y $30 \mathrm{~kg} / \mathrm{m}^{2}$, y en muchas células valores superiores que llegan a los 32 e incluso $34 \mathrm{~kg} / \mathrm{m}^{2}$. Tanto los valores de ecotop como los de VIL son reflejo del gran desarrollo de las estructuras convectivas, y de la presencia de valores altos de reflectividad en toda su extensión vertical, como consecuencia de las intensas corrientes ascendentes que han dado lugar a estas células convectivas. Por otro lado, estos valores tan intensos de VIL según diversos autores americanos como Greene y Clark (1972), Stewart (1991) o Kitzmiller et al. (1995), son un buen indicativo de la posible severidad y adversidad de las estructuras convectivas (granizo, vientos fuertes en superficie, precipitaciones intensas y/o tornados, entre otros fenómenos).

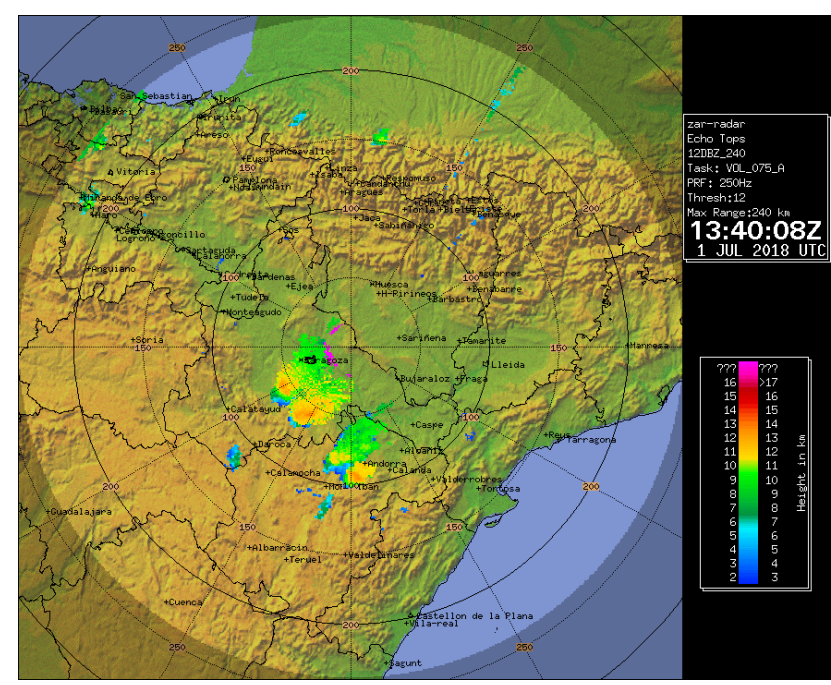

Figura 64. Imagen de ecotop del radar de Zaragoza correspondiente al día 1 de julio de 2018 a las 13:40 UTC.

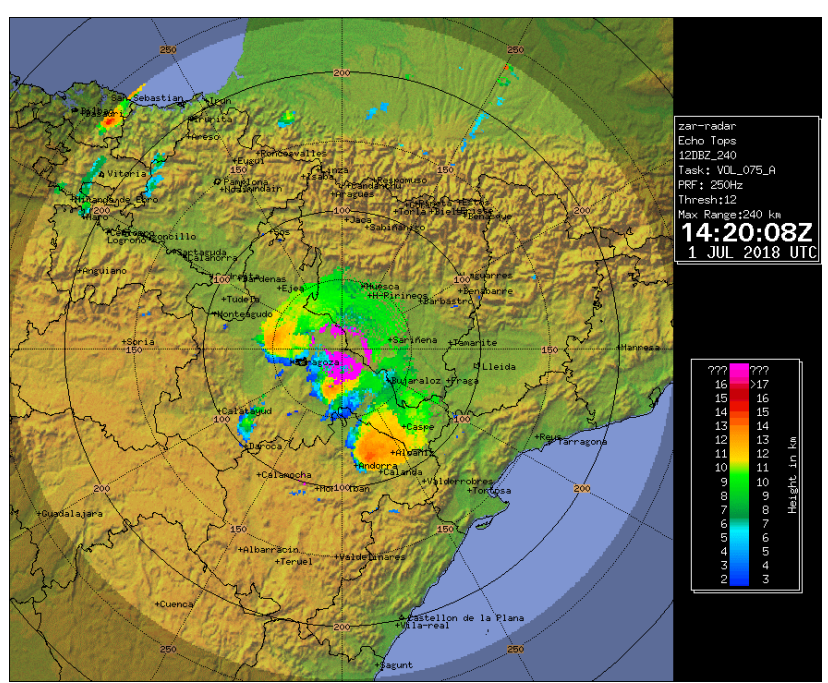

Figura 65. Imagen de ecotop del radar de Zaragoza correspondiente al día 1 de julio de 2018 a las 14:20 UTC.

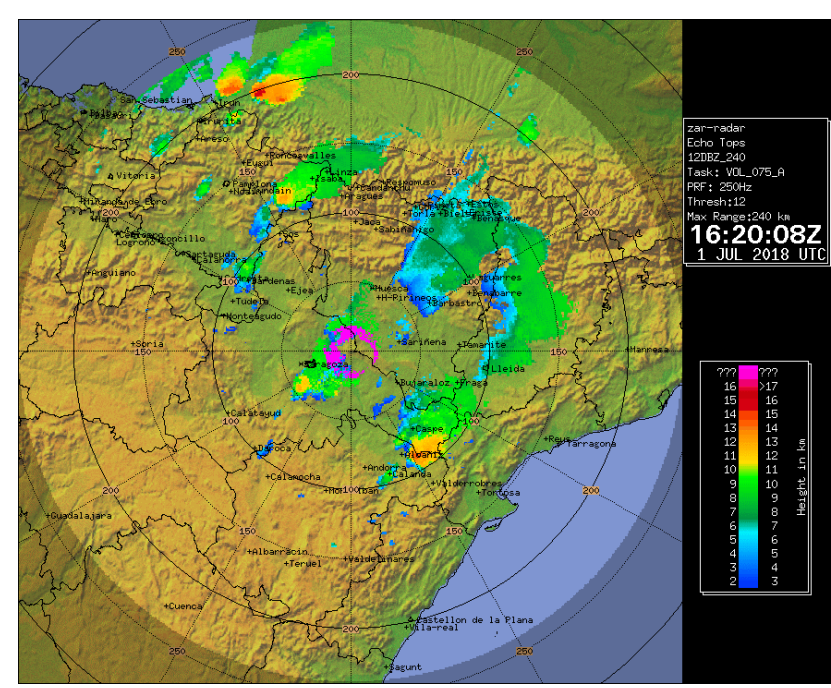

Figura 66. Imagen de ecotop del radar de Zaragoza correspondiente al día 1 de julio de 2018 a las 16:20 UTC.

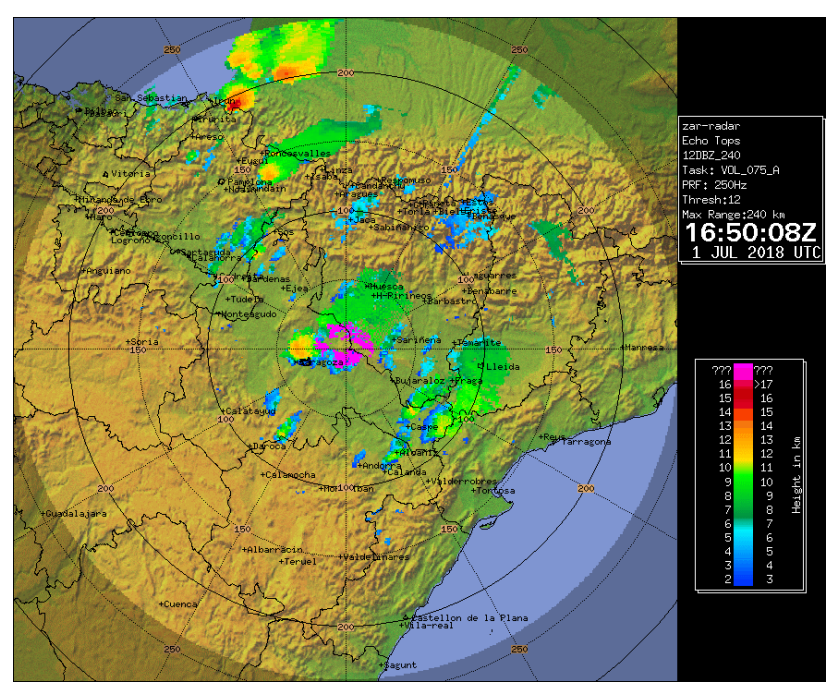

Figura 67. Imagen de ecotop del radar de Zaragoza correspondiente al día 1 de julio de 2018 a las 16:50 UTC. 


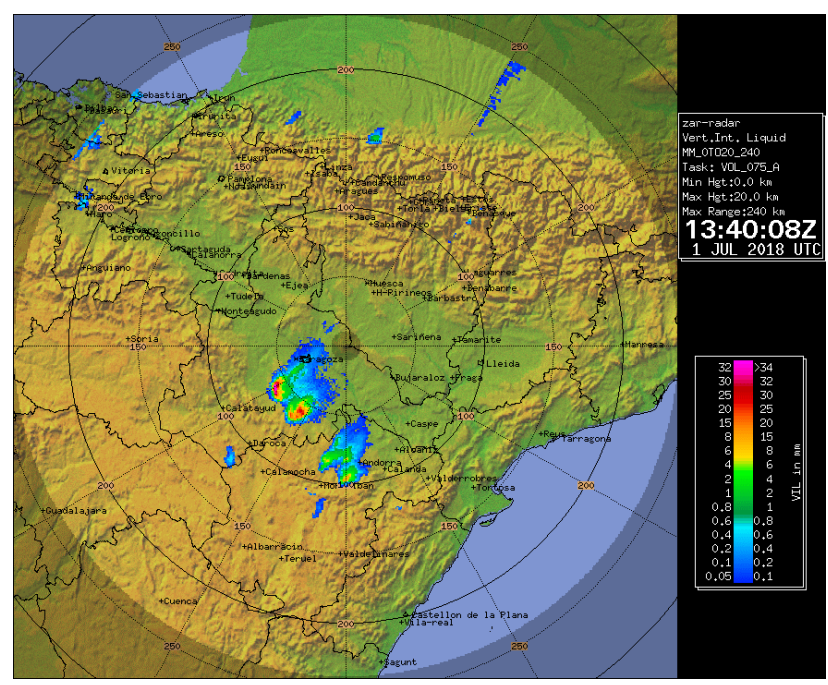

Figura 68. Imagen de VIL (vertically integrated liquid) del radar de Zaragoza correspondiente al día 1 de julio de 2018 a las 13:40 UTC.

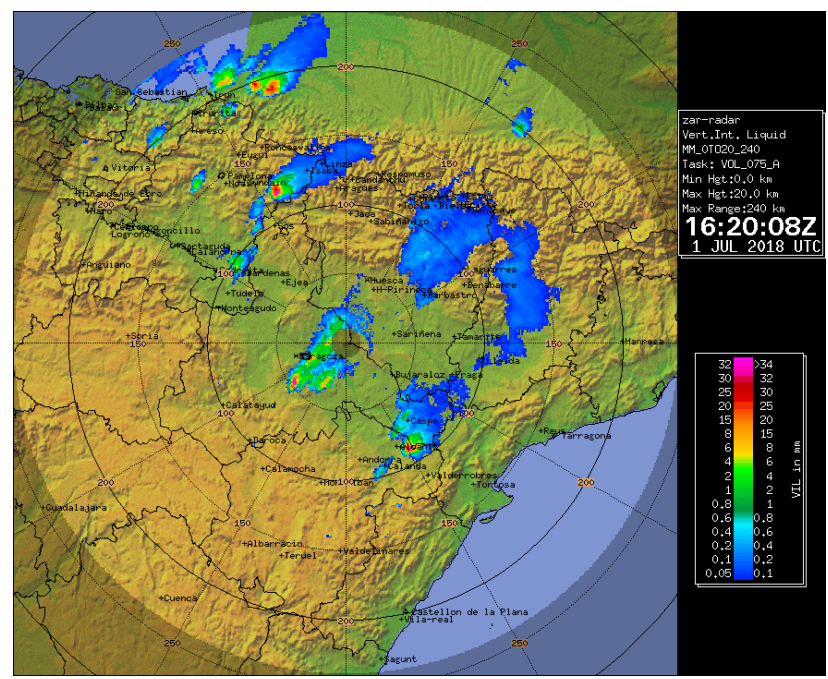

Figura 70. Imagen de VIL (vertically integrated liquid) del radar de Zaragoza correspondiente al día 1 de julio de 2018 a las 16:20 UTC.

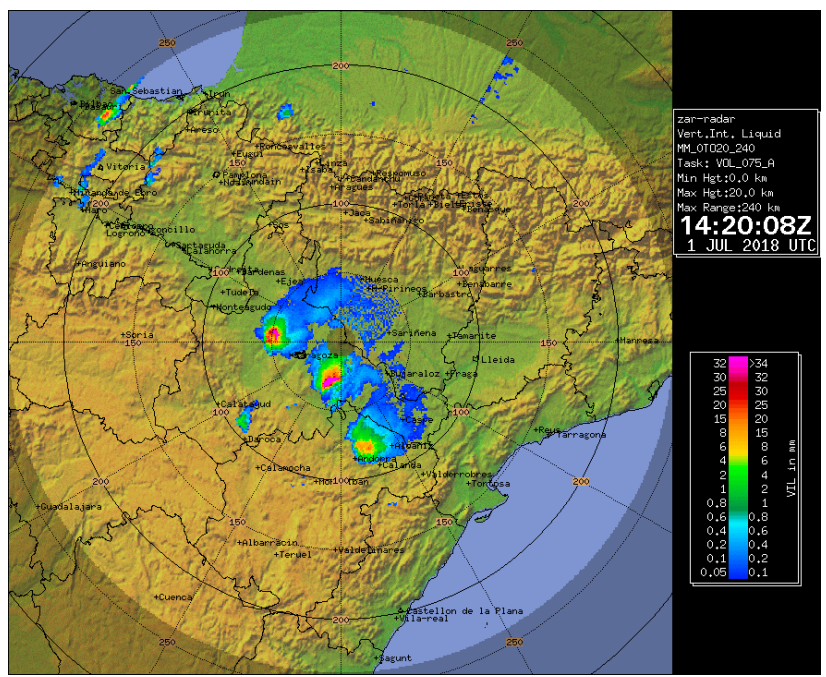

Figura 69. Imagen de VIL (vertically integrated liquid) del radar de Zaragoza correspondiente al día 1 de julio de 2018 a las 14:20 UTC.

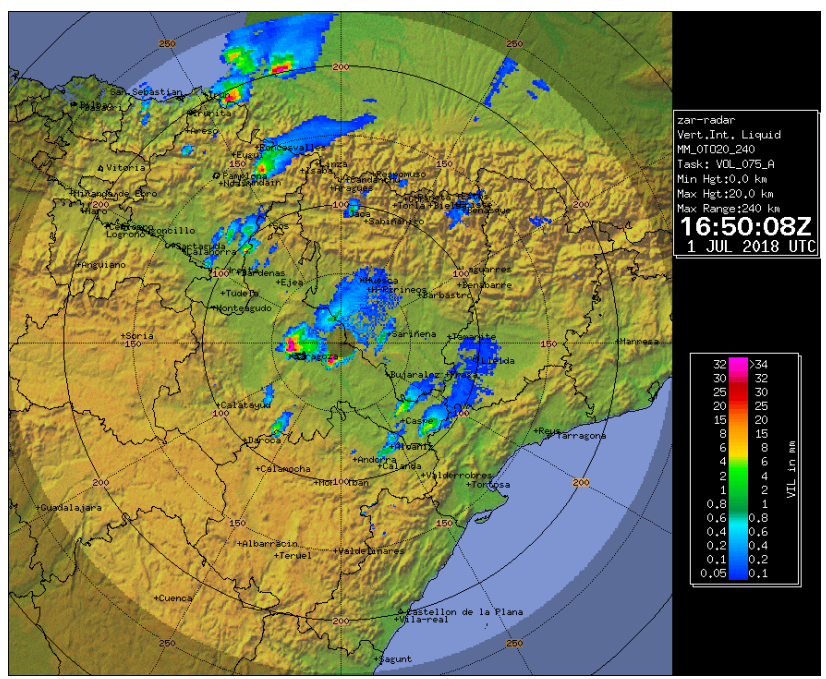

Figura 71. Imagen de VIL (vertically integrated liquid) del radar de Zaragoza correspondiente al día 1 de julio de 2018 a las 16:50 UTC.

Si observamos las imágenes combinadas de máximos de reflectividad en paneles (figuras 72 a 74), se puede apreciar en todas ellas un probable alto grado de organización de la convección, con un fuerte desarrollo vertical, que también quedaba reflejado en las imágenes ya descritas de ecotop y de VIL. Este supuesto alto grado de organización se aprecia en las estructuras con altos valores de reflectividad que llegan a gran altura y además tienen una marcada inclinación en la vertical, debido a que las corrientes ascendentes y descendentes de la tormenta están desacopladas. Se aprecia también en estas imágenes el proceso de storm splitting, así se puede ver en la figura 72 cómo dos intensas estructuras convectivas muy organizadas se van separando en las imágenes siguientes.

Se han podido efectuar cortes verticales en el volumen de datos de reflectividad que permiten apreciar mejor los patrones de organización de estas estructuras convectivas. Así, en las figuras 75 a 78 se ponen de manifiesto varias de estas características en tres de las estructuras convectivas. Por un lado se ve el gran desarrollo vertical de las mismas, llegando a alturas entre 12 y 14 km (cómo ya habíamos apreciado en las imágenes de ecotop) así como su marcada inclinación en la vertical. Se aprecian también valores muy intensos de reflectividad, 60 e incluso $64 \mathrm{dBZ}$, a alturas de 8 y $9 \mathrm{~km}$, y además fuertes gradientes horizontales de reflectividad. 
Se constata así mismo en estas imágenes la forma de gancho en la vertical de estas estructuras de reflectividad, con la presencia de una ZB (zona abalconada) encima de una RED (región de eco débil), así como la presencia en altura de una REDA (región de eco débil acotada), en definitiva valores altos de reflectividad suspendidos a gran altura sobre una región con valores pequeños de reflectividad. Este patrón podría corresponder al modelo conceptual de supercélula y sería consecuencia de la intensidad de las corrientes ascendentes, posiblemente en rotación, dentro de un entorno favorable para que aparezca este tipo de convección, muy organizada, originada además a partir de los procesos de storm splitting observados.

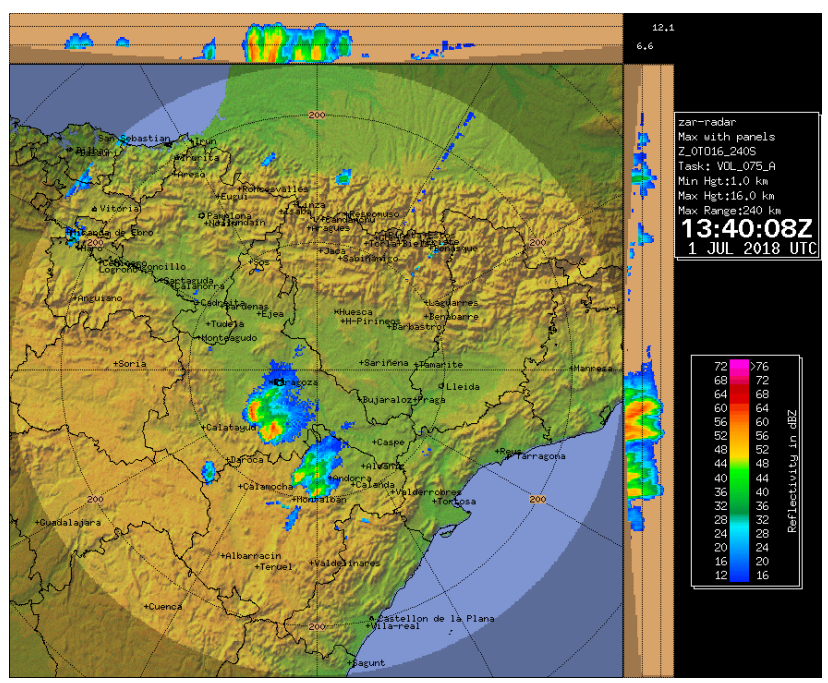

Figura 72. Imagen combinada de máximos de reflectividad en paneles del día 1 de julio de 2018 a las 13:40 UTC.

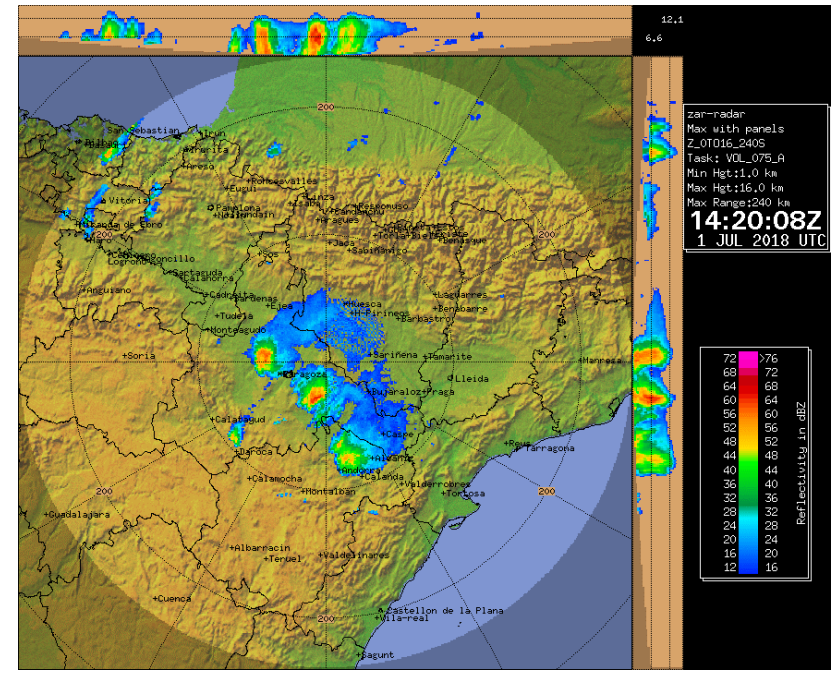

Figura 73. Imagen combinada de máximos de reflectividad en paneles del día 1 de julio de 2018 a las 14:20 UTC.

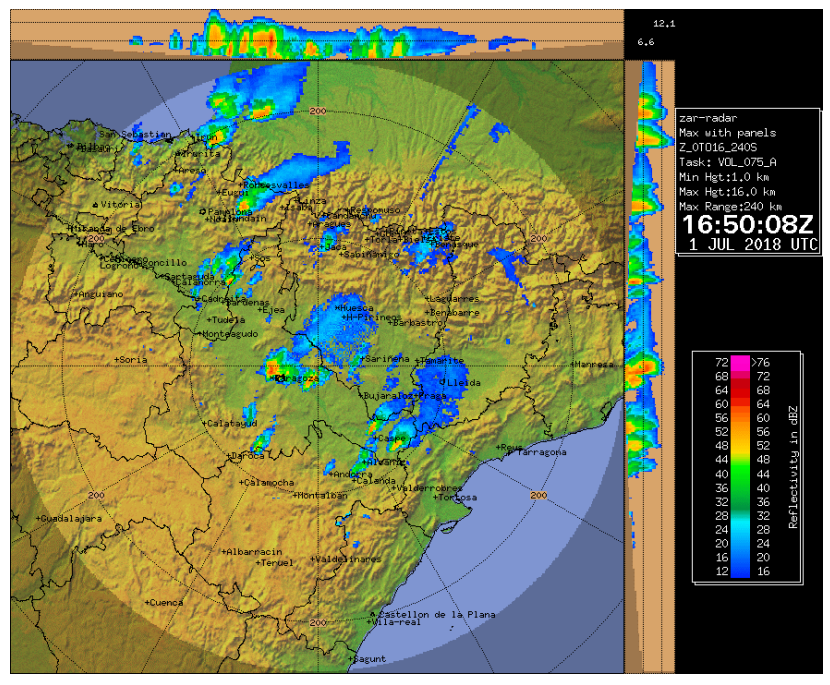

Figura 74. Imagen combinada de máximos de reflectividad en paneles del día 1 de julio de 2018 a las 16:50 UTC.

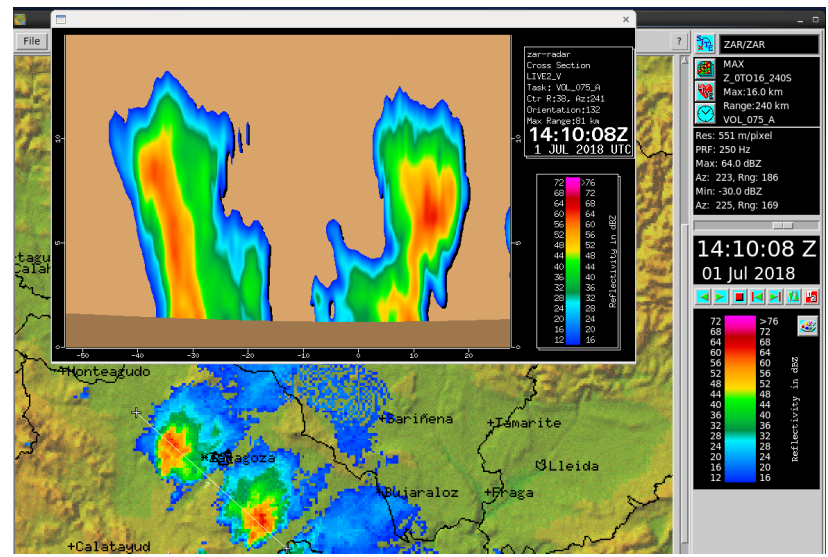

Figura 75. Corte vertical del volumen de datos de reflectividad de las dos células en el primer proceso de storm splitting del día 1 de julio de 2018 a las 14:10 UTC.

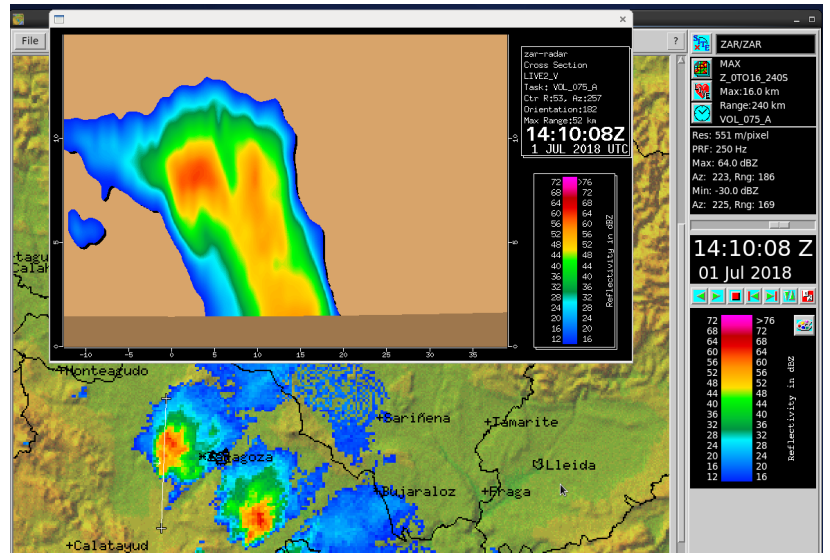

Figura 76. Corte vertical del volumen de datos de reflectividad de la supercélula anticiclónica en el primer proceso de storm splitting del día 1 de julio de 2018 a las 14:10 UTC. 


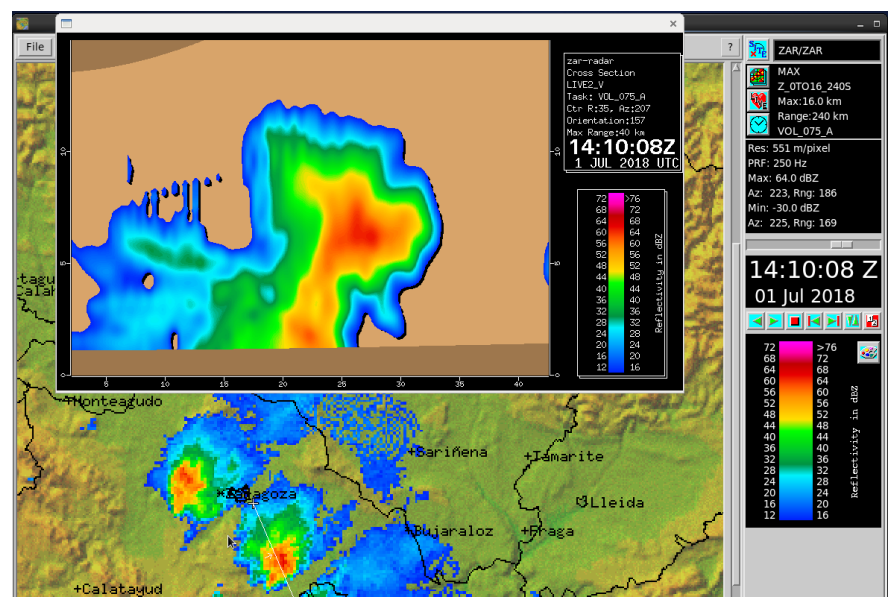

Figura 77. Corte vertical del volumen de datos de reflectividad de la supercélula ciclónica en el primer proceso de storm splitting del día 1 de julio de 2018 a las 14:10 UTC.

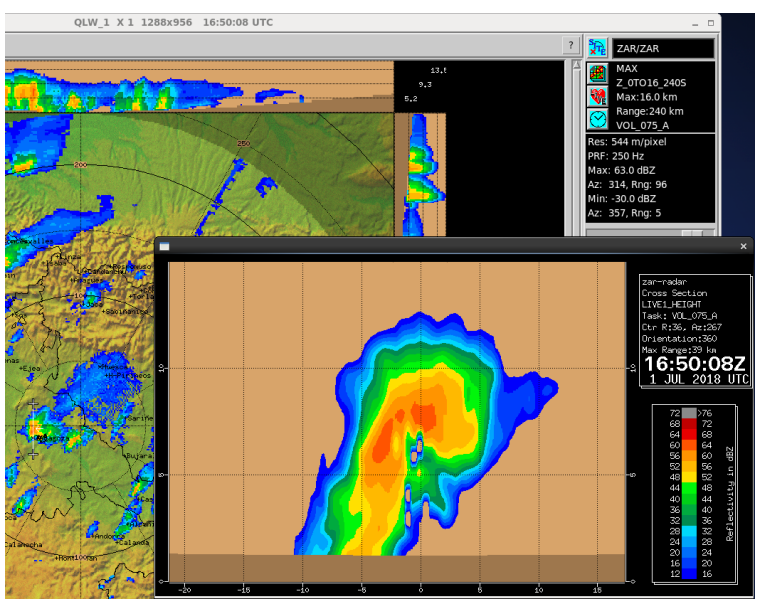

Figura 78. Corte vertical del volumen de datos de reflectividad de la supercélula que afectó al aeropuerto de Zaragoza el día 1 de julio de 2018 a las 16:50 UTC.

En las figuras 79 a 85 se presentan las salidas de los módulos 2D y 3D de la aplicación YRADAR para la identificación, caracterización, seguimiento y extrapolación de la convección (MARTín ET AL., 2001; Sanambrosio, 2011). En las imágenes que van desde las 13:30 hasta las 15:20 UTC (figuras 79 a 82), se puede identificar en las salidas 2D y en las 3D las dos estructuras convectivas iniciales que están empezando a sufrir el proceso de splitting storm y cómo estas estructuras se van separando en varias supercélulas cómo se ha descrito en apartados anteriores. En este intervalo de tiempo estas células identificadas por el módulo 2D muestran en general un tamaño considerable, y reflectividades máximas intensas, en general entre 58 y $62 \mathrm{dBZ}$, llegando a los $65 \mathrm{dBZ}$ en algún momento y moviéndose en direcciones consistentes con el proceso de división mencionado: la supercélula del Bajo Aragón y la que afectó a la Ribera del Ebro se desplazan hacia el NE, la otra supercélula se desplaza hacia el $\mathrm{N}$, en dirección a las Cinco Villas.

En las imágenes del módulo 3D aparecen identificadas estas mismas células, todas ellas con gran desarrollo vertical y caracterizadas por parámetros que delatan su posible adversidad o severidad: reflectividades muy altas, entre 50 y $65 \mathrm{dBZ}$, espesores en general entre 9 y $12 \mathrm{~km}$, ecotops entre 10 y $12 \mathrm{~km}$, e incluso hasta $14 \mathrm{~km}$ en algún momento, y densidad de VIL muy alta, en general entre 4,0 y $5,0 \mathrm{~g} / \mathrm{cm}^{3}$, llegando en algún momento a los $5,9 \mathrm{~g} / \mathrm{cm}^{3}$.
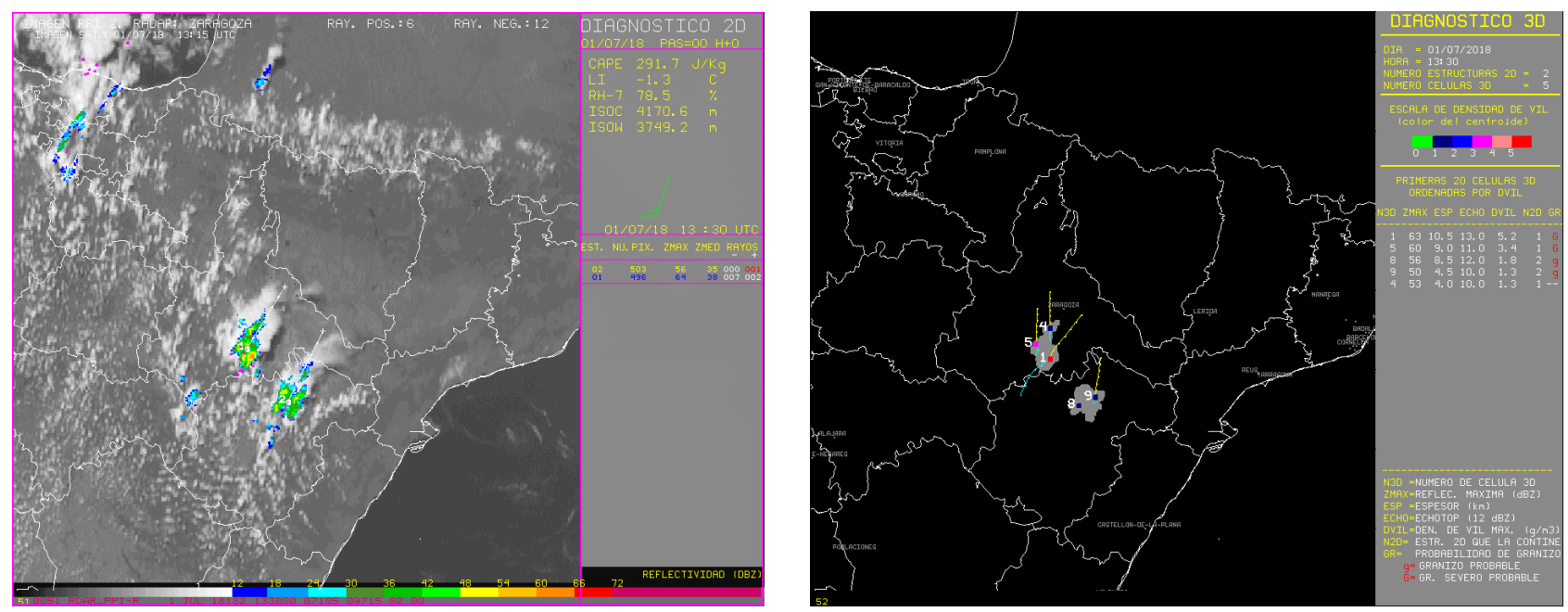

Figura 79. Imágenes de la aplicación YRADAR del día 1 de julio de 2018 a las 13:30 UTC, salida del módulo de diagnóstico 2D (izquierda) y del módulo de diagnóstico 3D (derecha). 

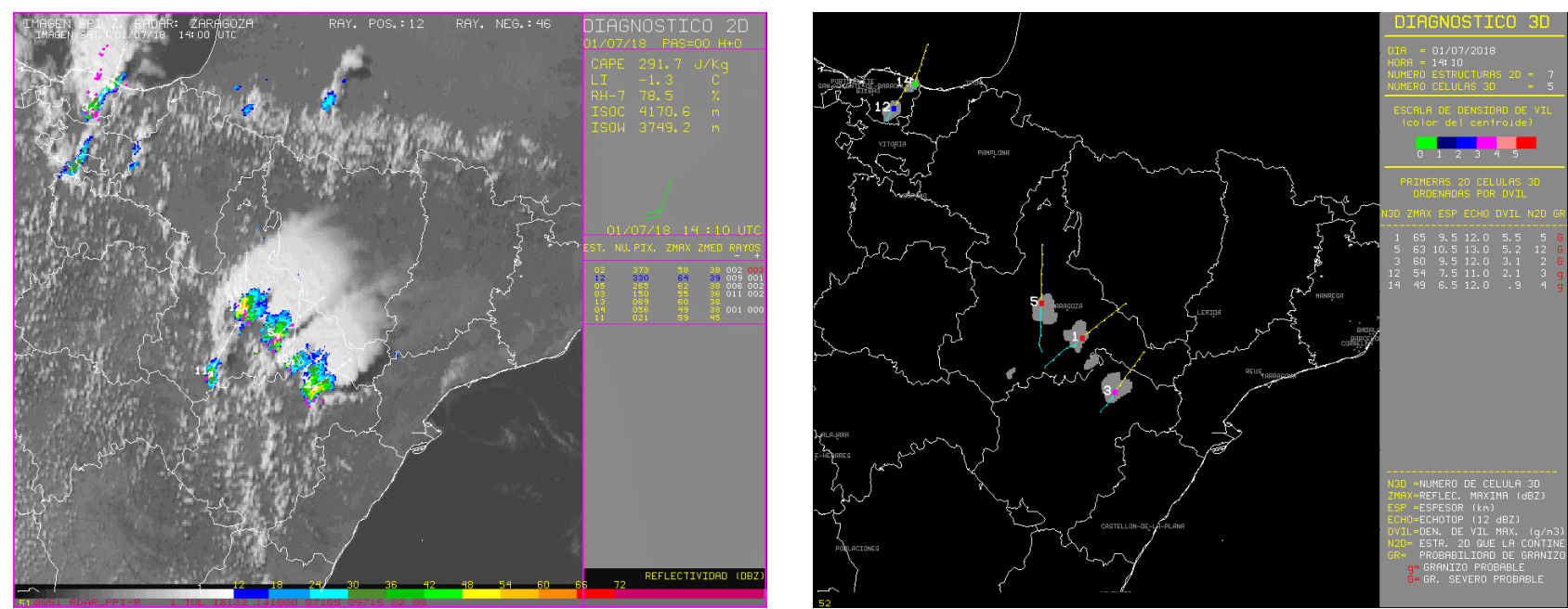

Figura 80. Imágenes de la aplicación YRADAR del día 1 de julio de 2018 a las 14:10 UTC, salida del módulo de diagnóstico 2D (izquierda) y del módulo de diagnóstico 3D (derecha).
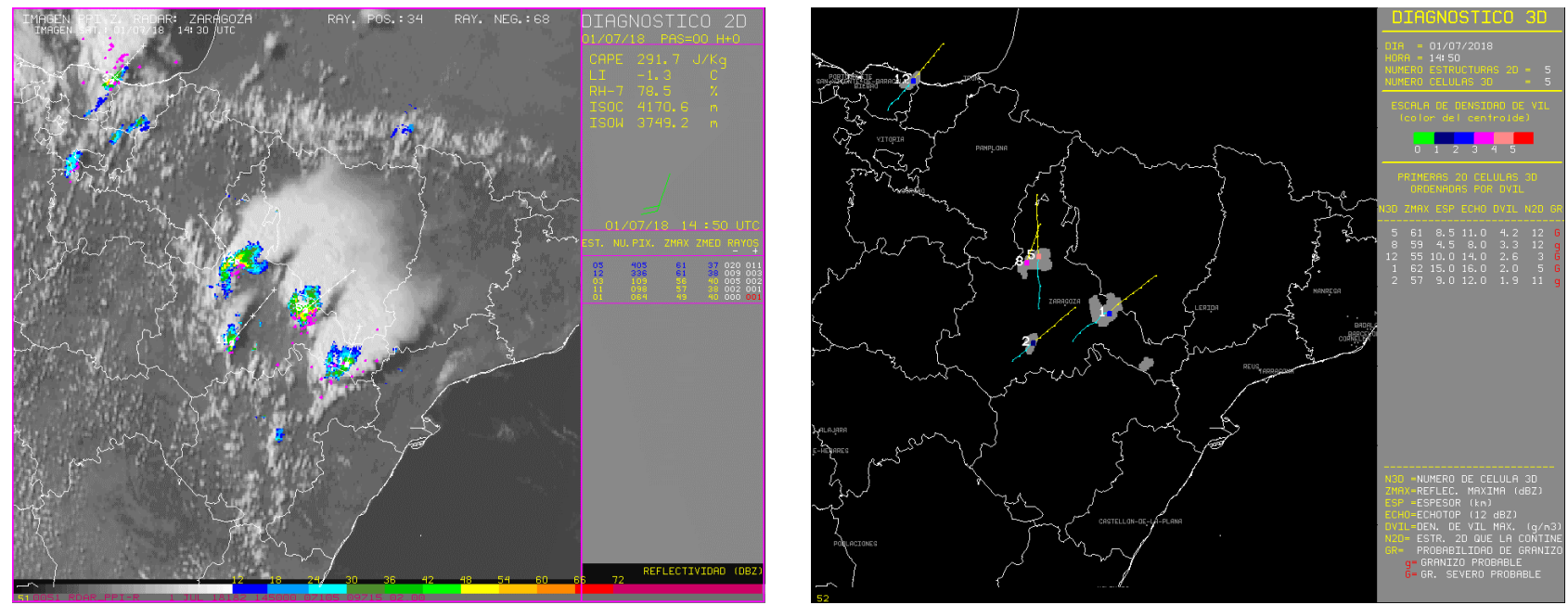

Figura 81. Imágenes de la aplicación YRADAR del día 1 de julio de 2018 a las 14:50 UTC, salida del módulo de diagnóstico 2D (izquierda) y del módulo de diagnóstico 3D (derecha).
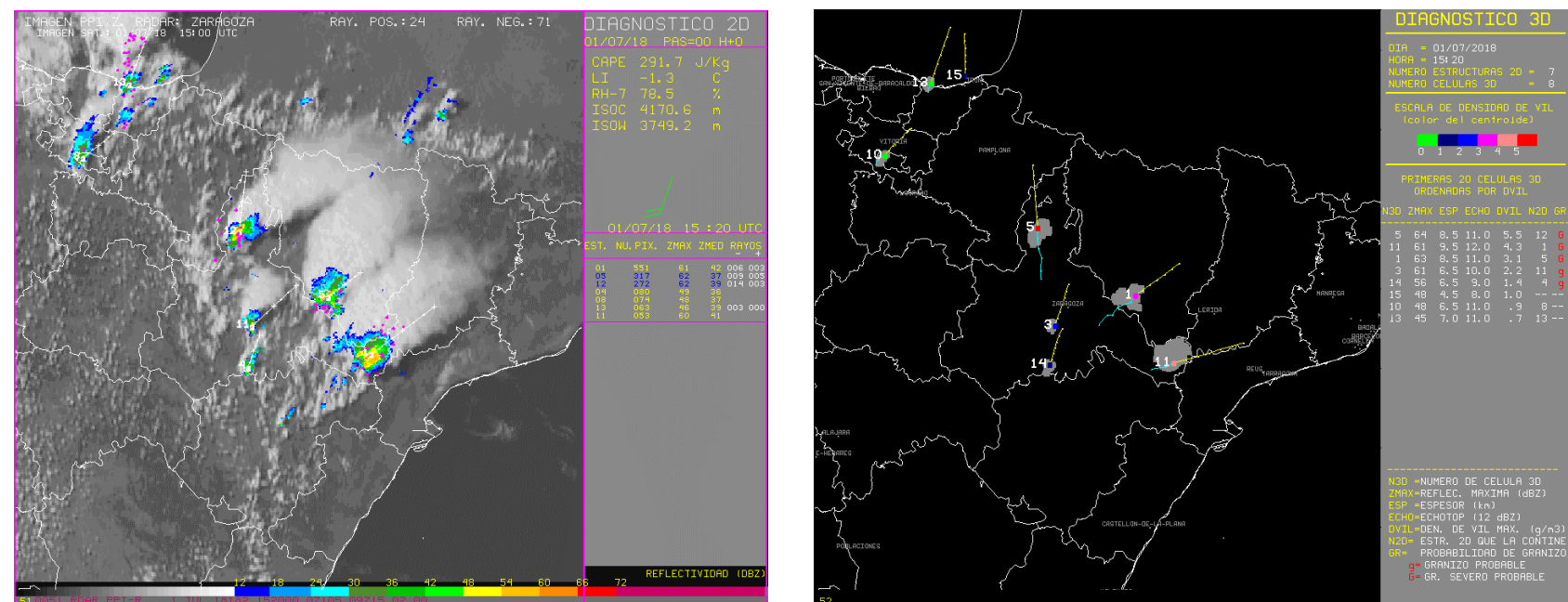

Figura 82. Imágenes de la aplicación YRADAR del día 1 de julio de 2018 a las 15:20 UTC, salida del módulo de diagnóstico 2D (izquierda) y del módulo de diagnóstico 3D (derecha). 
A partir de las 15:30 UTC se inicia el segundo proceso de splitting storm que tiene como consecuencia la aparición de la célula convectiva que afectó al aeropuerto de Zaragoza, y que queda también perfectamente identificada por medio de las salidas de esta aplicación (figuras 83 a 85). Así, en el módulo 2D esta estructura mantiene prácticamente hasta las 18:30 UTC reflectividades en torno a los 60 dBZ, llegando hasta los 65 en algún momento, mientras se desplaza hacia las Cinco Villas, en dirección N. Las imágenes del módulo 3D identifican también en esta ocasión una célula convectiva potencialmente muy adversa, con reflectividades muy altas (por encima de $60 \mathrm{dBZ}$ ) y valores similares a los mencionados más arriba para los demás parámetros (ecotop, espesor y densidad de VIL). Como vemos en estas células convectivas, las características mencionadas se mantienen de manera persistente a lo largo, al menos, de un intervalo de unas 5 horas mientras afectan a las zonas de interés. La densidad de VIL fue introducida como parámetro de diagnóstico para la convección por AMBURN y Wolf (1997). Trata de normalizar el valor del VIL con respecto a la extensión vertical de la tormenta, y ha sido utilizada con bastante éxito para discriminar entre nubes convectivas generadoras de granizo severo y no severo. Este parámetro no necesita información del entorno y solo se basa en datos del propio radar. Estos autores señalan valores de $3,5 \mathrm{~g} / \mathrm{cm}^{3}$ en EE. UU. como umbral para separar células potencialmente generadoras de granizo severo. En nuestro entorno (SANAMBROSIO, 2004) parece que con valores inferiores el riesgo de encontrar granizo severo es ya importante.
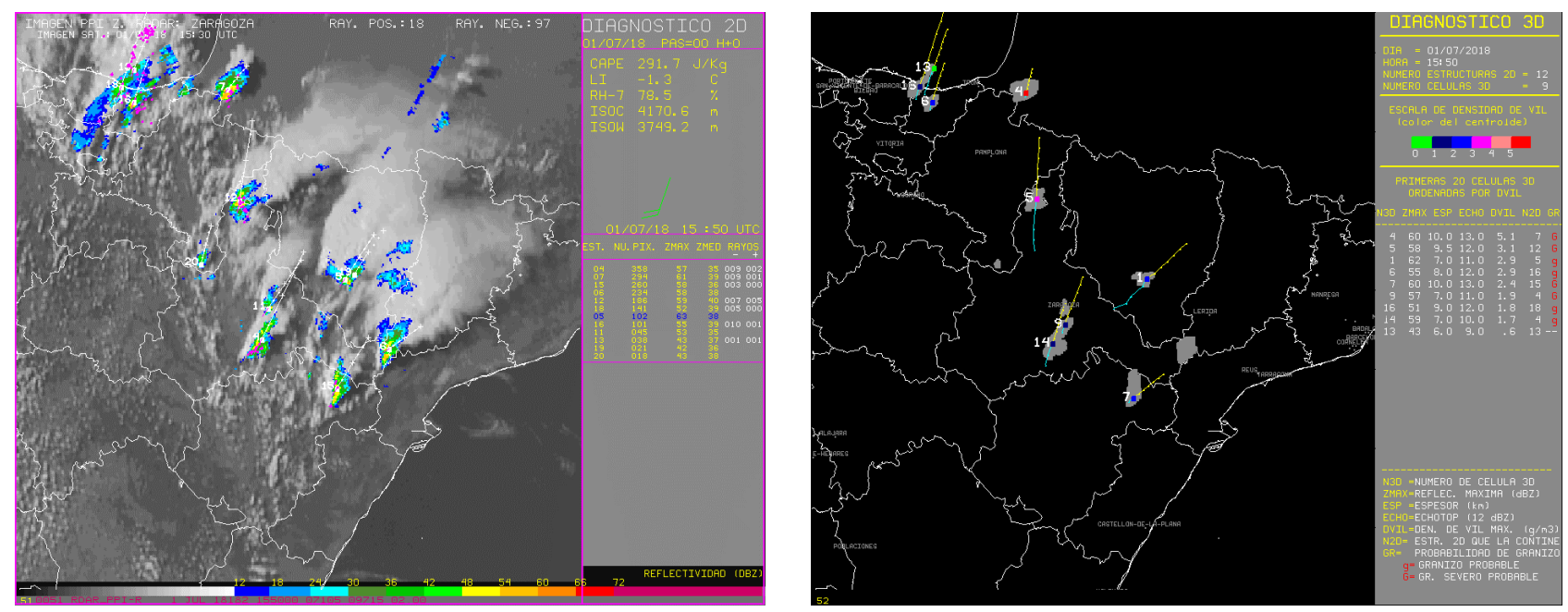

Figura 83. Imágenes de la aplicación YRADAR del día 1 de julio de 2018 a las 15:50 UTC, salida del módulo de diagnóstico 2D (izquierda) y del módulo de diagnóstico 3D (derecha).
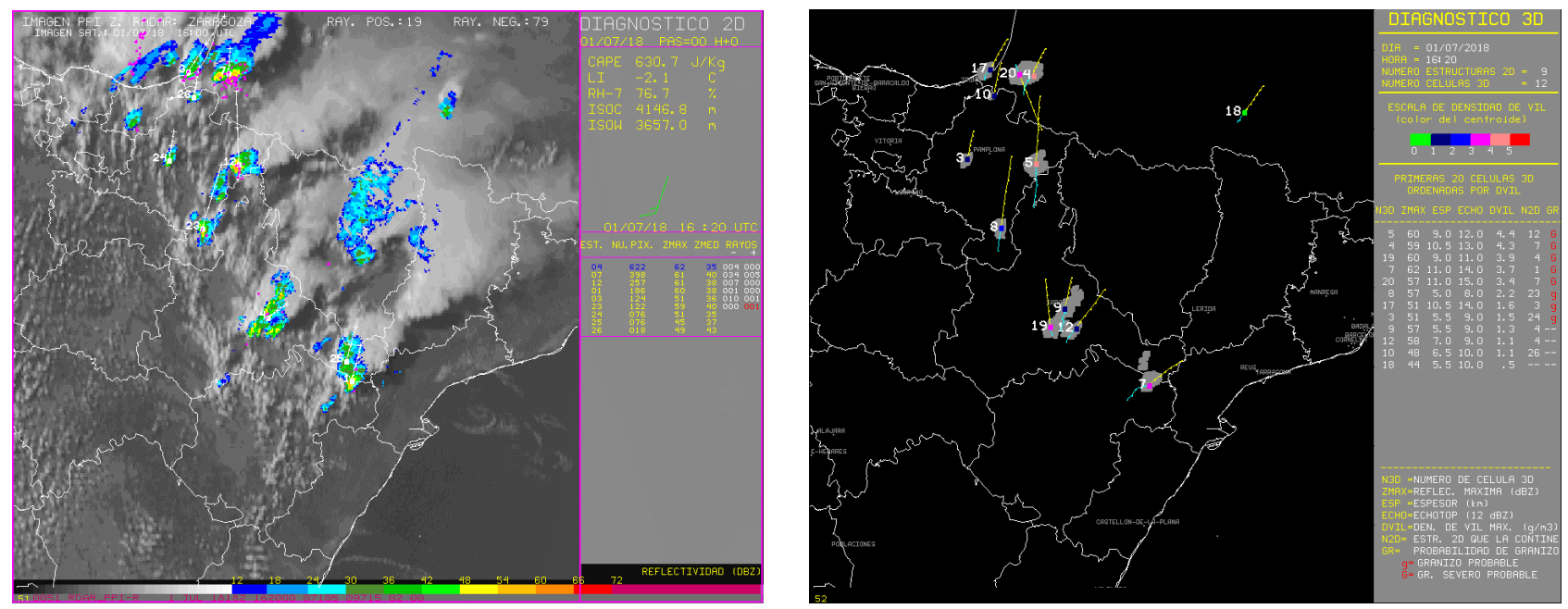

Figura 84. Imágenes de la aplicación YRADAR del día 1 de julio de 2018 a las 16:20 UTC, salida del módulo de diagnóstico 2D (izquierda) y del módulo de diagnóstico 3D (derecha). 

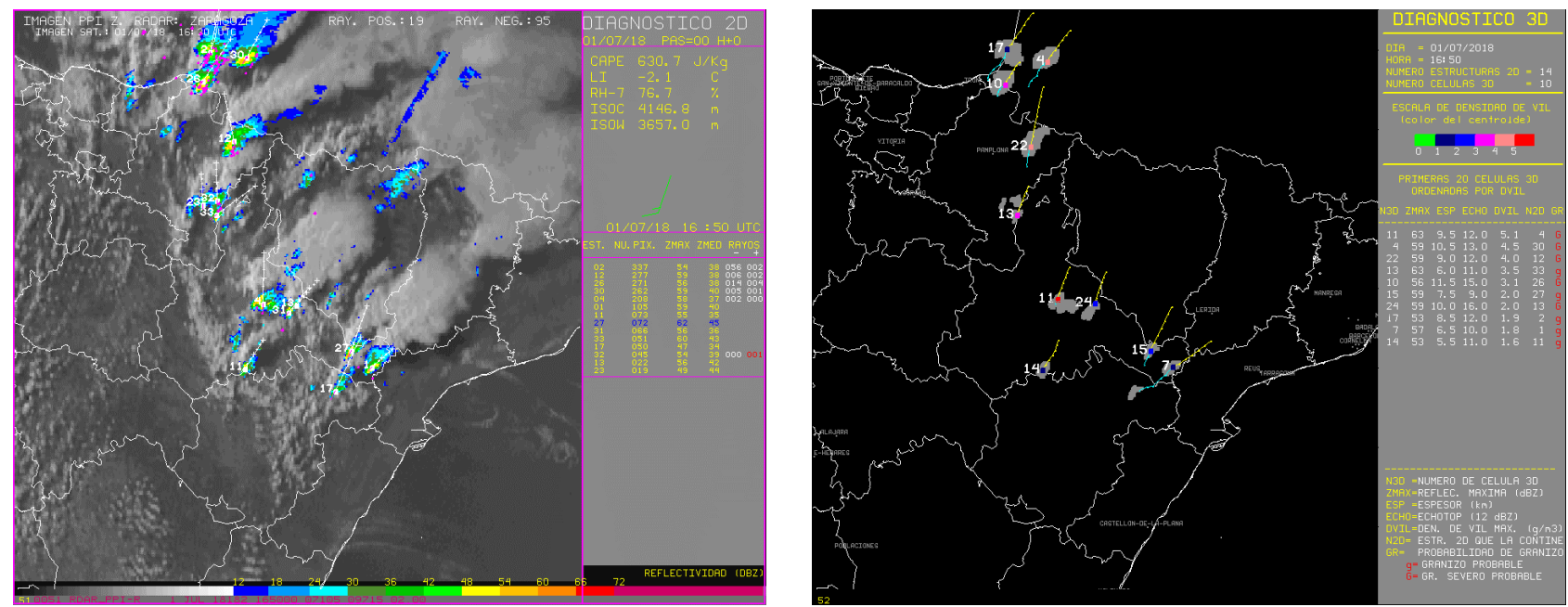

Figura 85. Imágenes de la aplicación YRADAR del día 1 de julio de 2018 a las 16:50 UTC, salida del módulo de diagnóstico 2D (izquierda) y del módulo de diagnóstico 3D (derecha).

Hemos podido analizar las salidas de datos VAD del radar de Zaragoza, estos datos permiten conocer el perfil vertical de vientos en la posición del radar. En ellos, figura 86, se puede comprobar que el perfil vertical de vientos que se obtiene es bastante similar a los perfiles que hemos visto antes en al apartado de sondeos (figuras 25 a 32). En esta figura presentamos el perfil VAD de las 13 UTC y la evolución cada 30 minutos entre las 12 y las 18 UTC. Los perfiles de viento que vemos aquí y los que se obtienen a partir del modelo HARMONIE-AROME y del HIRLAM 0.16 para diferentes localidades son muy similares. En ellos destaca en especial la fuerte cizalladura vertical del viento, situada por debajo de los 2,5 o $3 \mathrm{~km}$ de altura, y además podemos ver en la hodógrafa de las 13 UTC una muy ligera curvatura, en el nivel más bajo, en el sentido de las agujas del reloj, y que en los niveles superiores pasa a ser una cizalladura unidireccional. Este tipo de cizalladura supone un entorno favorable a la organización de la convección en forma de supercélulas, y por otro lado la curvatura de la hodógrafa que parece casi unidireccional posibilita un desarrollo similar de las que tengan giro ciclónico y anticiclónico. Es fácil constatar también a partir de la hodógrafa que el movimiento de ambas supercélulas coincide con el movimiento observado en las imágenes radar y con el previsto en la figura 19 con el campo de helicidad relativa y vector velocidad de supercélulas hacia la derecha y hacia la izquierda.
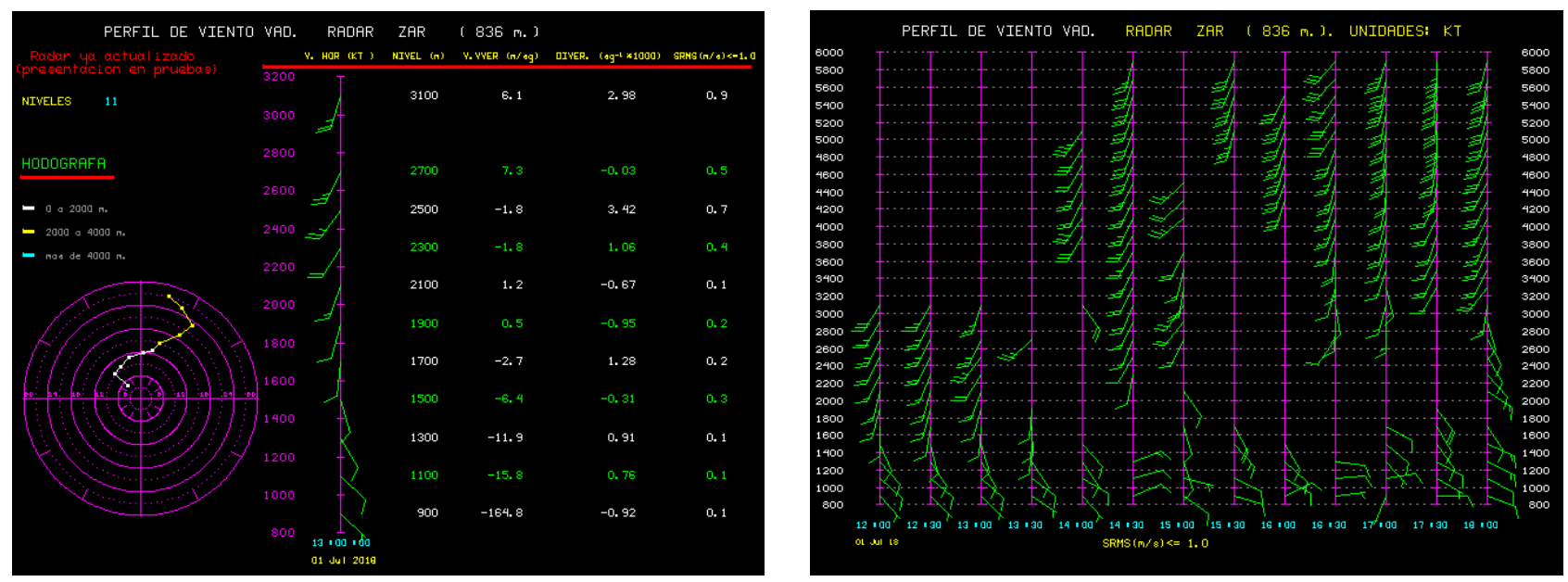

Figura 86. Perfiles de viento VAD del radar de Zaragoza el día 1 de julio de 2018.

Perfil de las 13:00 UTC con hodógrafa (izquierda) y perfiles semihorarios entre las 12:00 y la 18:00 UTC (derecha). 
En las salidas del módulo 2D, figuras 79 a 85, se pueden ver también los datos de la red de detección de descargas eléctricas. Se puede comprobar que en el área de cobertura del radar de Zaragoza hay una considerable actividad eléctrica asociada a las diferentes estructuras convectivas identificadas. Como se ve en las imágenes presentadas se detectan cantidades de unos 100 a 150 rayos cada 10 minutos, aunque la actividad eléctrica más importante se sitúa en las proximidades del golfo de Vizcaya. En el área que nos afecta, en especial en la provincia de Zaragoza y $\mathrm{S}$ de la de Huesca hay una actividad moderada y que podemos considerar significativa. Por otro lado dentro de la aplicación YRADAR se hace una asignación de rayos a las diferentes estructuras convectivas identificadas. Así, se puede comprobar que en el intervalo de tiempo considerado las células convectivas que hemos analizado tienen asignado un número de rayos que apenas supera la decena y que como mucho en algún momento llegan a los 30 rayos en 10 minutos, apreciándose ocasionalmente un ligero predominio de rayos positivos. Hay que señalar que la red de detección de descargas eléctricas de AEMET solo detecta descargas nube-tierra, y no nube-nube, con lo cual podría haber habido actividad eléctrica de este último tipo no detectada. Según algunos autores (QUIRANTES ET AL., 2014) esta actividad eléctrica intranube es la que constituye mayoritariamente el abundante aparato eléctrico que acompaña a las supercélulas.

Las supercélulas son estructuras convectivas con un grado de organización interna muy alto que se caracterizan por poseer una zona persistente de fuertes corrientes ascendentes en rotación (mesovórtice), que suele ser de tipo ciclónico (mesociclón). Datos registrados en EE. UU. revelan que el $90 \%$ de las supercélulas llevan asociados fenómenos severos en superficie: tornados, granizo de gran tamaño o vientos muy intensos (BURGESS \& LEMON, 1991). La mitad de las mismas generan tornados violentos en superficie (BURGESS \& LEMON, 1990; Moller ET AL., 1994). Las supercélulas con mesovórtices en niveles bajos (1-3 km sobre el suelo) son las más proclives a generar tornados (BURGESS ET AL., 1995).

Para caracterizar estas estructuras supercelulares es importante poder detectar esas rotaciones mesoescalares, lo cual en ocasiones se puede hacer con datos volumétricos del radar en modo Doppler. Aun así, la presencia de un mesovórtice en altura no implica la presencia de un tornado en superficie, ya que en muchas ocasiones dicho mesovórtice no se desploma hacia superficie y no se produce el tornado. Además, existen también tornados, habitualmente no muy violentos, que se pueden generar por otros mecanismos no asociados a las supercélulas. Por lo tanto, el hecho de disponer de los datos del radar de Zaragoza en modo normal (reflectividad) y en modo Doppler (reflectividad y velocidad radial de los ecos) que nos permitan identificar las características tridimensionales de la estructura de reflectividad y la presencia de rotaciones típicas de una supercélula, no supondría tampoco una condición necesaria ni suficiente para certificar la existencia de un tornado. Sí que sería, sin duda alguna, un elemento clave muy importante de cara a garantizar la existencia de unas condiciones idóneas para el desarrollo del mismo, pero seguiríamos necesitando evidencias directas del tornado tomadas sobre el terreno.

Teniendo en cuenta todo esto se han analizado las imágenes de viento radial entre las 14:06 y las 17:06 UTC. La primera señal significativa aparece en la imagen de las 14:36 UTC (figura 87), en la cual se puede distinguir un dipolo de velocidades (pareja de velocidades radiales de signo opuesto) bastante claro, que se corresponde con un posible mesociclón situado en la célula que afectó al Bajo Aragón (círculo azul en la figura), y que en este momento se sitúa ligeramente al E de Andorra (Teruel). En esta misma imagen en relación con las otras dos posibles supercélulas no se distinguen nada más que dos áreas de singularidades que como mucho podrían ser reflejo de fuertes convergencias asociadas a estas células convectivas. En las imágenes de las 14:46, 15:06 y 15:46 UTC (figuras 88,89 y 91) aparece con bastante claridad un dipolo de velocidades en la zona de las Cinco Villas (círculos azules en todas las figuras), que sería un indicio de la presencia de una corriente ascendente en rotación anticiclónica, en la de las 15:06 UTC se pueden intuir también posibles mesociclones asociados a las otras dos supercélulas situadas en el Bajo Aragón y en la Ribera del Ebro. 


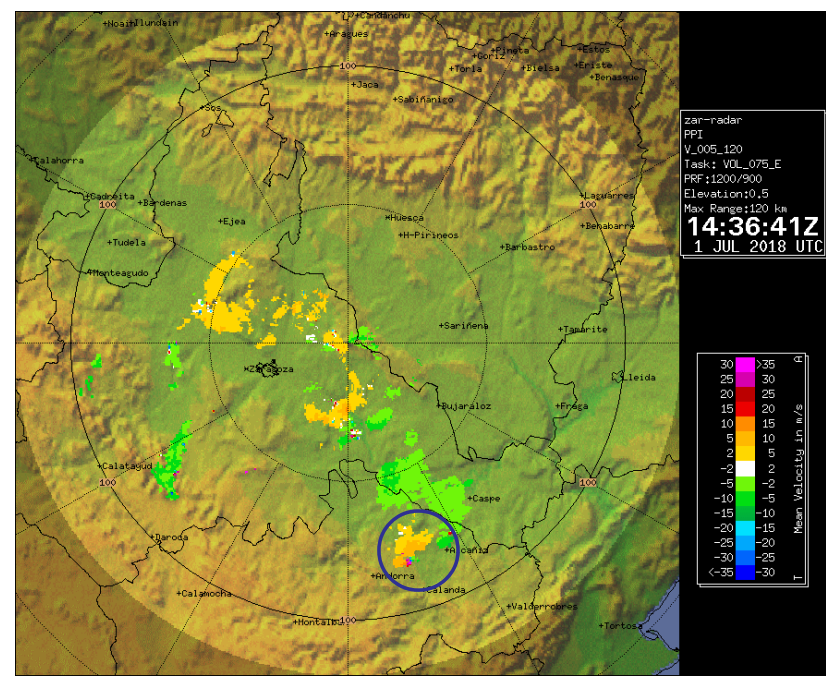

Figura 87. Imagen de viento radial del radar de Zaragoza del día 1 de julio de 2018 a las 14:36 UTC.

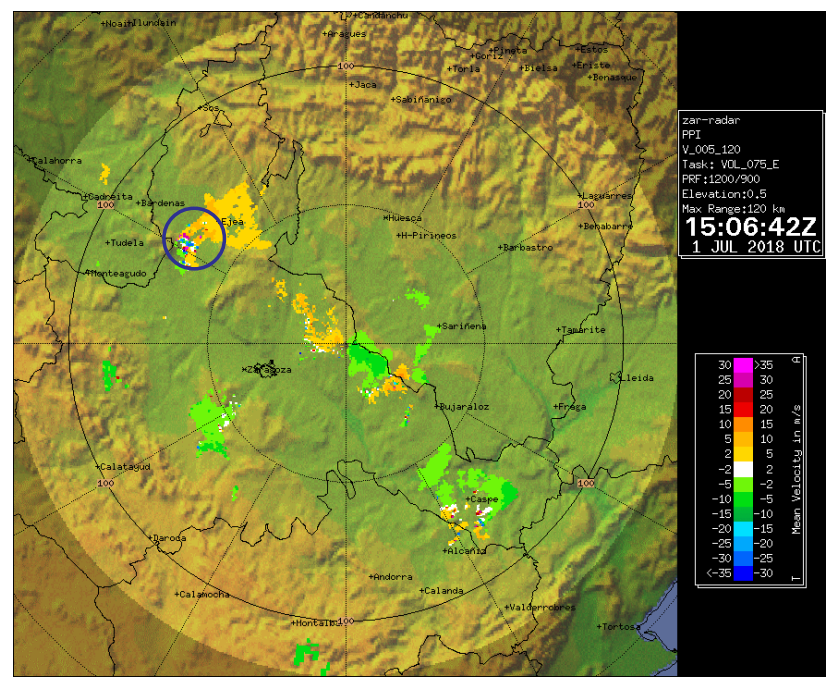

Figura 89. Imagen de viento radial del radar de Zaragoza del día 1 de julio de 2018 a las 15:06 UTC.

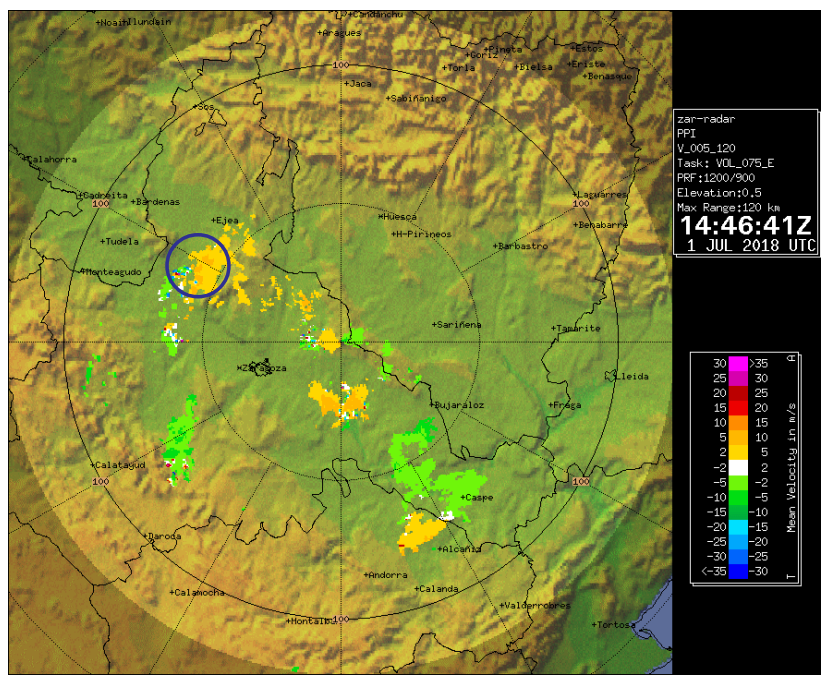

Figura 88. Imagen de viento radial del radar de Zaragoza del día 1 de julio de 2018 a las 14:46 UTC.

En la figura 90 se puede ver una ampliación del posible mesoanticiclón de las Cinco Villas a las 15:06 UTC. En la imagen de las 16:46 UTC (figura 92) se puede ver otra singularidad en el viento radial al lado de Zaragoza, y en la figura 93 una ampliación de dicha estructura, en esta ocasión asociada a la posible supercélula que afectó al aeropuerto de Zaragoza. Se pueden distinguir unos máximos de viento que podrían corresponder a los dipolos del posible mesoanticiclón (círculos azules en las figuras), aunque no está muy claro el sentido de giro del mesovórtice. Teniendo en cuenta por otro lado la limitación de estas imágenes en cuanto a que solo disponemos de un

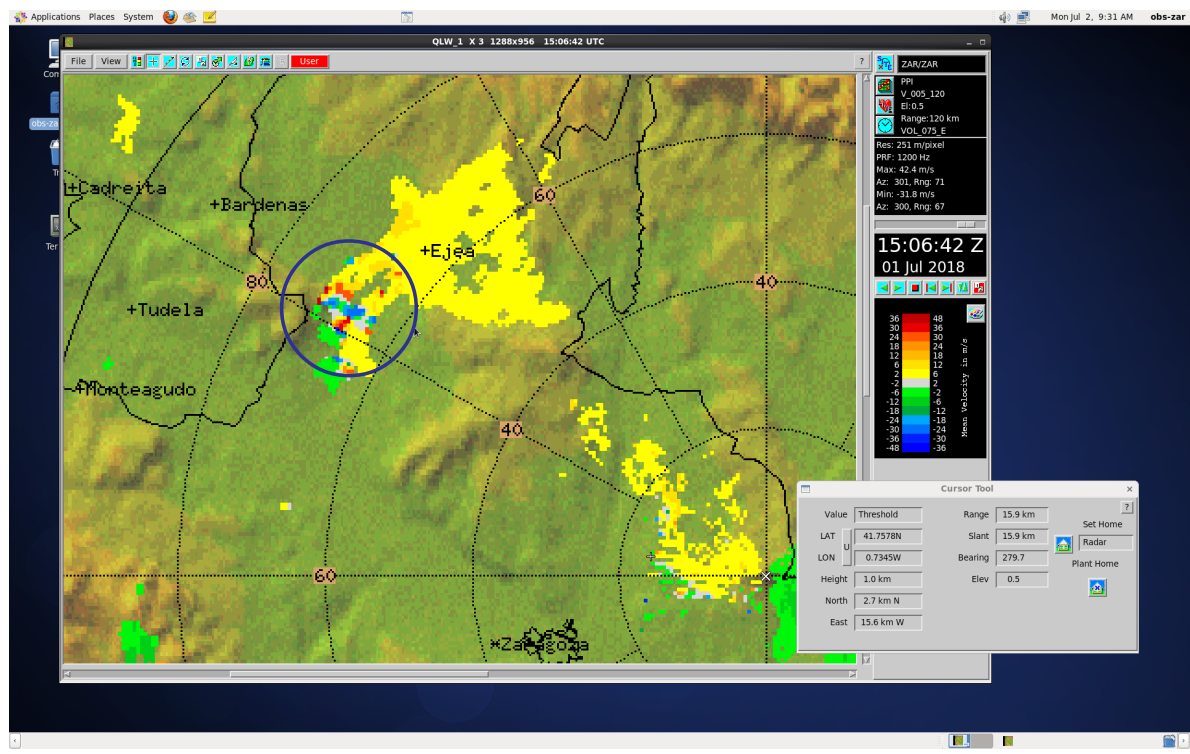

Figura 90. Ampliación en la zona de las Cinco Villas del viento radial del radar de Zaragoza del día 1 de julio de 2018 a las 15:06 UTC. 


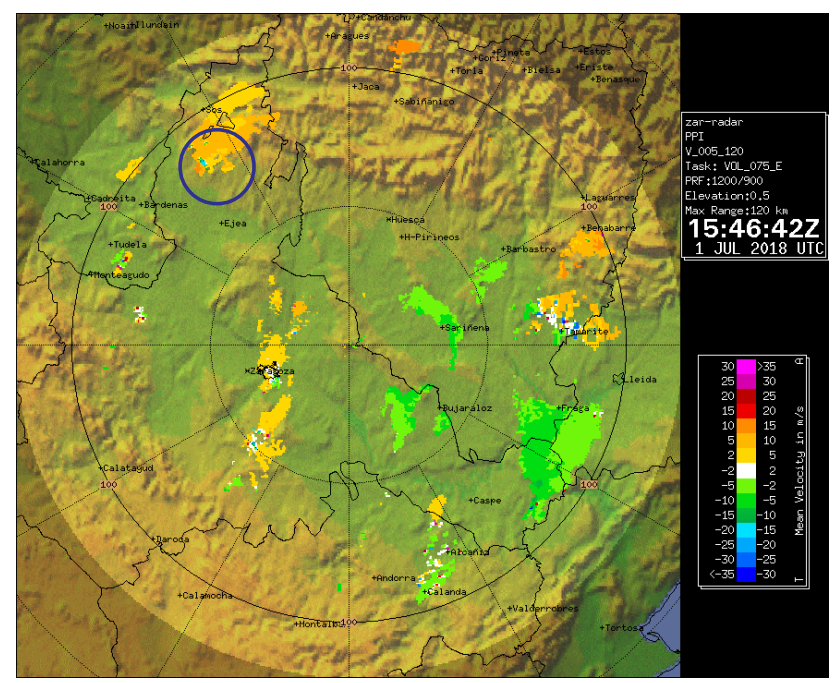

Figura 91. Imagen de viento radial del radar de Zaragoza del día 1 de julio de 2018 a las 15:46 UTC.

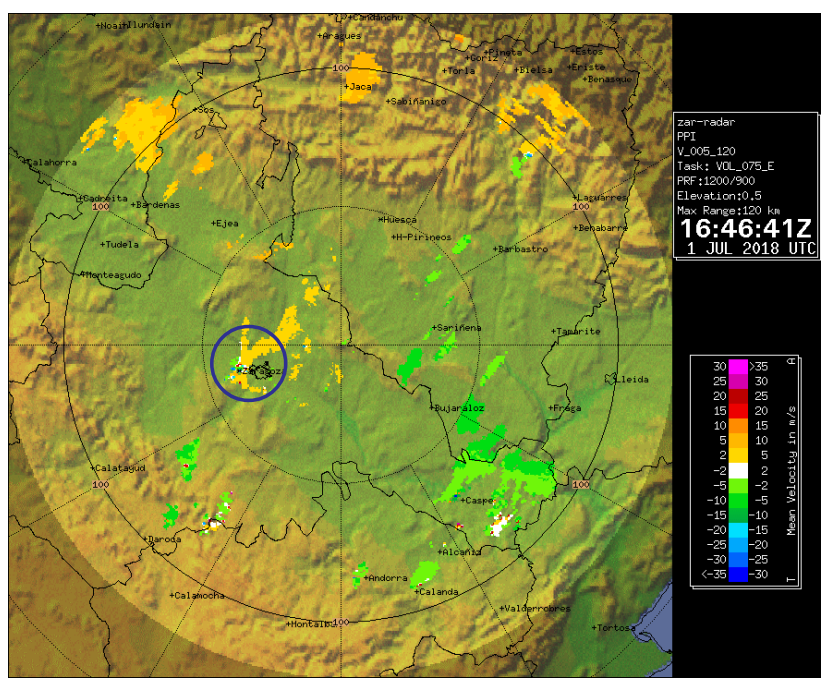

Figura 92. Imagen de viento radial del radar de Zaragoza del día 1 de julio de 2018 a las 16:46 UTC.

PPI de viento radial y no podemos analizar la estructura vertical de las corrientes ascendentes, sí que tenemos una evidencia razonable de la presencia de corrientes ascendentes en rotación que permiten constatar la presencia de supercélulas ciclónicas y anticiclónicas en la zona de interés.

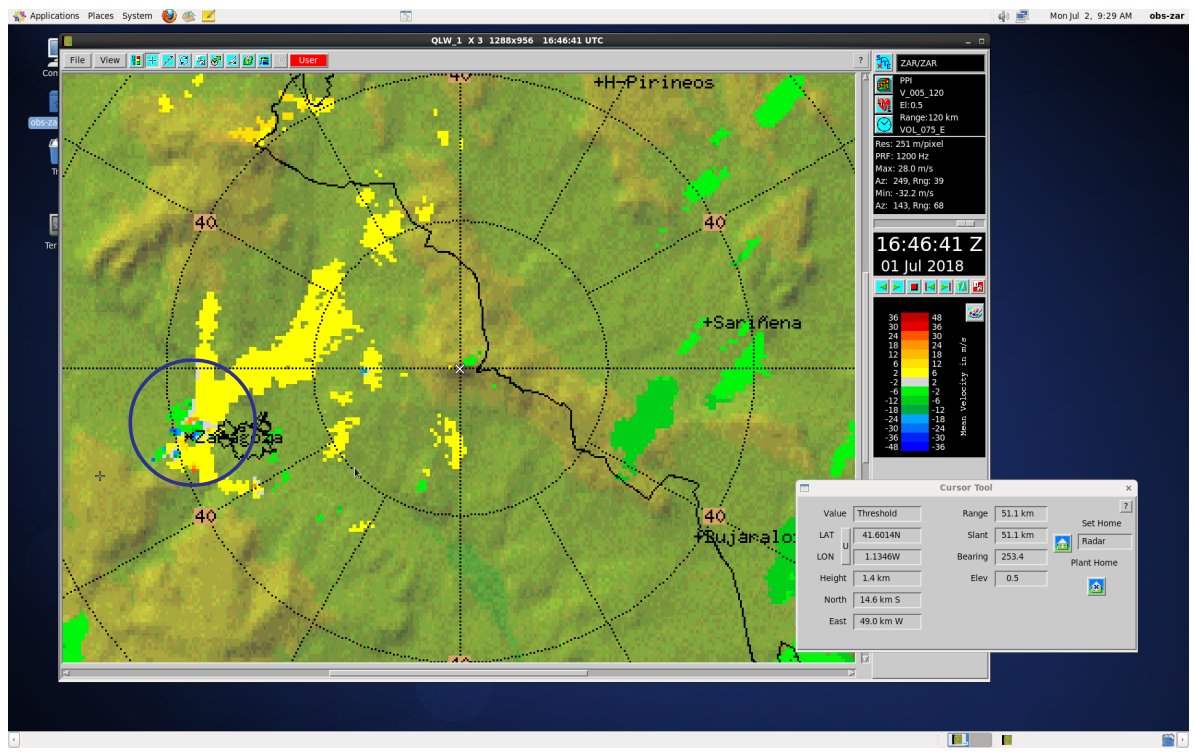

Figura 93. Ampliación de la zona del aeropuerto de Zaragoza de la imagen de viento radial del radar de Zaragoza del día 1 de julio de 2018 a las 16:46 UTC. 


\section{ANÁLISIS DE LOS DATOS DE OBSERVACIÓN}

Las figuras 94 y 95 muestran la ubicación de las distintas cabeceras de pista y del jardín de observación sinóptica dentro de la infraestructura aeroportuaria del aeropuerto y Base Aérea de Zaragoza. En la tabla 1 se muestra el valor de las rachas máximas alcanzadas en las cabeceras y el jardín sinóptico y su dirección. Todas las rachas máximas se alcanzaron a las 16:50 UTC. Tras consulta con la empresa DTN, responsable de la programación de los dataloggers de las cabeceras y consulta de los pliegos técnicos de la estación sinóptica, se concluye que el método de cálculo de la racha máxima es el siguiente para ambos tipos de estaciones de medida: «El valor máximo de los promedios calculados cada segundo a partir de las 12 últimas muestras de viento obtenidas por el sensor cada 0,25 segundos (media móvil de los tres últimos segundos)». Por tanto, los valores de ambos tipos se pueden considerar comparables. Los sensores duplicados de viento en cada una de las cabeceras dieron valores similares en su muestreo lo que aún da mayor seguridad a la hora de valorar las rachas alcanzadas.

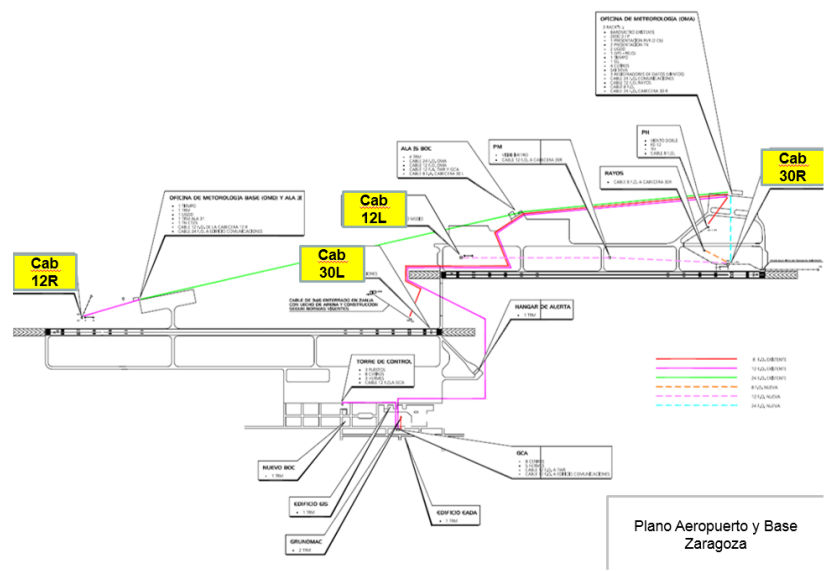

Figura 94. Plano del aeropuerto de Zaragoza y ubicación de las cabeceras.

$\begin{array}{lcc}\text { Ubicación } & \text { Racha máxima }(\mathrm{km} / \mathrm{h}) & \text { Dirección }\left(^{\circ}\right) \\ \text { Cabecera 30R } & 157 & 130(\mathrm{SE}) \\ \text { Cabecera 12L } & 118 & 130(\mathrm{SE}) \\ \text { Cabecera 30L } & 96 & 110(\mathrm{ESE}) \\ \text { Cabecera 12R } & 39 & 150(\mathrm{SSE}) \\ \text { Estación sinóptica } & 135 & 190(\mathrm{~S})\end{array}$

Tabla 1. Rachas máximas alcanzadas en cada ubicación a las 16:50 UTC, hora en la que se registró la racha máxima en todos los puntos.

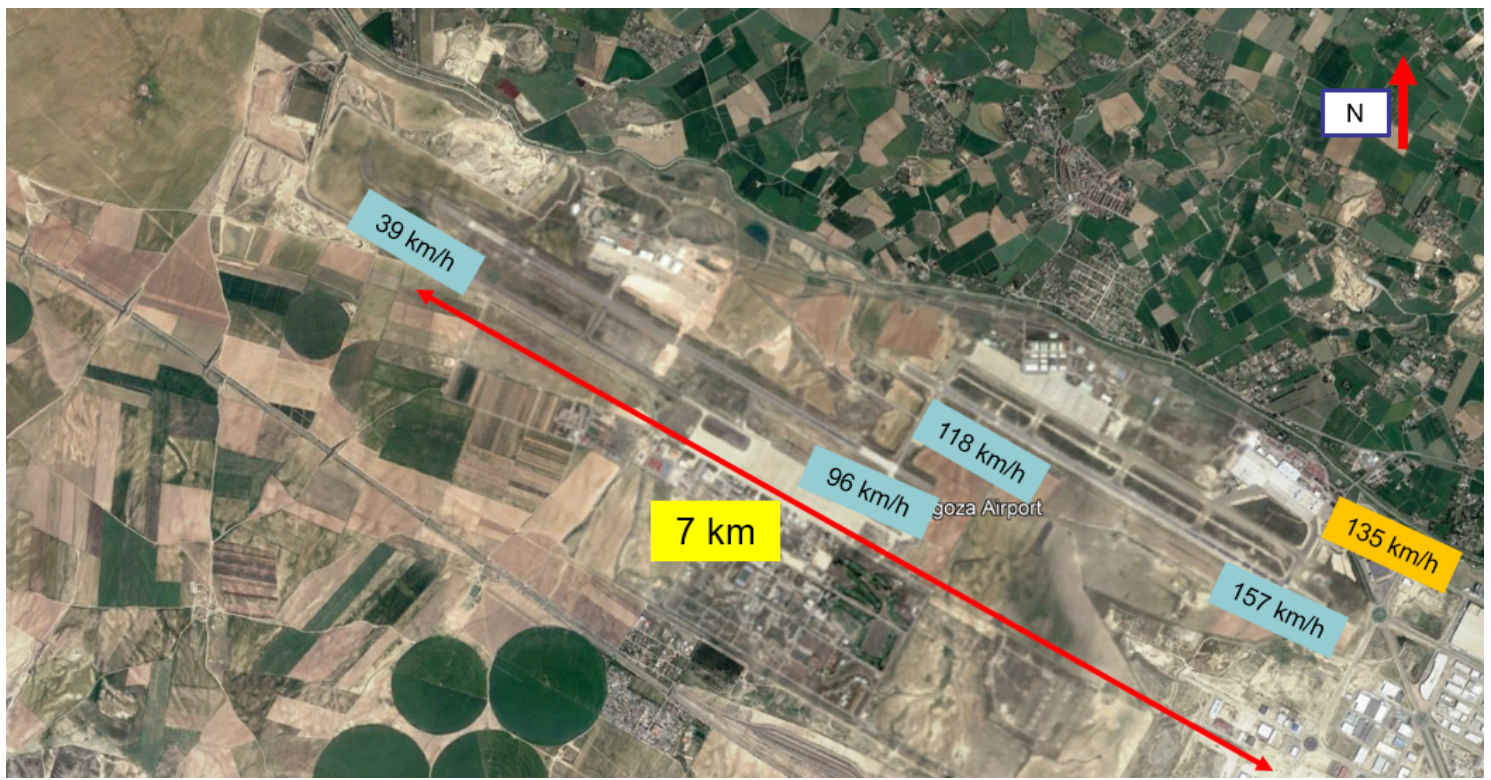

Figura 95. Plano satélite con la ubicación y velocidad de la racha máxima en cada cabecera (azul) y en el jardín sinóptico (naranja) y distancia máxima entre los puntos de medida. 


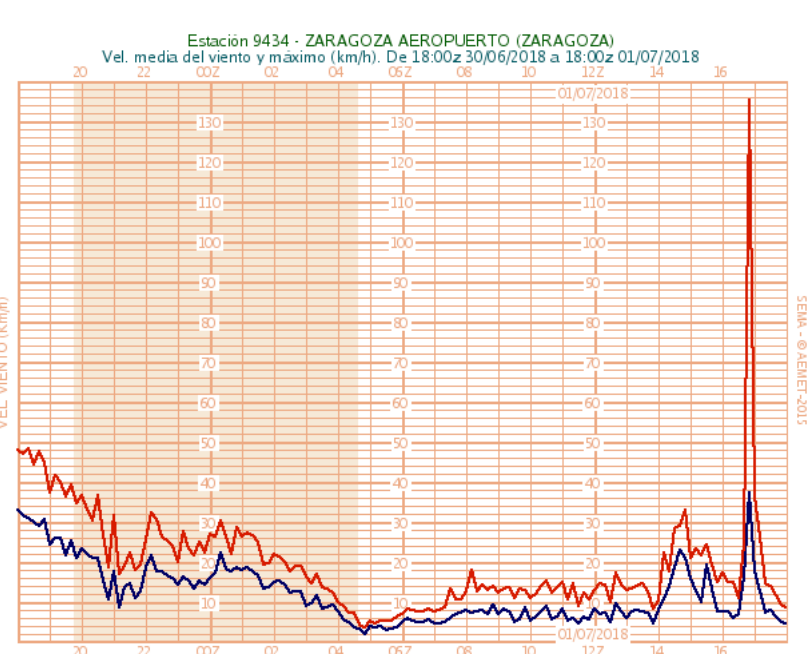

Figura 96. Racha máxima de 37,6 m/s (135 km/h) con una variación de $30,8 \mathrm{~m} / \mathrm{s}(111 \mathrm{~km} / \mathrm{h})$ en 10 minutos.

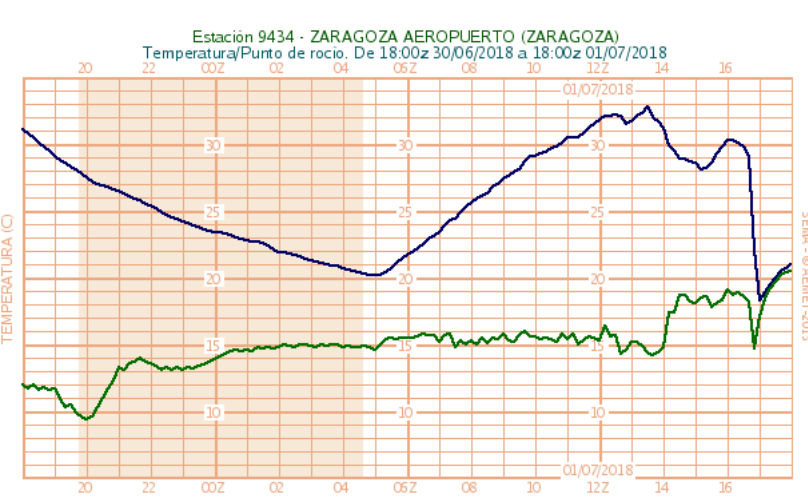

Figura 97. Registro de temperatura durante la tormenta con una variación negativa de $10,7^{\circ} \mathrm{C}$ en 10 minutos.

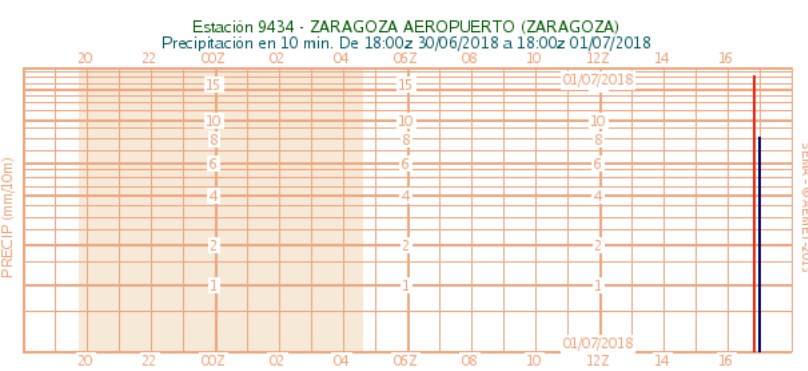

Figura 98. Precipitación acumulada durante el paso de la tormenta de $24 \mathrm{~mm}$ con intensidades de $36 \mathrm{~mm} / 10 \mathrm{~min}$.

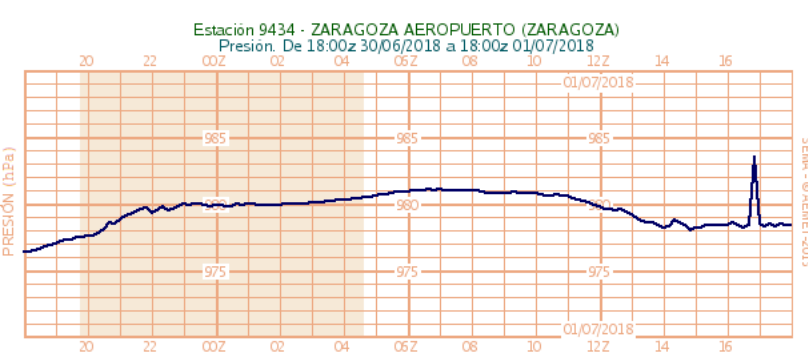

Figura 99. Presión durante el paso de la tormenta con variaciones de $6 \mathrm{hPa}$.
Es reseñable que en distancias menores de $7 \mathrm{~km}$ hay una diferencia de $118 \mathrm{~km} / \mathrm{h}$ en la racha máxima, lo cual da indicios de cómo de local fue el fenómeno y de la gran variación espacial de los datos registrados en fenómenos de este tipo.

En la estación automática del jardín sinóptico, que a todos los efectos de efemérides es la oficial, se registraron variaciones temporales muy elevadas en diversas variables meteorológicas. Las figuras 96 y 97 muestran cambios muy bruscos del viento y la temperatura durante el paso de la tormenta, que superan los umbrales habituales y que por tanto fueron etiquetados como sospechosos por el sistema de control de SIGROBS (Sistema Integrado para la Gestión de las Redes de Observación). En la gráfica de la figura 97 destaca la temperatura alcanzada durante la tormenta, $18,3^{\circ} \mathrm{C}$, tras una variación en 10 minutos de $10,7^{\circ} \mathrm{C}$, y que a su vez se corresponde con la temperatura mínima de este día. La figura 98 muestra una precipitación acumulada durante la tormenta de tan solo $24 \mathrm{~mm}$ en apenas 20 minutos, pero al analizar el muestreo minutal de este evento de precipitación se obtiene una intensidad de $36 \mathrm{~mm}$ en 10 minutos, lo que corresponde a una intensidad torrencial. Otro dato interesante a destacar es la variación de presión positiva de $6 \mathrm{hPa}$ (figura 99) y que solo puede ser explicada por el descenso brusco de aire (reventón) asociado a la precipitación intensa y su evaporación parcial en la capa subnubosa.

Finalmente cabe reseñar también que en otra estación sinóptica, Valdespartera, distante tan solo $6 \mathrm{~km}$ de la del aeropuerto de Zaragoza, la racha máxima fue de $39 \mathrm{~km} / \mathrm{h}$, se acumularon solo $4,2 \mathrm{~mm}$ y apenas hubo variación apreciable de temperatura. Este dato confirma de nuevo el carácter extremadamente local del fenómeno convectivo registrado en el aeropuerto. En otras estaciones automáticas de la red de AEMET se registraron algunas precipitaciones significativas que en todos los casos fueron cantidades inferiores a la registrada en el aeropuerto de Zaragoza, así destacan en especial los 19,8 mm recogidos en Lanaja (Huesca) con una intensidad torrencial, ya que $17,0 \mathrm{~mm}$ cayeron en $10 \mathrm{minu}$ tos. Se registraron también $11,8 \mathrm{~mm}$ en Torla (Huesca), 8,6 mm en Castejón de Valdejasa (Zaragoza) y $5,8 \mathrm{~mm}$ en Andorra (Teruel), entre otros. 


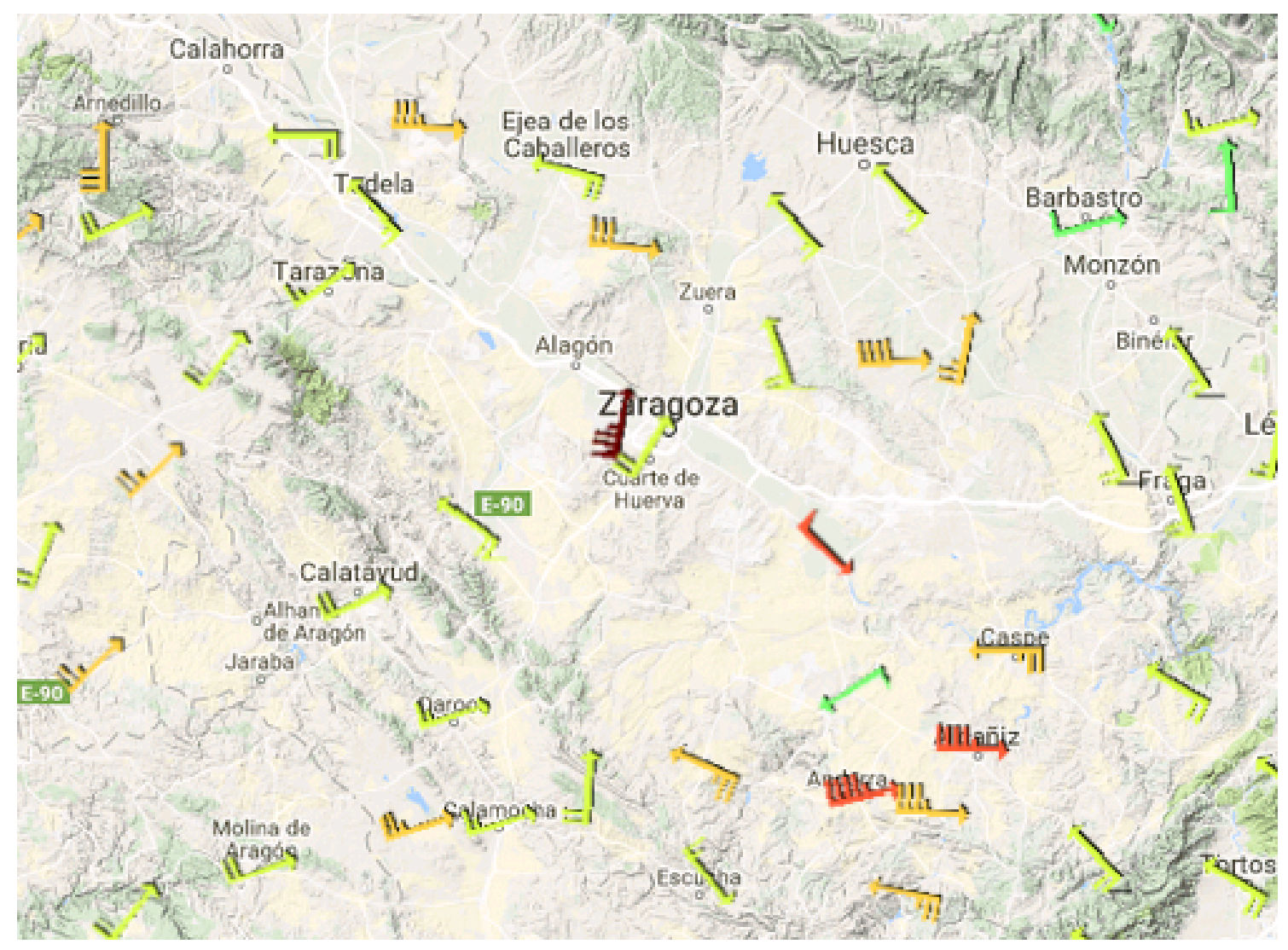

Figura 100. Rachas máximas registradas en la zona de estudio.

La figura 100 muestra que también hubo otras rachas máximas significativas, el mayor valor de las cuales se alcanzó en Quinto de Ebro (Zaragoza) con $89 \mathrm{~km} / \mathrm{h}$. Otros registros que cabe resaltar son los de Andorra y Alcañiz (Teruel), donde se alcanzaron respectivamente 82,8 y $81,0 \mathrm{~km} / \mathrm{h}$. En Lanaja (Huesca) se llegó a $72,7 \mathrm{~km} / \mathrm{h}$ y en Calanda (Teruel) a $67,0 \mathrm{~km} / \mathrm{h}$, como valores más destacables. Todos estos registros de rachas máximas estuvieron asociadas a los distintos fenomenos convectivos de este episodio pero sin embargo quedaron muy lejos de la severidad del fenómeno en el aeropuerto de Zaragoza.

La zona del aeropuerto estaba afortunadamente muy monitorizada por sensores de viento, precipitación y temperatura y por tanto nos puede ser de utilidad para poner en valor la veracidad de rachas similares en localizaciones de la zona en las que no hay aparatos de medida y que pudieron causar destrozos similares. 


\section{VISITA DE CAMPO}

El jueves 5 de julio se realizó una visita de campo a Osera de Ebro, uno de los municipios afectados por este episodio. Dicha visita tuvo lugar en una finca privada y se llevó a cabo por una petición de informe meteorológico que llegó a la Delegación Territorial de AEMET en Aragón.

Accedimos a dicha finca acompañados por su propietaria, doña María Gloria Gotor Forcén. En ella pudimos apreciar daños importantes aunque aislados, como se aprecia en la fotografía de la figura 101. El resto de la finca apenas sufrió daños, ni siquiera otros objetos de menor porte fueron derribados, como los que se muestran en la figura 102. En las afueras de la finca, nuevamente se apreciaron daños aislados que no podemos asegurar que fueran causados por el fenómeno, figuras 103 y 104.

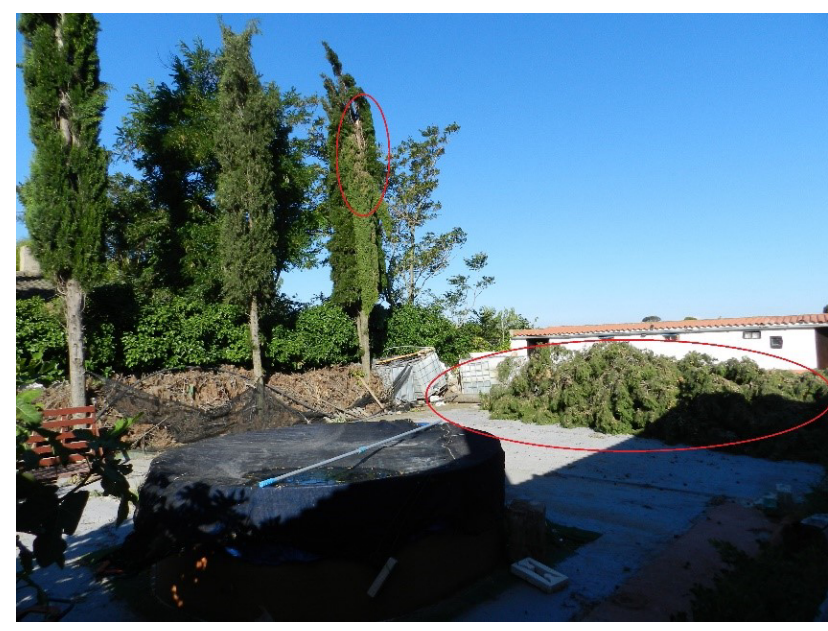

Figura 101. Árbol caído y rama dañada. Osera de Ebro.

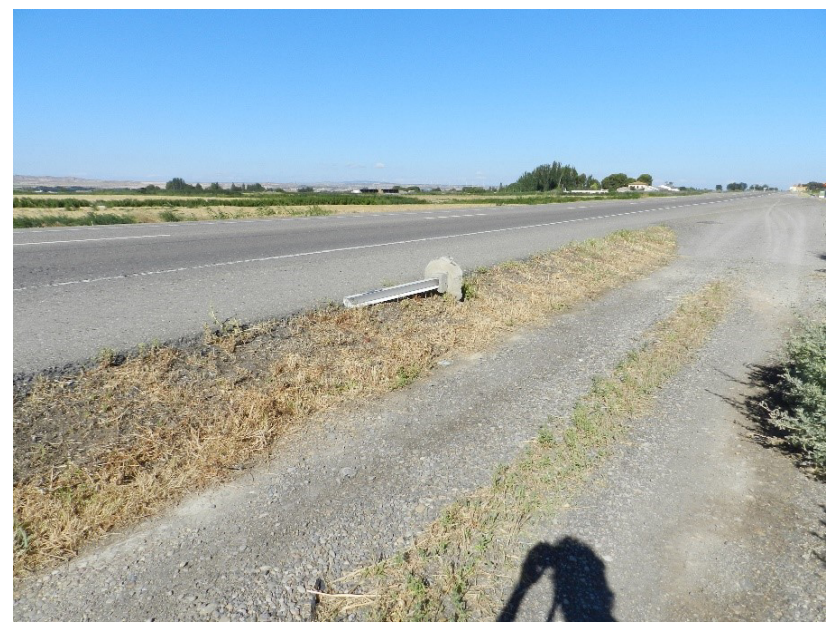

Figura 103. Señal de tráfico de pequeño tamaño derribada. Osera de Ebro.

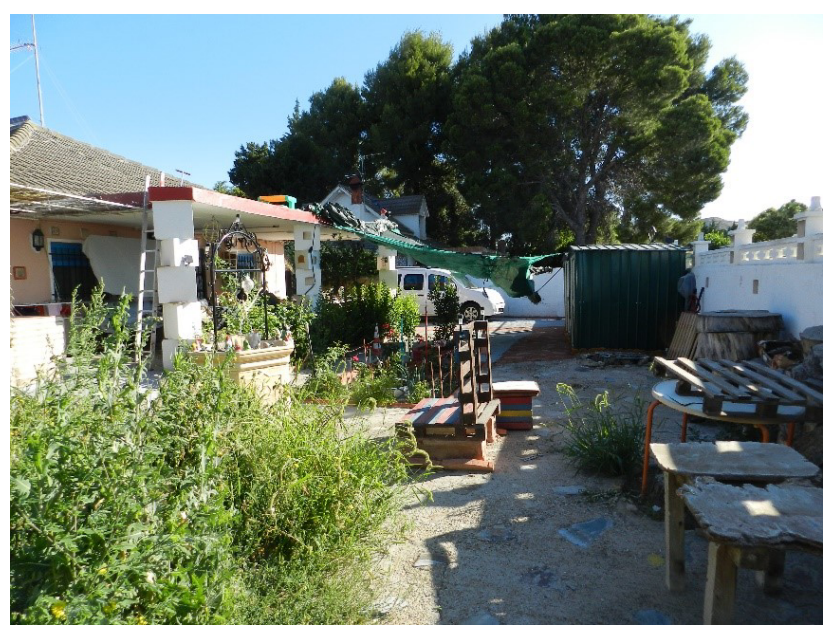

Figura 102. Zonas sin daños en el interior de la finca de la figura 101. Osera de Ebro.

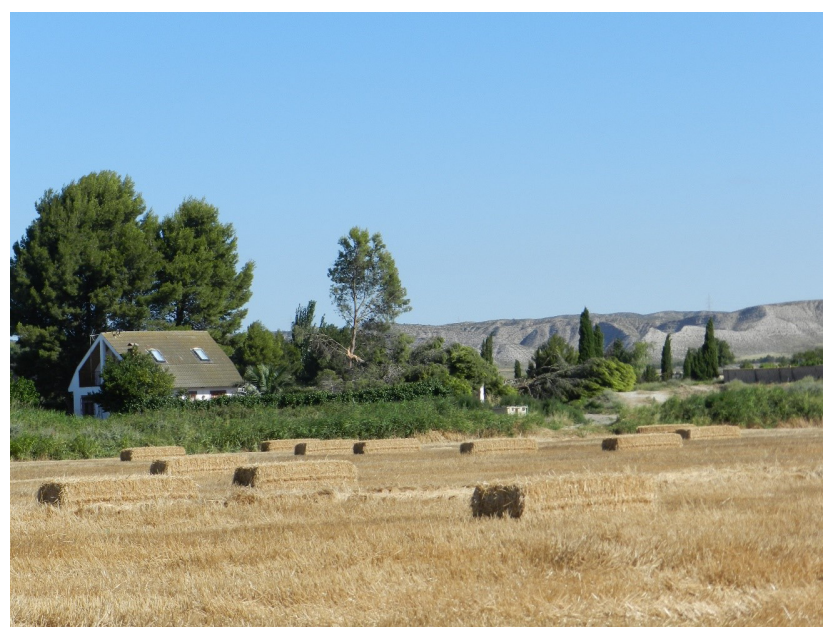

Figura 104. Árboles caídos en otra finca privada, a la que no se accedió. Osera de Ebro. 
En el mapa de la figura 105 se señalan, de manera aproximada, los daños mostrados en las figuras anteriores. En la figura 104 se aprecia el campo que separaba las dos fincas donde se fotografiaron los árboles derribados. Por la naturaleza del mismo se entiende la dificultad que supone encontrar nuevos indicios del carácter severo del fenómeno que afectó a esta zona y poder precisar si pudo o no tratarse de un tornado.

También se mantuvo una entrevista con el colaborador de Osera de Ebro, don Juan Andrés Prades Carrera, que informó de daños en las vallas de las piscinas de la localidad de Osera de Ebro, así como de la precipitación registra$\mathrm{da}$, un total de $17,1 \mathrm{~mm}$ repartidos en dos tormentas diferentes. Por otro lado, en las redes sociales y en la información en prensa aparecieron fotos de daños en otras localidades, como las que se muestran a continuación (fi-

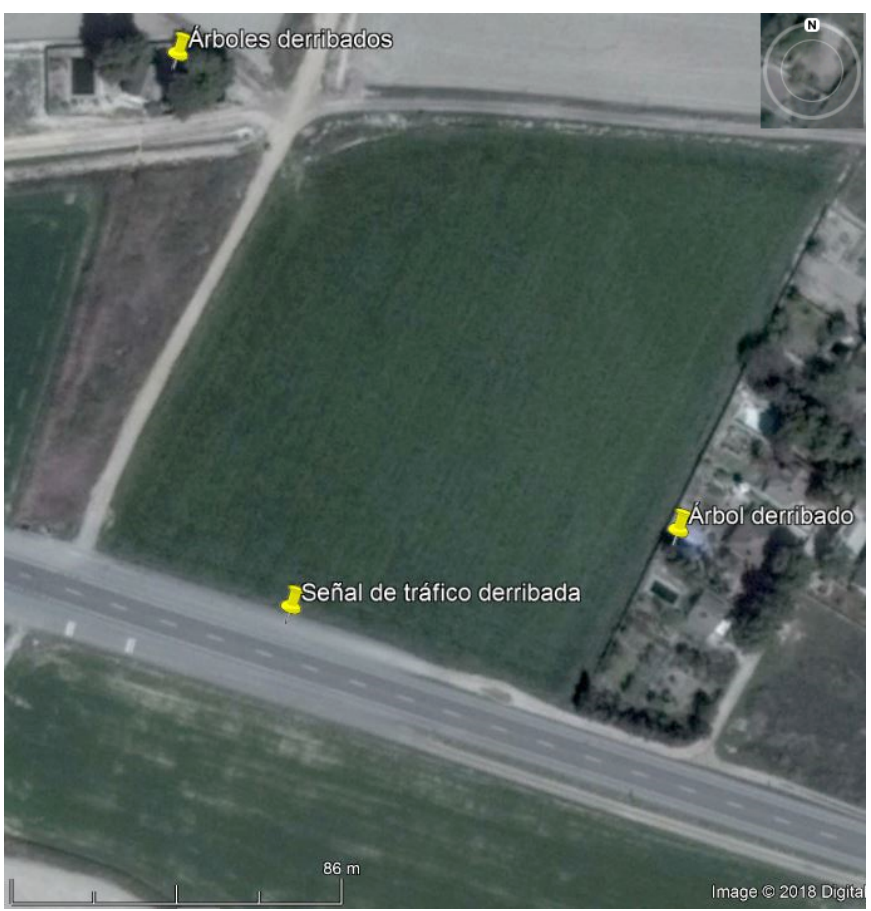

Figura 105. Situación aproximada de los daños apreciados. La finca de la derecha es a la que se accedió. guras 106 a 111).

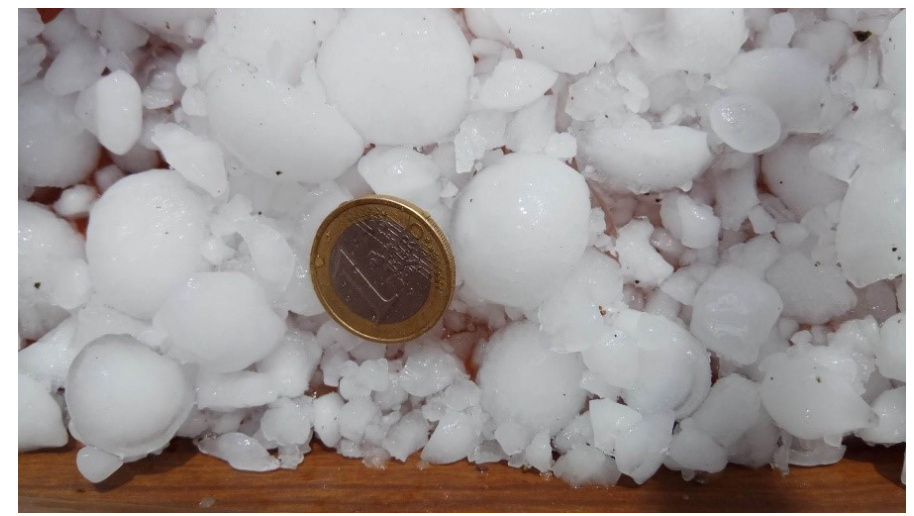

Figura 106. Granizo en Alagón.

Fuente:Twitter@LuiskaHevia.

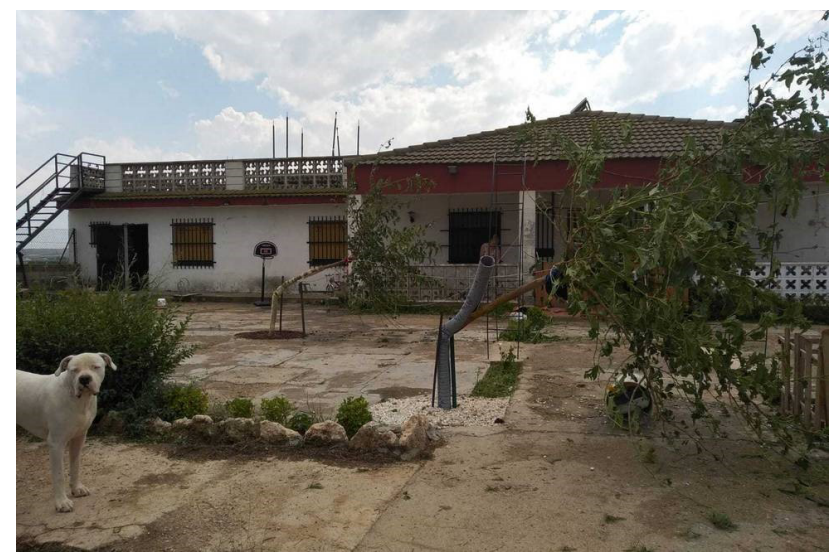

Figura 107. Destrozos en Bárboles. Resulta significativo que los dos árboles se inclinaron o quebraron en el mismo sentido. Fuente: Heraldo de Aragón.

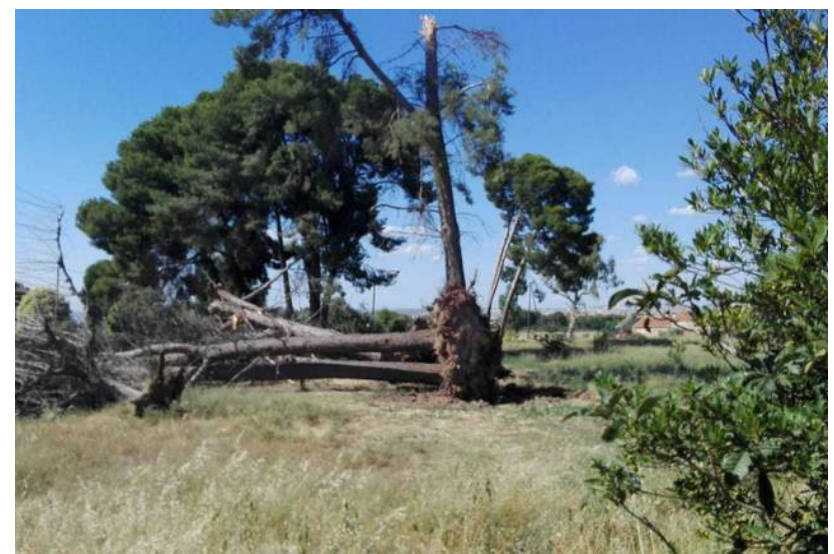

Figura 108. Árboles caídos y partidos en Garrapinillos. Fuente: Heraldo de Aragón. 


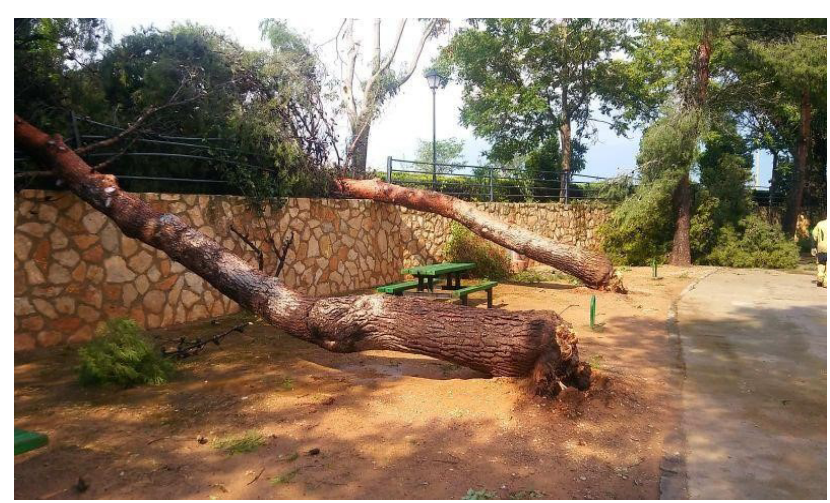

Figura 109. Árboles caídos en Longares. Fuente: EFE.

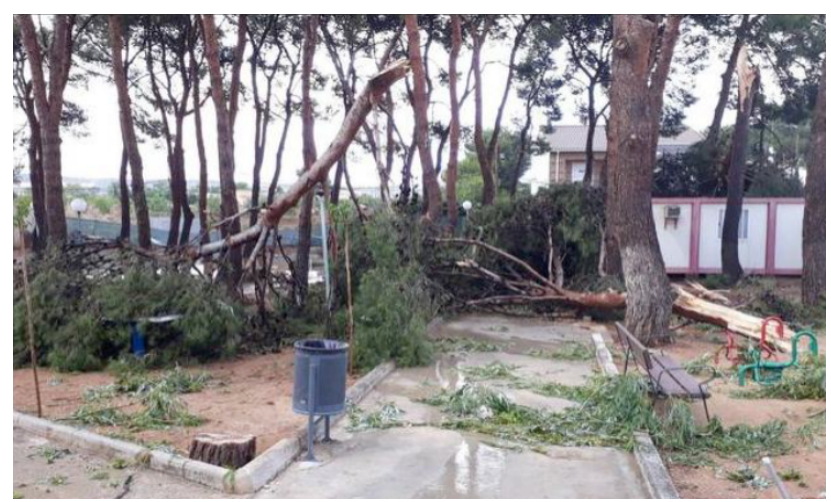

Figura 110. Árboles caídos en Longares.

Fuente: Heraldo de Aragón.

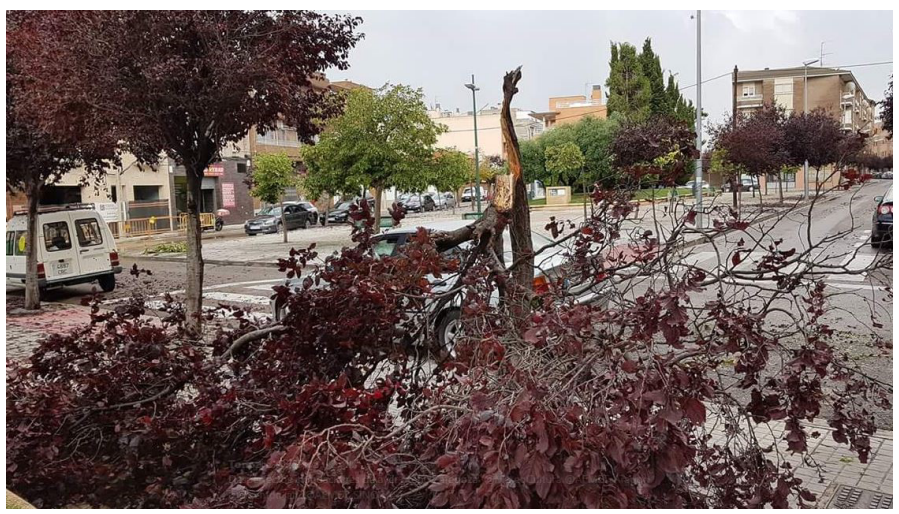

Figura 111. Árbol partido en Utebo.

Fuente:Twitter @62Pina.

A continuación (figura 112) se muestra el mapa de daños realizado a petición del Consorcio de Compensación de Seguros para la localidad de Longares (Castán Bañeras, 2018-2), donde destaca un silo derribado, una antena doblada, daños en tejados y construcciones, varios árboles tronchados o arrancados y varias torres de tensión también derribadas.

El mismo perito, también a petición del Consorcio de Compensación de Seguros, realizó un estudio de afecciones en la zona de Garrapinillos (Castán Bañeras, 2018-1) en el cual reporta daños en cubiertas, tejados y árboles arrancados. Asimismo, señala que las afecciones en el aeropuerto de Zaragoza, que limita al sur con esta población, fueron limitadas, lo que ilustra con varias fotografías tomadas en la zona norte de las instalaciones aeroportuarias donde no se aprecian daños significativos.

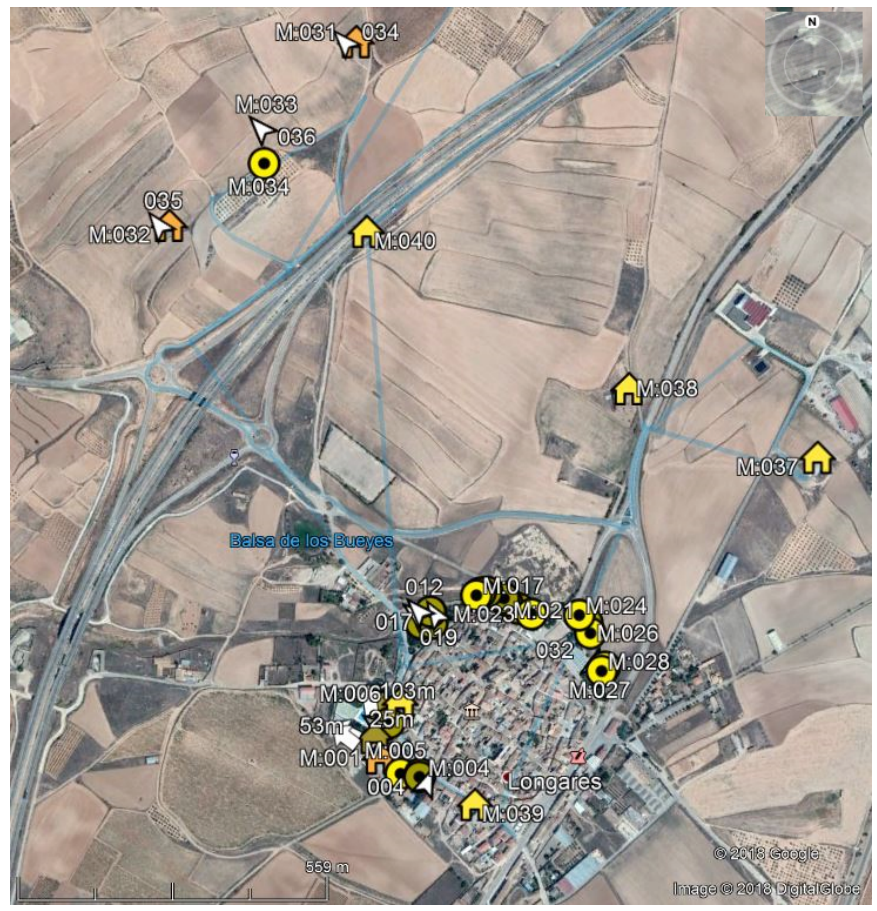

Figura 112. Daños en Longares registrados (Castán Bañeras, 2018-2). 
En la figura 113 se aprecia la zona de pistas del aeropuerto, donde no se pudo realizar estudio de daños, que es donde se registraron las rachas más intensas del episodio, aunque también mostrando una gran variabilidad espacial, tal como se ha detallado en el apartado 7 de este informe.

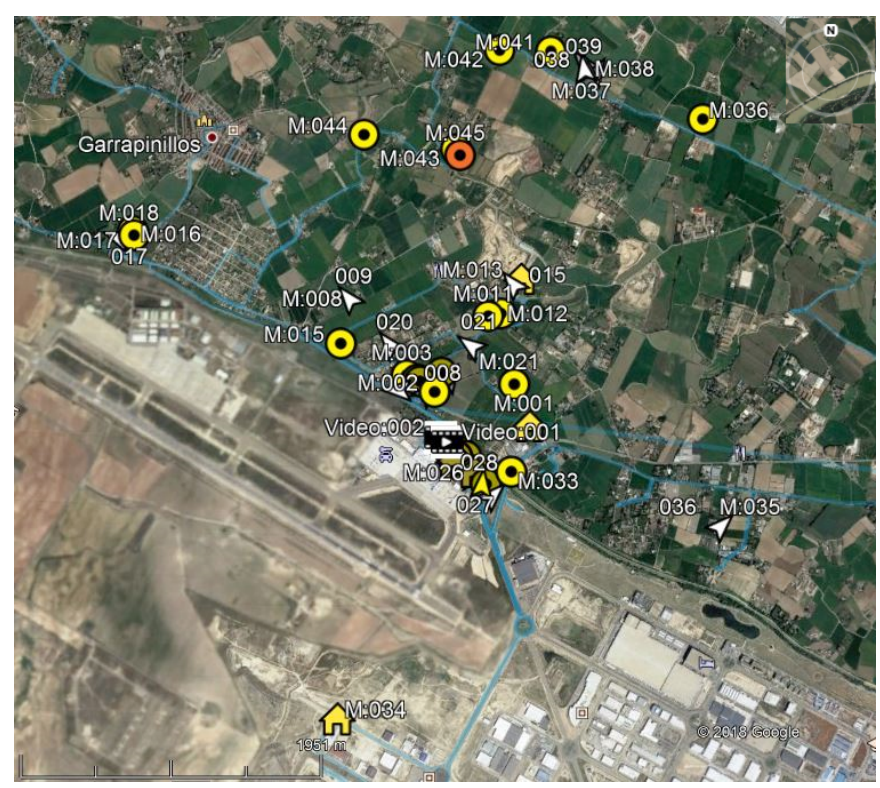

Figura 113. Daños en Garrapinillos

(Castán Bañeras, 2018-1). 


\section{CONCLUSIONES}

- A partir del análisis sinóptico y mesoescalar se confirma que había un entorno favorable para el desarrollo de convección.

- El estudio de los índices de diagnóstico convectivo nos indica que había una marcada inestabilidad, fuerte cizalladura vertical del viento y valores en general significativos de la SRH (helicidad relativa a la tormenta) en áreas del Levante peninsular, cordilleras Cantábrica e Ibérica y valle del Ebro fundamentalmente. Este entorno preconvectivo era especialmente favorable para el desarrollo de convección profunda muy organizada.

- A partir de datos de sondeos previstos por modelos numéricos (HIRLAM 0.16 y HARMONIE-AROME) en diferentes puntos de la región y de los datos VAD del radar de Zaragoza, se concluye que la cizalladura vertical del viento era elevada entre la superficie y unos 4 o $5 \mathrm{~km}$ de altura, mientras que no parece ser especialmente significativa por debajo de los $3 \mathrm{~km}$. Esto supone que nos encontramos en un entorno favorable al desarrollo de convección profunda, y especialmente favorable a la formación de supercélulas (células convectivas con una corriente ascendente en rotación en su seno).

- Cabe resaltar también el diferente aspecto de las hodógrafas en zonas más orientales respecto a las de zonas más interiores de Aragón. En las primeras la cizalladura vertical del viento tiende a presentar un giro horario, compatible con el desarrollo de supercélulas con un mesovórtice con giro ciclónico. En las de zonas más alejadas del Mediterráneo las hodógrafas presentan un aspecto prácticamente unidireccional, lo cual es compatible con el desarrollo de las dos supercélulas, una con giro ciclónico y otra con giro anticiclónico, en el caso de que se presente un proceso de storm splitting.

- A través de las imágenes de satélite y de las imágenes de reflectividad del radar de Zaragoza se puede observar cómo la convección fue profunda, muy organizada, y cómo se formaron varios procesos de storm splitting. Todos estos procesos se iniciaron en el norte y/o nordeste de la provincia de Teruel (cerca del límite con la provincia de Zaragoza). Las supercélulas desarrolladas se desplazaron en unos casos (células con giro ciclónico) en dirección nordeste, afectando en especial a zonas del Bajo Aragón, ribera baja y media del Ebro e incluso centro y sur de la provincia de Huesca, y en otros casos en dirección norte (células con giro anticiclónico) afectando al oeste de la provincia de Zaragoza, proximidades de la capital aragonesa (como la que afectó al aeropuerto de Zaragoza) hasta llegar a las Cinco Villas.

- Por otro lado, en las imágenes de viento radial del radar de Zaragoza se aprecian, en varias ocasiones, configuraciones significativas de viento que son compatibles con la presencia de mesociclones asociados a posibles supercélulas.

- Con todo esto, y sin disponer de más evidencias sobre el terreno, lo más probable es que los daños observados en las zonas y municipios mencionadas se hayan producido por la aparición de corrientes descendentes muy fuertes (downbursts) asociadas a estructuras convectivas altamente organizadas, que en muchos casos se puede confirmar que se trataba de estructuras de tipo supercelular. Se puede informar, así mismo, que los vientos registrados 
en el aeropuerto de Zaragoza, con rachas de hasta $157 \mathrm{~km} / \mathrm{h}$ (rachas huracanadas), son perfectamente compatibles y consistentes con fenómenos de este tipo. Del mismo modo es también compatible con este tipo de estructuras la gran variabilidad espacial de los datos de viento registrados en el aeropuerto. Se puede, por lo tanto, afirmar que otros daños observados en otras localidades son igualmente compatibles con los fenómenos convectivos aquí descritos, aunque no se hayan registrado datos de la intensidad del viento en estaciones de AEMET. Todo ello, así mismo sería compatible con la formación de tornados de origen supercelular, aunque no haya evidencias directas sobre el terreno de la presencia de los mismos. 


\section{BBiLIOGRAFíA}

Amburn, S. A. y P. L. Wolf, 1997. VIL Density as a Hail Indicator. Wea. and Forecasting, 12, 473-478.

Bluestein, H. B., 1993. Synoptic-Dynamic Meteorology in Midlatitudes. Oxford University Press.

BuISÁn, S. Episodio de actividad convectiva tormentosa intensa acaecido el 1 de septiembre de 2009 en la ciudad de Huesca. Agencia Estatal de Meteorología.

BuRgess, D. W. y L. R. Lemon, 1990. Severe thunderstorm detection by radar. Radar in Meteorology, D. Atlas, Ed., American Meteorological Society, Boston, MA, 619-647.

Burgess, D. W. y L. R. Lemon, 1991. Characteristics of mesocyclones detected during a NEXRAD test. Preprints, 25th Int. Conf. on Radar Meteorology, Paris, France, Amer. Meteor. Soc., 39-42.

Burgess, D. W., R. L. Lee, S. S. Parker, S. J. Keighton y D. L. Floyd, 1995. A Study of mini supercells observed by WSR-88D radars. Preprints, 27th Conference on Radar Meteorology, Vail, Colorado, American Meteorological Society.

CASTÁn BAÑeras, S., 2018. Informe de efectos. Posible tornado. Aeropuerto de Zaragoza - Garrapinillos (provincia de Zaragoza). Agencia Pericial.

CASTÁn BAÑERAS, S., 2018. Informe de efectos. Posible tornado. Longares, comarca de Campo de Cariñena, provincia de Zaragoza. Agencia Pericial.

ConesA, A. Tornado de Valdealgorfa de 23 de julio de 2003. Instituto Nacional de Meteorología.

CONESA, A. Tornado de Corbalán (Teruel), 28 de agosto de 2004 (estudio preliminar). Instituto Nacional de Meteorología.

Doswell, C. A., H.E. Brooks y R. A. Maddox, 1996. Flash Flood Forecasting: An Ingredients-Based Methodology. Weather and Forecasting, 11(4), 560-581.

ElIzAGA, F., 1998. Revisión del uso operativo de campos derivados en McIDAS. Nota Técnica del STAP no 30. Instituto Nacional de Meteorología.

ElizAGA, F. y F. Martín. Uso de modelos numéricos para la predicción operativa de convección severa. Instituto Nacional de Meteorología.

Espejo, F. y R. SAnz. El tornado del 28 de agosto de 1999 en la Sierra del Rayo (Teruel). Instituto Nacional de Meteorología.

Greene, D. R. y R. A. Clark, 1972. Vertically integrated liquid: a new analysis tool. Mon. Wea. Rev., 100. 548-552.

GutiérRez Rubio, D. y J. D. Soriano Romero, 2017. Informe preliminar sobre la posibilidad de ocurrencia de tornado en El Rompido (Huelva) el 11 de mayo de 2017. Agencia Estatal de Meteorología. 
KitZmilleR, D. H. y J.P. BReIDenBACH, 1995. Detection of severe local storm phenomena by automated interpretation of radar and storm environment data. NOAA Technical Memorandum NWS TDL 82, National Weather Service, NOAA, US Department of Commerce, 33 pp.

Kitzmiller, D. H., M. E. Churma y M. T. FILIAGGI, 1995. Severe local storm and large-hail probability algorithms in the System for Convection Analysis and Nowcasting (SCAN). Techniques Development Laboratory, Silver Spring, Mayland.

Martín, F. et AL., 2001. Diagnóstico y predicción de la convección profunda. Nota Técnica STAP no 35. Instituto Nacional de Meteorología.

MARTín, F. ET AL., 2003. Supercélula severa en el área mediterránea. Nota Técnica STAP no 37. Instituto Nacional de Meteorología.

Markowskı, P. y Y. Richardson, 2010. Mesoescale Meteorology in Midlatitudes. Wiley_Blackwell.

Módulos COMET. https://www.meted.ucar.edu/I (Principles of Convection I, II, III).

Módulos COMET. https://www.meted.ucar.edu/l (Skew T - Mastery).

Moller, A. R., M. P. Foster y G. R. Woodall, 1994. The operational recognition of supercell thunderstorm environments and storm structures. Wea. Forecasting, 9, 327-347.

Perea Hitos, C., C. Jiménez Alonso y J. Riesco Martín, 2014. Guía de campos y parámetros operativos de interés en el diagnóstico convectivo. Nota Técnica de AEMET.

Quirantes Calvo, J. A., J. Riesco Martín y J.Á. Núñez Mora, 2014. Características básicas de las supercélulas en España. Ministerio de Agricultura, Alimentación y Medio Ambiente. Agencia Estatal de Meteorología.

Rasmussen, E. N., 2003. Refined supercell and tornado forecast parameters. Wea. Forecasting, 18, 530-535.

Requena, R. y F. Espejo. Tornado del 30 de abril de 2007 en Arnedo (La Rioja). Instituto Nacional de Meteorología.

RodríGUEZ, F. J., 2011. Episodio de actividad convectiva con rachas de viento muy fuertes asociadas el día 6 de junio de 2011 en la zona de Tauste. Informe especial (D. T. de AEMET en Aragón).

SAnAmbrosio, I., 2004. Módulo para la estimación de granizo basado en datos radar. Nota Técnica STAP no 44. Instituto Nacional de Meteorología.

SAnAmbrosio Beirán, I. y B. P. López López, 2014. Informe sobre las rachas de viento huracanadas asociadas a la convección profunda y muy organizada del día 4 de octubre de 2013 en Biota (Zaragoza). Agencia Estatal de Meteorología.

Soriano Romero, J. D., 2016. Informe preliminar sobre la posibilidad de ocurrencia de tornados en Palos de la Frontera y Lepe (Huelva) el 1 de diciembre de 2016. Agencia Estatal de Meteorología.

STEWART, S. R., 1991. The prediction of pulse-type thunderstorms gusts using Vertically Integrated Liquid Water Content (VIL) and the Cloud Top penetrative downdraft mechanism. NOAA Technical Memorandum NWS SR-136. 

AEMet 